University of Redlands

\title{
Analyzing Southern California Residential Real Estate Prices: A Spatio-Temporal Approach
}

A Major Individual Project submitted in partial satisfaction of the requirements

for the degree of Master of Science in Geographic Information Systems

By

Pil Kwon

Fang Ren, Ph.D.

Douglas Flewelling, Ph.D.

August 2012 
Analyzing Southern California Residential Real Estate Prices: A Spatio-Temporal Approach

Copyright @ 2012

by

Pil Kwon 
The report of Pil Kwon is approved.
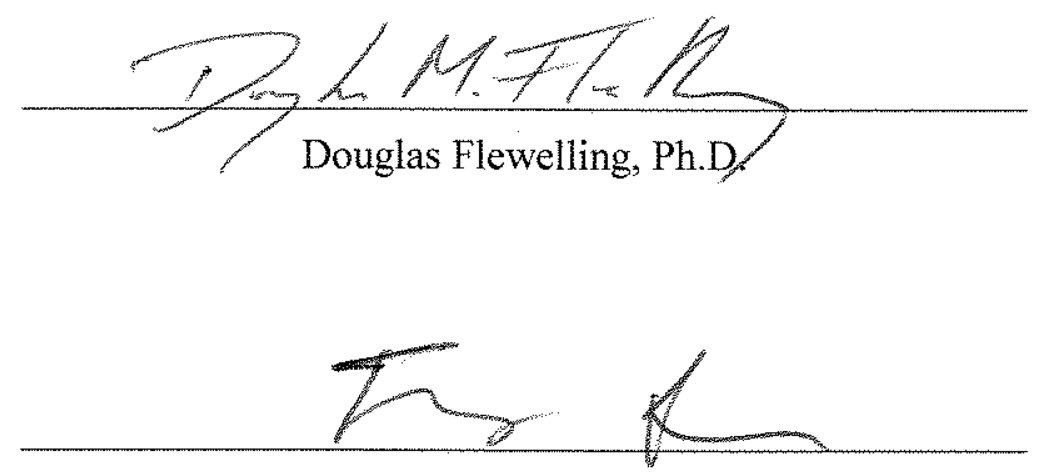

Fang Ren, Ph.D., Committee Chair

August 2012 


\section{Acknowledgements}

I had a very hard time, for this was my first time writing a technical report. I needed much help even though I had spent much time in the U.S. Thanks to Holland and Mark for helping make my engRish to English. Gordon, I thank you kindly for your quick responses and help without hesitation. Dami, your edits right before leaving to San Diego for Esri User Conference helped very much.

May, 2012, I was very discouraged, that my project did not go through well. However, thanks to Dr. Fang Ren and Dr. Douglas Flewelling, I was able to restart my project. I really don't know how to express my appreciation to these two faculties. Especially, Dr. Fang Ren - my advisor, without your endless, relentless, and yet precious edits with life lessons, I would not have been able finish this program. I owe you my life.

Special appreciation to Professor Mark Stewart, I am really thankful to your invitation during the holidays. I will never forget you and that I fell asleep in church during and the time I spent with you and Jane.

My "Midwest" friend Rocky; it sucked that you, Wilma and I were the last three people to be defended in August. You don't know but you mentally prepared me which helped a lot (sometimes you were annoying but it's okay). You and Wilma are being really good friends. Hopefully soon, we'll run a bar in Korea, right?

Ragnhild, your smartness and logic from your forehead surprises me and I'll miss our trip to Subway and Panda Express for lunch and late night (arguing/discussions/presentation rehearsal, etc.)

Yasser and Albanki, you guys are magicians. Your help is cannot be described.

Ari, I don't like your defensive attitude, but I like your attitude toward to foreign students, like Pil.

Pon, my only Asian classmate, your technical background probably helped me get an A in database design and python classes; otherwise, I would have been failed.

Elena, I am really thankful to your concerns about my MIP even after the program and distance help!

To my parents, I'm sorry that all your income had to come to the program tuition but I will payback by being decent Geospatial Analyst or Geostatistician or whatever my future title will be. My sister, Jin, I thank you for your salary to help pay for my tuition.

From September 2011 to August 2012, I am very certain that I learned so much. Especially, spending time with great people from all over the world and different backgrounds made me realize how little I know about GIS and life. I, however, believe all the pain that I went through will be very valuable time for my career and life in the future.

Finally, thank you God that I have an education and finished this successfully. 


\begin{abstract}
Analyzing Southern California Residential Real Estate Prices:

A Spatio-Temporal Approach

by

Pil Kwon

This project focused on examining housing price changes from 2000 to 2009 in Los Angeles, Orange, Riverside, and San Bernardino counties in southern California. In particular, the project sought to detect the spatio-temporal autocorrelation of residential pricing across different counties, cities, and neighborhoods over the 10 -year period. A set of GIS tools was implemented to clean and prepare the raw data for multivariate Moran and Local Indicators of Spatial Association analysis. The findings from the analysis will enhance readers' understanding of the real estate market in the study area and help better predict the spatio-temporal patterns of housing price changes in the future.
\end{abstract}




\section{Table of Contents}

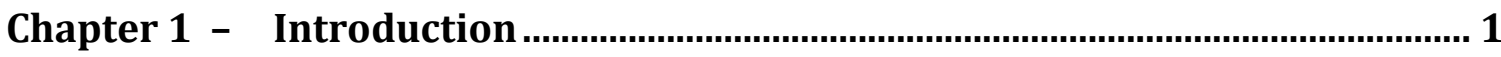

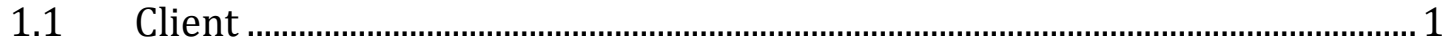

$1.2 \quad$ Problem Statement …………………………………………………………....

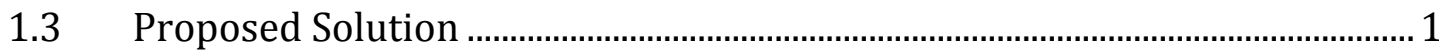

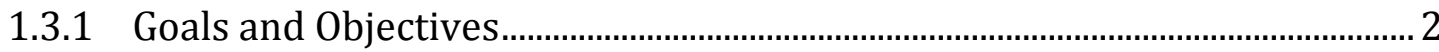

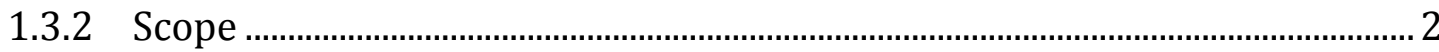

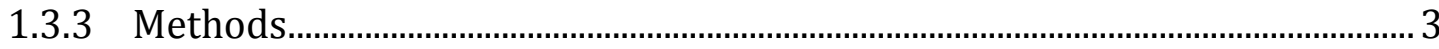

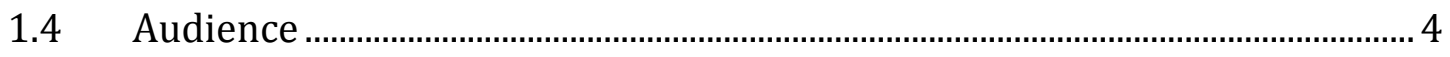

1.5 Overview of the Rest of this Report...................................................................... 4

Chapter 2 - Background and Literature Review................................................. 5

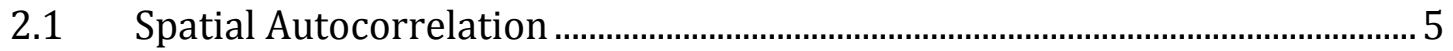

2.1.1 Global Measures for Spatial Autocorrelation........................................................

2.1.2 Local Measures for Spatial Autocorrelation........................................................ 6

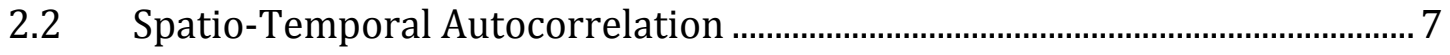

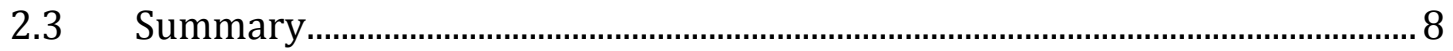

Chapter 3 - Systems Analysis and Design ….....................................................11

$3.1 \quad$ Problem Statement …………………………………………………………... 11

3.2 Requirements Analysis......................................................................................... 11

3.2.1 Functional Requirements ................................................................................ 11

3.2.2 Non-Functional Requirements........................................................................ 11

3.3 System Design ..................................................................................................... 12

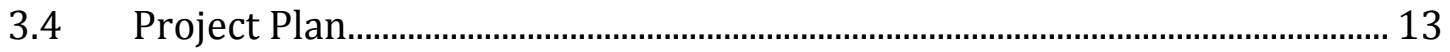

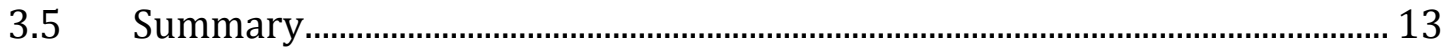

Chapter 4 - Database Design ...........................................................................14

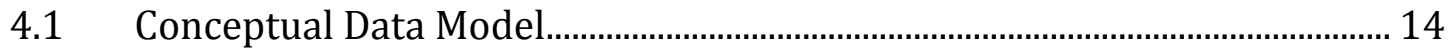

4.2 Logical Data Model ............................................................................................... 14

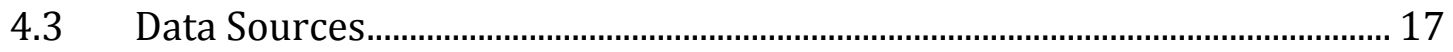

$4.4 \quad$ Data Scrubbing and Loading .................................................................................. 17

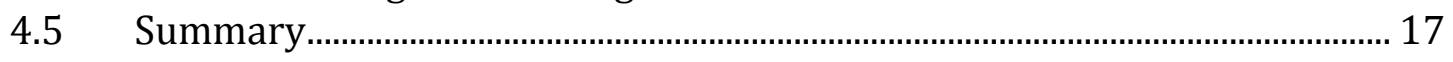

Chapter 5 - Implementation ........................................................................19

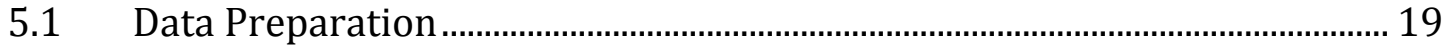

5.1.1 Cleaning and Organizing Data ........................................................................... 20

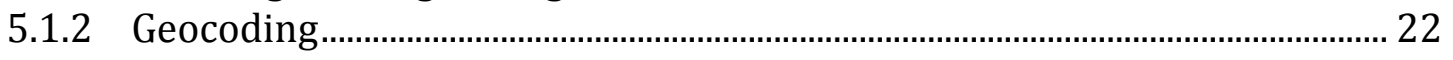

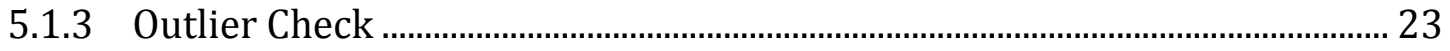

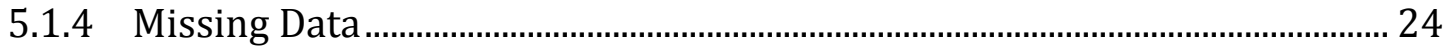

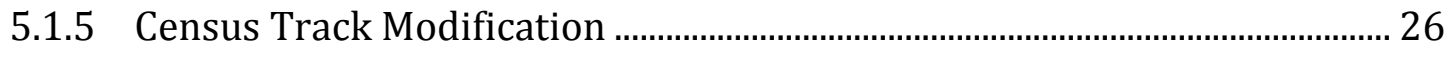

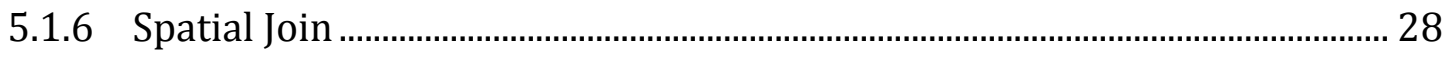

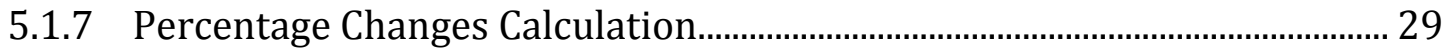

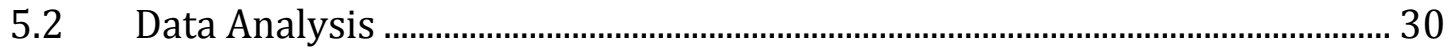

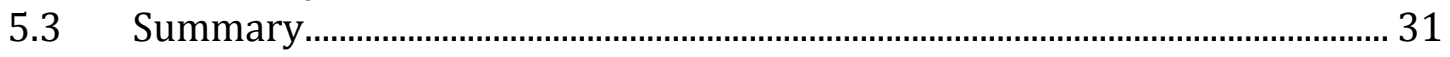


Chapter 6 - Results and Analysis................................................................32

6.1 General Pattern of Housing Unit Prices in Southern California ....................32

6.2 Spatial Patterns of Housing Prices per Square Foot............................................34

6.3 Spatial Pattern of Percentage Changes ……………………………………….....37

6.4 Summary ………………………………………………………………………...

Chapter 7 - Conclusions and Future Works ……..................................................42

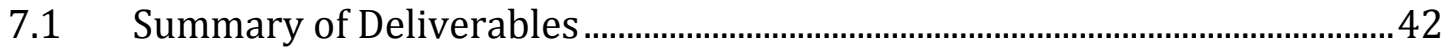

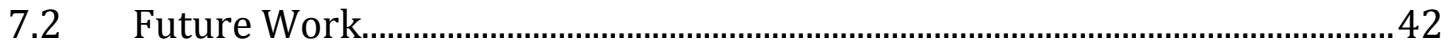

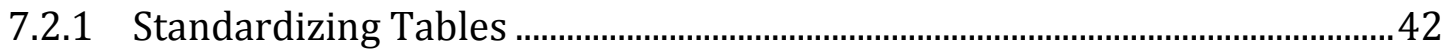

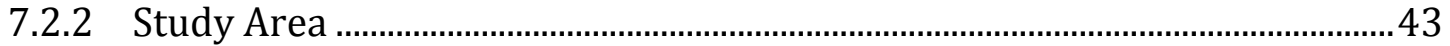

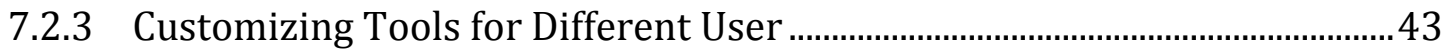

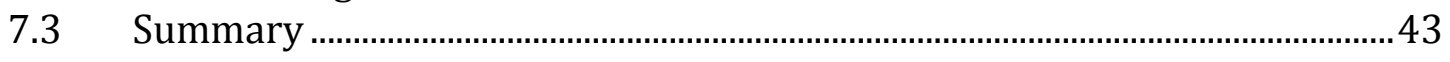

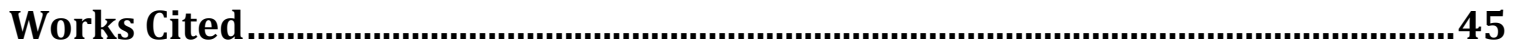

Appendix A. Python Script (1). Data Filtering and Cleaning ............................49

Appendix B. Python Script (2). SingleFamilyQuery_QuarterGenerator...........51

Appendix C. Python Script (6). PercentageChanges ............................................53

Appendix D. Python Script (2.5). MissingDataFiltering ……..............................54

Appendix E. Local Moran's I ......................................................................56

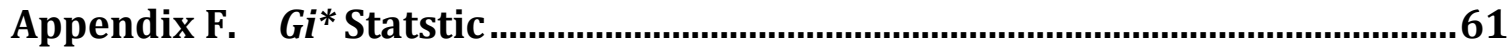

Appendix G. Gi* Statistic of Percentage Changes...............................................66

Appendix H. Local Moran's I of Percentage Changes.........................................71

Appendix I. ModelBuilder Image (3).Geocode and Projection ........................77

Appendix J. ModelBuilder Image (4). Census Tract Integer Aggregation ......79

Appendix K. ModelBuilider Image (5). Spatial Join ...............................................81

Appendix L. ModelBuilder Image (3.5). Missing Data and Original Data

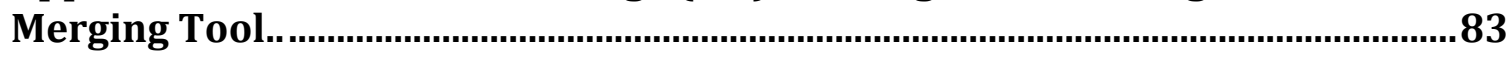

Appendix M. ModelBuilder Image (6.5). DivideByCounty …..............................85 


\section{Table of Figures}

Figure 1-1: Study Areas and Sample Cities with Housing Points ............................... 3

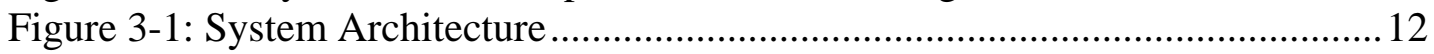

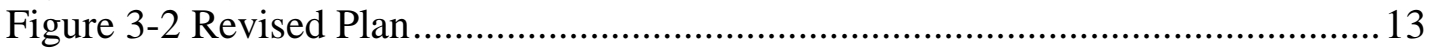

Figure 4-1: Conceptual Data Model ........................................................................ 14

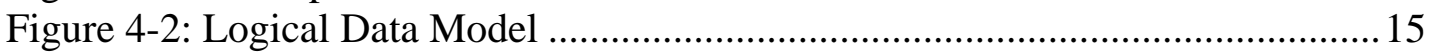

Figure 4-3: Tables, Feature Datasets, and Feature Classes...................................... 15

Figure 4-4: Spatial Joined Feature Dataset ......................................................... 16

Figure 4-5: A Sample Feature Class Attribute Fields ............................................ 16

Figure 5-1: Workflow of the Delivered Tool. Dashed lines represent the workflow of the missing data, which is not needed for future analysis. Solid lines represent the

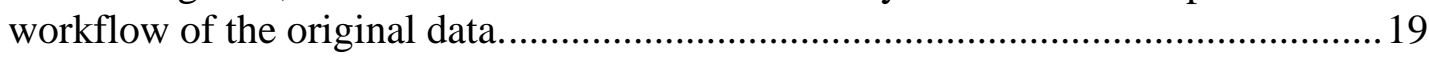

Figure 5-2: Developed Geoprocessing Tools ......................................................20

Figure 5-3: User Interface of Data Filtering and Cleaning Tool .............................21

Figure 5-4: SingleFamilyQuery_QuarterGenerator Tool .....................................22

Figure 5-5: Geocoding Tool Interface .................................................................. 23

Figure 5-6: Spatial Outliers (Dots represent housing sale records in different year) 24

Figure 5-7: Missing Data in PDF (top) and Same Data in Excel (bottom)................. 25

Figure 5-8: Missing Data and Original Data Merging Tool ..................................26

Figure 5-9: Census Tract Integer Aggregation Tool ..............................................26

Figure 5-10: Census Tract Border Reform ............................................................. 27

Figure 5-11: Census Tract 9800s in Los Angeles County ......................................28

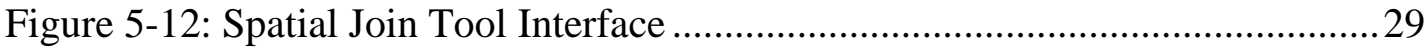

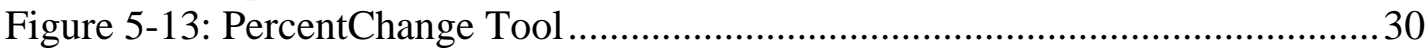

Figure 6-1: Mean Housing Unit Prices by County (Unit: \$/Sq.Ft)........................... 32

Figure 6-2: Price Variations in Orange County ...................................................... 33

Figure 6-3: Housing Price Changes in Orange County during 2005 and 2006 ......... 34

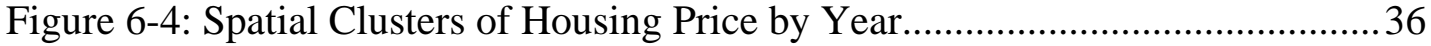

Figure 6-5: Local Moran's I of Percentage Changes..................................................38 



\section{List of Tables}

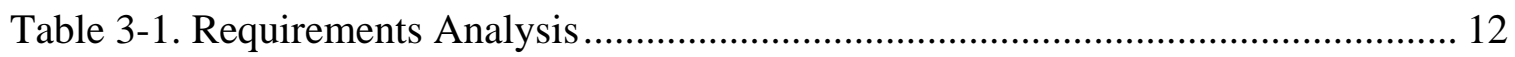

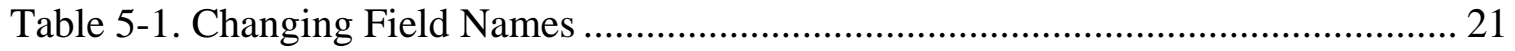

Table 6-1. Highest Housing Unit Prices in Each County .............................................. 32

Table 6-2. Moran's I of Housing Unit Prices from 2000 to 2009 by Census Tracts......... 35

Table 6-3. Moran's I of Percentage Changes of Housing Unit Prices from 2000 to 200837

Table 6-4. Gi* Statistic Hot/Cold Spot Census Tracts Numbers by Cities ..................... 39

Table 6-5. Local Moran's I Cluster and Outlier Types Census Tract Numbers by Cities 40 



\section{List of Acronyms and Definitions}

FIPS Federal Information Processing Standard

GIS Geographic Information System

ISEA the Institute for Spatial Economic Analysis

NAD North American Datum

PDF Portable Document Format

Q Quarter

SaTS Spatial and Space-Tine Scan Statistics

TSGP Time Series Genetic Programming Software

UML Unified Modeling Language 



\section{Chapter 1 - Introduction}

In America today, a home is typically a person's most expensive investment. The subprime mortgage crisis that began in 2006 changed the lives of home owners and mortgage holders. According to Schiller (2008), the economic disaster was so severe that it might take years for the market to recover. It has been almost six years since the subprime mortgage crisis began; yet, based on real estate and business cycle theory, after such a recession prices should eventually recover. Dr. Mak Kaboudan, the client, for this project hypothesized that in Southern California there is always an area that is a leading indicator of price changes, whether ascending or descending. With 10 years of accumulated historical data, including property locations, the geographical patterns of the money flow were able to be determined. Based on these patterns, a geographic information system (GIS) was utilized as an analysis tool to correlate property value with space and time. The results of the patterns may be useful for those interested in the housing market recovery. Most of work was performed with ArcGIS Desktop and Microsoft Excel.

\subsection{Client}

Dr. Mak Kaboudan, a professor in the School of Business at the University of Redlands, was the client for this project. Dr. Kaboudan has academic interests in forecasting real estate prices, GIS, spatial statistics, and economics. Dr. Kaboudan has published several articles with Time Series Genetic Programming Software (TSGP), a regression model generating tool that he developed. He has successfully used TSGP to find regression models of the United States housing market prices and to forecast sunspot numbers.

Dr. Kaboudan wished to understand the spatial autocorrelation of housing markets in Southern California and how housing prices have changed over time. With these results, he plans to contribute to the forecasting of real estate market prices for his own research.

\subsection{Problem Statement}

People generally know which areas are expensive or inexpensive; however, most do not know which specific neighborhoods fall into these categories. Moreover, when prices fluctuate, people usually cannot identify which areas affect other areas. Even for real estate professionals, it is complicated to tell which neighborhoods are the most influential in terms of housing prices. The client wanted to know spatio-temporal autocorrelation of real estate market prices in Southern California, and which areas were leading the price fluctuations in Southern California housing markets.

\subsection{Proposed Solution}

To answer clients' questions, the proposed solutions were to develop a set of tools for processing the raw data provided by the client and to conduct various temporal and spatial analyses with the housing sale data from 2000 to 2009. Section 1.3.1 restates the 
problem and section 1.3.2 outlines the project scope. The methods used in this project are discussed in section 1.3.3.

\subsubsection{Goals and Objectives}

The overall goal for this study was to find spatial and temporal correlations of housing prices between Southern California residential areas. More specifically, the major goals were to examine the spatial autocorrelation of housing prices within a time period and to find temporal correlation of real estate market prices within a study area.

In order to achieve these goals, data from the client had to be processed and put into a proper format for specific software: Esri's ArcGIS and Microsoft's Excel. The objectives for the data reformatting were to reduce data preparation time and to facilitate faster analyses.

\subsubsection{Scope}

The primary goals for this project were to examine the spatio-temporal autocorrelation. To achieve the goals, a set of tools that organize, filter, and geocode the raw data was needed. Various temporal and spatial analyses using the processed data were the major components in the project. The map outputs and statistics were also the final deliverables.

There was a 10-month time constraint for this project. Because of this timeframe, the scope was narrowed down to two manageable sections: data organization and preparation, and data analyses. The data analyses were also restricted to specific areas instead of the entire Southern California region. The selected study areas were Orange, Los Angeles, Riverside, and San Bernardino counties. The client wanted to further narrow the analysis down to four cities in each of those counties (Figure 1-1). The cities were arbitrarily chosen by the client. 


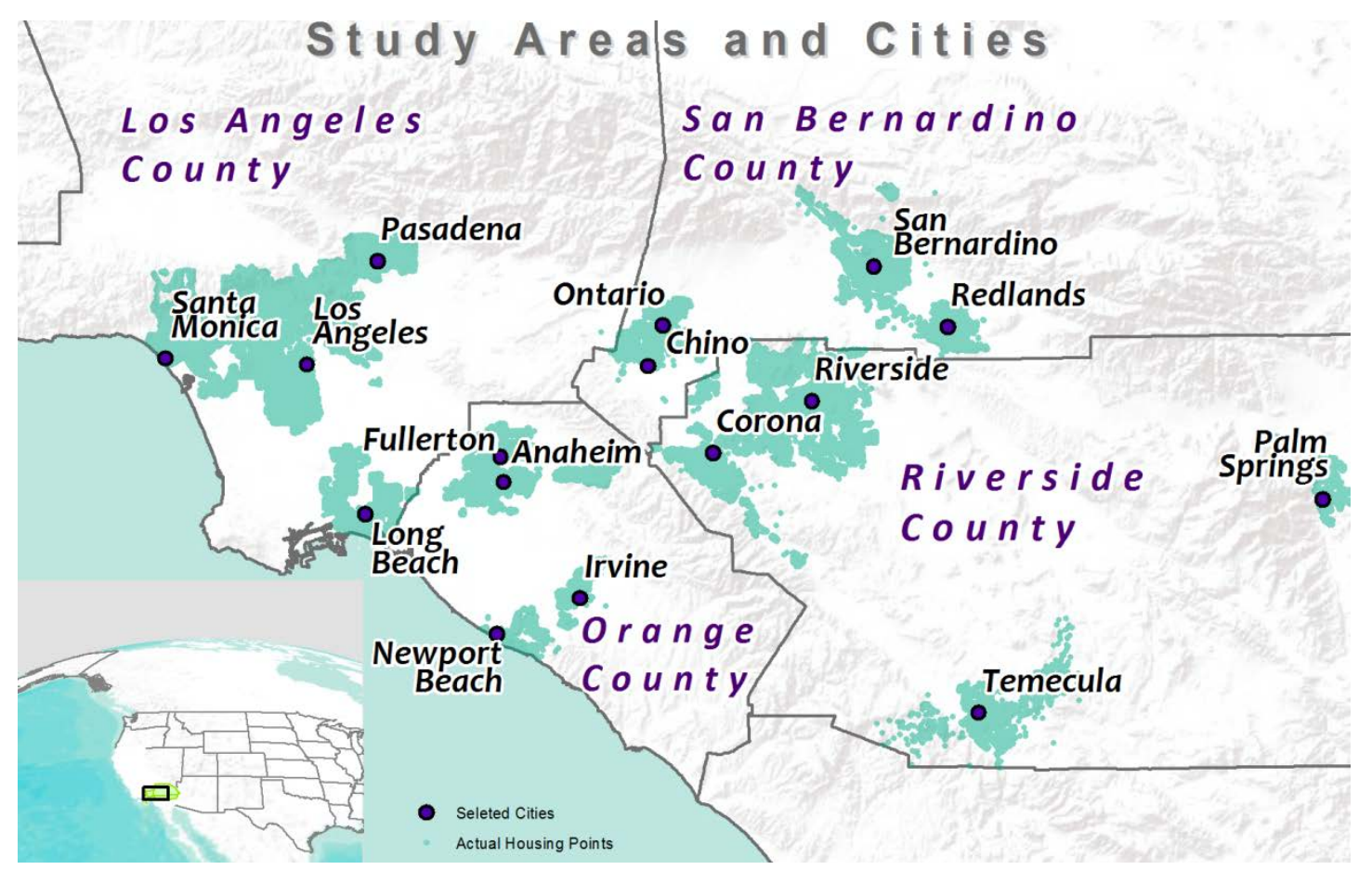

Figure 1-1: Study Areas and Sample Cities with Housing Points

The deliverable tools were solely used for data trimming. The spatial and temporal analyses were done using built-in ArcGIS tools and Microsoft Excel.

\subsubsection{Methods}

The client first provided the data for this project in compressed files of Microsoft Excel spreadsheets. But these spreadsheets were of limited value because they did not contain any spatial references. Therefore, Esri's ArcGIS Desktop was proposed to convert the tables to spatial data based on their housing addresses.

Before they were geocoded, the tables contained unnecessary information on the houses (i.e., previous owner, community number, etc.). This information was removed to achieve better performance of the software. The ArcGIS online geocoding services provided by Esri and NAVTEQ were mostly accurate in terms of finding location with addresses, but there were some offsets. These location errors were not treated as serious problems because the client wanted the housing points to generalize census tracts boundary; hence, as long as the points fell near their exact location, the offsets were accepted.

The point data were then spatially joined with the boundary based on the client's request; census tract, which returns summary statistics of the aggregated points, such as mean house values or median house values for each aggregate unit. For the quantitative geographic analysis, global and local spatial autocorrelations were examined.

The data for this project needed to be downloaded, converted, stored, reformatted, and calculated. It was downloaded in a few different formats. Although the data from the client were readable in the ArcGIS environment, they were converted and stored in a geodatabase for better performance and compatibility with ArcGIS tools. Next, it was 
reformatted for specific usages. For instance, data in the geodatabase were cleaned up based on the client's requirements. Spatial data from the U.S. Census Bureau were reformatted and projected to specific projection used in the project. The data were then calculated for spatio-temporal analysis.

\subsection{Audience}

This research was prepared for those who are interested in real estate markets with GIS process. To understand this study, audiences need to understand how GIS tools work. A background in spatial statistics would also be advantageous.

\subsection{Overview of the Rest of this Report}

Project related-journals, background, and literature reviews are examined in Chapter Two. Chapter Three discusses system analysis and design. Database design and its illustration are described in Chapter Four. Chapter Five contains implementation of the project. Chapter Six discusses the results and analysis. Future work and conclusions are proposed in Chapter Seven. 


\section{Chapter 2 - Background and Literature Review}

In this chapter, literature on spatial autocorrelation and spatio-temporal autocorrelation will be discussed. The chapter was organized into two sections: spatial autocorrelation and spatio-temporal autocorrelation. While spatial autocorrelation section explains global and local measures for spatial autocorrelation, spatio-temporal autocorrelation introduces real world examples of the method.

\subsection{Spatial Autocorrelation}

Although Dr. John Snow's “On The Mode of Communication of Cholera” (1849) was a significant contribution to the use of maps to represent water-borne diseases and their geographical patterns, the first spatial statistics maps were implemented in Dr. Robert Baker's “cholera plan” of the city of Leeds, England in 1833 (Gilbert, 1958) . These pioneers introduced mapping spatial patterns to the research community. Various analytical methods have since been developed to examine the spatial patterns of point data, lattice data, and field data. For lattice data (e.g., census tracts or block groups), one of the common research questions is whether an attribute of the area units, such as median or mean household income, presents spatial autocorrelation.

"Spatial autocorrelation is defined as the correlation of a variable with itself over space” (Burt, Barber, \& Rigby, 2009, p. 544). This concept was encapsulated in Waldo Tobler's First Law of Geography: "Everything is related to everything else, but near things are more related than distant things" (Tobler, 1970). When neighbors in the study have similar attribute values, or if there is a concentration of similar values, a variable of interest may be positively autocorrelated (i.e., positive number). However, in the case where neighbors show distinctive characteristics, the spatial pattern of the variable tend to be negative spatial autocorrelation (i.e., negative number).

Several measures have been developed to calculate spatial autocorrelations. For instance, Getis (2008) summarized the commonly used spatial autocorrelation measures, including Moran's I, Geary's $C$, Getis and Ord's $G$, Ripley's $K$, the cross-product statistic $T$, the spatial autoregressive parameters $\rho$ and $\lambda$, Getis and Ord's $G_{i}$ and $G_{i}{ }^{*}$, Anselin's $I_{i}$ and $C_{i}$, Ord and Getis' $O$, Matheron's $1 / \gamma$. Among these measures some are called global measures that are used to evaluate the overall spatial autocorrelation, while others are called local measures are used to measure how to spatial autocorrelation varies across space.

\subsubsection{Global Measures for Spatial Autocorrelation}

Both Moran's I and Geary's $C$ are commonly used global measures for spatial autocorrelation. The difference between the two measures is the cross-product (i.e., multiplication of deviation). While the cross-product in the formula of Moran's $I$ is based on the deviations from the mean between nearby locations, the cross-product Geary's $C$ in the formula uses the actual values of the nearby locations (Briggs, 2010).

Several other scholars have studied and compared the two methods. Sawada (2009) compared these two measures and found that Moran's $I$ had been used in almost all studies on spatial autocorrelation. Getis and many other statisticians noted that Moran's I 
statistic is the most commonly used measure of and test for spatial autocorrelation (Getis, 2008). Getis cited Cliff and Ord (1981) in which they mentioned that Moran's I was as the most commonly used measure for spatial autocorrelation (Getis, 2008).

The mainstream use of Moran's $I$ for testing global spatial patterns seems to be universal judging from the literature, despite differences in the author's academic fields.

When Severe Acute Respiratory Syndrome (SARS) occurred in Hong Kong, Lai, Wong, Hedley, Lo, Leung, Kong, and Leung (2004) analyzed spatial pattern of the disease cases between February to June 2003 (25 weeks). In this study, they plotted patients' residential addresses and aggregated the points to circles. They then modified the size of the circles (dot density) in relation to the magnitude of disease occurrences in the community. Their full-scale research was done by a combination of Moran's $I$ and hotspot analysis. One kernel's size was assigned to $300 \times 300 \mathrm{~m}^{2}$ and covered the entire study area of Hong Kong. Instead of Getis and Ord's Gi* statistic for their hotspot analysis, they used one kernel to have infection rates per 1,000 population. The results were mapped with 15 classes of infection rate to see hotspots of the SARS cases. To enhance their analysis, Lai and others added Moran's I indexes of the SARS infection rates in different weeks (Lai, et al., 2004).

Although these global measures are useful in detecting spatial autocorrelations, they are not designed to investigate beyond the general autocorrelation characteristics of a space because finding individual centers of clustering is problematic when testing global autocorrelation (Ord \& Getis, 2001). To identify individual centers of clustering, various local measures have been developed.

\subsubsection{Local Measures for Spatial Autocorrelation}

The scholars who developed local spatial autocorrelation tests admitted that finding individual centers of clustering is problematic in the face of global autocorrelation (Ord \& Getis, 2001).

Miller (2004) defined spatial autocorrelation as "quantitative techniques for analyzing correlation relative to distance or connectivity relationships.” Miller also added that spatial autocorrelation tends to be regarded as an unimportant variable that correlates with both the dependent and independent variables in regression models. Spatial autocorrelation shows the spatial association between geographic features. Spatial heterogeneity, which explains the spatial outliers of the overall patterns of geographical characteristics, is different from spatial autocorrelation. Spatial autocorrelation describes the spatial associations between geographic objects and shows the intensity and pattern of spatial associations. Therefore, in order to produce first-rate exploratory and confirmatory analyses in spatial relations, the use of two methods (spatial heterogeneity and spatial association) was critical. To identify spatial association (local clusters) and spatial heterogeneity (local outliers), local Moran's I developed by Anselin, and the Gi* statistic developed by Getis and Ord (1996) are suggested in the literature (Boots \& Tiefelsdorf, 2000, p. 320).

Local Indicator of Spatial Association (LISA) has been proven to be more suitable for identifying spatial patterns for smaller areas. For example, Jepsen, Simonsen, and Ethelberg (2009) analyzed the spatial pattern of Campylobacter cases using local Moran's $I$. Their study was conducted in the county of Funen in Denmark, and their spatio-temporal model included data from 1995 to 2003. After dividing the entire study 
area (4900 $\mathrm{km}^{2}$ ) into 5 x $5 \mathrm{~km}$ square cells (209 cells total), they ran the local Moran's I and the results indicated that 12 features were identified as clusters of Campylobacter. Two feature clusters were located in the central western part and 10 in the northwestern part of the study areas.

In another study, Can (1998) performed a local spatial autocorrelation analysis using $G_{i}{ }^{*}$ statistics, and found that it is able to identify spatial trends and distinguished spatial concentrations of high and low values. She also used the Moran scatterplot for the distribution of mean mortgage activity for census block groups in Dade County, Florida.

The Moran's scatterplot works for both a single variables and for multiple variables. In the latter case, it is called a bivariate (multivariate) Moran scatterplot. According to GeoDa Center (No Date), in the bivariate Moran scatter plot, two different variables exist. One of the neighboring two different variables is regressed on the other variable.

The multivariate Moran scatterplot visualizes a spatial autocorrelation statistic as the slope of the regression line in a scatterplot with the spatial lag on the vertical axis and the original variable on the horizontal axis (Anselin, Syabri, \& Smirnov, 2002). Tenkorang and Bridges (2008) examined the spatial autocorrelations between ethanol production and corn in the U.S. using the multivariate Moran scatterplot. They explained that the Moran scatterplot's upper right (first) quadrant indicates high-high regions, (a target feature has high value and the neighbors have high values). The lower left (third) quadrant indicates low-low areas (a target feature has low values the neighbors have lower value and the neighbors also have low values). The second and forth quadrants specify low-high (a target feature has lower value and the neighbors have high values) and high-low (a target feature has high value and the neighbors have low values), respectively. The Moran's scatterplot analysis indicated that there was a spatial dependence among nearby low corn producing counties, and also among nearby high corn producing counties. That is, there are no spatial dependency between the corn production and ethanol production

In summary, local spatial autocorrelation indicators like local Moran's I and the Gi* statistics can represent hot spots or possible centers of statistically significant clustering that cannot be measured by global measures (Getis, 2008).

\subsection{Spatio-Temporal Autocorrelation}

Several scholars from various academic fields have published studies about spatiotemporal autocorrelation in medical, physical, and ecology journals (Eyanoer, Singhasivanon, Kaewkungwal, \& Apisarnthanarak, 2011), (Chang \& Kwon, 2007), (Kim \& Baik, 2005), (Gilbert, 1958).

For example, Astuik, Rahayudi, Iskandar, Fitriani, and Murtini (2011) found spatialautocorrelation patterns of dengue fever in Indonesia by using multivariate Moran scatterplot and LISA. Their study covered over 38 districts in East Java, Indonesia, and eight years of historical dengue fever incidence cases. Astuik, et al. (2011) displayed temporal changes of the clusters of the cases by district levels (spatial) over different time periods. They found a spatial pattern of dengue fever cases in many different regions in different time.

In another example, Chang, Gunnell, Wheeler, Yip, and Sterne (2010) studied the historical (temporal) and geographic (spatial) patterns of charcoal-burning suicides in Taiwan. The study area encompassed the entire island of Taiwan (in township boundaries) for the time period of 1999 to 2007. The township boundaries were 
aggregated to seven different urbanization levels, with level 1 as the most urbanized and level 7 as the least urbanized. As in previously introduced literature, Moran's $I$ was used for statistical testing on spatial clustering. By examining the temporal trend of charcoalburning suicides using maps showing the island over different times, patterns in the data were revealed.

Nakhapakorn and Jirakajohnkool (2006) also found temporal and spatial autocorrelation of dengue fever in the northern part of Thailand. Their data were collected over a five-year period in nine different districts. Moran's $I$ and Geary's $C$ were used as their spatial autocorrelation measures. Similar to the approaches used by other researchers, the scholars displayed spatio-temporal autocorrelation results chronologically and found the resulting patterns. Excluding the fact that they used Geary's $C$, their other methods of were very similar.

Hui, Xu, Chen, Cheng, Liang, Huang, Fang, Yang, Zhou, Yang, Zhou, Cao, and Gong (2009) used descriptive methods and a GIS system to conduct spatio-temporal analysis of the distribution of malaria in Yunnan Province in China. Their use of GIS technique helped improve the public health in this region. As in previous studies, global Moran's I and Moran's scatterplot were implemented to analyze spatial clustering of malaria and local clusters and outliers of malaria. However, unlike the aforementioned approaches to visualizing the temporal trend, they overlapped the spatial patterns of malaria cluster cases in a single choropleth map where different levels of clusters at different times are represented by different colors. Several colors were generated to display how the malaria cluster areas changes over time. Hui, et al., also used several line charts and tables to illustrate the temporal changes of malaria incidence in their study region. The graph helped readers to visualize which year and which month had the highest incidence rates. If there were too many lines on the graph, making it illegible, the literatures divided it into two separate graphs (beginning years and later years), keeping the timeline intact.

Three-dimensional (3D) maps were also used in a few studies of spatial autocorrelation. Jepsen, Simonsen, and Ethelberg (2009) used Spatial and Space-Time Scan Statistics (SaTS), ArcGIS, and Netlogo software to represent temporal changes of incidence of Campylobacter cases in 3D space where the $x$ and $y$ axes representing the study areas and the $z$ axis represented the time. The significant local clusters of Campylobacter cases indicated by local Moran's I were then displayed.

In summary, it seems that the representation of spatio-temporal autocorrelation is often achieved by showing the spatial clusters or outliers on a series of maps sorted by time or representing the spatial patterns in a 3D environment. Although they are very useful for exploring how the spatial patterns have changed over time, robust numeric measures are in demand in order to quantify the temporal lags between different spatial locations.

\subsection{Summary}

Global Moran’s I and local Moran’s I, Gi* statistic, and Moran’s scatterplot were introduced in this literature review. Anselin (1998) introduced measures of spatial statistics in different cases. According to Anselin, Moran's I, Geary’s C, Gamma, Spatial Correlogram were the measures for global spatial autocorrelation. Conversely, he 
introduced local Moran, local Geary, local Gamma, Gi and Gi* statistics, and Moran’s scatterplot for local spatial autocorrelation measures.

Based on spatial statisticians' opinions in the literature, Moran's I, local Moran's I, $G i^{*}$ statistic were chosen for this project for measuring spatial autocorrelation over the study areas.

The examination of temporal changes of spatial autocorrelation usually begins by laying out spatial autocorrelation results chronologically and then finding the patterns of temporal changes. This approach was followed in this project.

The next chapter introduces systems analysis and design. 



\section{Chapter 3 - Systems Analysis and Design}

In most GIS projects, effective project plans and well-organized system designs are helpful to get a project finished on time. This chapter discusses the requirement analysis, system design specifications, and project work plan.

The requirements can be categorized as either functional or non-functional. The former is the fundamental system components (both software and hardware) process needed to produce outputs (Carnes, 2012). The latter is software requirements and design, which can be subjective. Technical, operational, and transitional requirements are the key examples of non-functional requirements.

\subsection{Problem Statement}

The public is generally aware that from the Clinton era, housing prices gradually increased until the 2008 subprime mortgage crisis, which depressed housing prices in California. Many people, however, do not know exactly which neighbors experienced the most price rise and the most loss of value in their homes during that period. Analyzing the spatial patterns of real estate values before and after the subprime mortgage crisis was the goal of this project.

\subsection{Requirements Analysis}

The requirements analysis is introduced in this section. In order to initiate the project, the system requirements needed to be fulfilled. These requirements would help the reader understand the project more clearly in details of the deliverables. Four types of requirements were considered: functional, technical, operational, and transitional.

\subsubsection{Functional Requirements}

The requirements of the tools and systems were as follows:

1. The tools should simplify data processing to remove surplus information from the raw data.

2. The tools should produce spatially referenced housing sale data based on the addresses.

3. Housing sale data should be aggregated to specified spatial boundaries.

4. The tools should calculate percentage changes of housing prices between two different time periods.

5. Spatial patterns and temporal changes in housing prices should be analyzed and visualized.

\subsubsection{Non-Functional Requirements}

Non-functional requirements involve technical requirements, operational requirements, and transitional requirements. The technical requirements detail the requirements of the data format while operational requirements review the software requirements for this project. Finally, transitional requirements refer to the project deliverables. 
Table 3-1 lists all three requirements. Technical requirements demanded that the data be readable and workable in the ArcGIS Desktop environment. In order to process the data in an organized manner in ArcGIS Desktop, the data had to be imported into a geodatabase.

Because the tools developed in this project were created specifically for the ArcGIS Desktop using Python scripts and ArcGIS ModelBuilder, ArcGIS Desktop 10.0 and Pythonwin (a graphical user interface for Python scripting) are required. Therefore, the user's computer needs to satisfy the minimum requirement for ArcGIS Desktop 10.0 in order to execute the tools developed in this project.

Transitional requirements simply asked what the deliverables were. The final results of this project would be the file geodatabase with all of the data, a set of GIS tools, and the manual for the tools, maps, and documents.

\section{Table 3-1. Requirements Analysis}

\begin{tabular}{l|l}
\hline & Requirements \\
\hline Technical & $\begin{array}{l}\text { Data conversion for ArcGIS Desktop 10.0 environment } \\
\text { Data stored in geodatabases }\end{array}$ \\
\hline Operational & $\begin{array}{l}\text { ArcGIS Desktop 10.0 } \\
\text { Pythonwin }\end{array}$ \\
\hline Transitional & Provide geodatabases, GIS tools, documents, maps, and manuals of the tools \\
\hline
\end{tabular}

\subsection{System Design}

The system architecture design introduced in this section gives a more detailed explanation of the project components. Figure 3-1 describes the system architecture, which includes raw data, geodatabase, delivered tools, and spatial autocorrelation analysis.

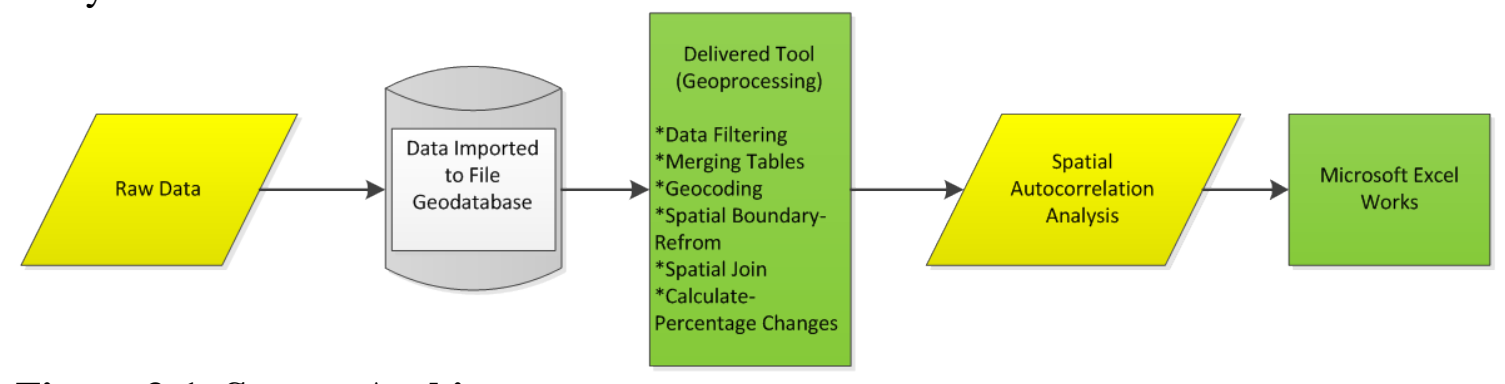

Figure 3-1: System Architecture

First, raw data from the client was imported to an ArcGIS file geodatabase. Then, the data were cleaned, organized, and processed by the delivered geoprocessing tools. Various spatial autocorrelation analyses were conducted to analyze the spatial patterns of housing prices and the changes in price. To visualize the temporal changes in housing prices, Microsoft Excel was used. The Excel tables were generated by exporting the corresponding tables from the file geodatabase. 


\subsection{Project Plan}

In the beginning, the client did not require tools and maps. Instead, he wished to do an indepth spatial and temporal analysis on the real estate market in the study area. In order to correspond to the client's requests, it was required to have much domain knowledge. Therefore, the project plan was changed to include the development of geoprocessing tools.

Figure 3-2 shows the modified project plan. The first step was to understand the project problem, define project scope, and analyze project requirements. The project data were also acquired in this stage. Following this stage was project planning, where a detailed time table of major tasks was outlined. Literature review was intended after, as this would help to identify the appropriate methods for spatial and temporal analysis of housing prices. Once the methods were determined, the project implementation stage began, which included developing both geoprocessing tools and conducting spatiotemporal analysis. The geoprocessing tools would be created for data cleaning, organizing, and processing. The developed tools could be reused by the client to process further housing data for his own research. Once the spatiao-temporal analysis was conducted using the developed geoprocessing tools along with ArcGIS embedded tools, the results were displayed. The results (maps) were animated to see the spatial patterns over time, as well as with static maps (Appendix E to H).

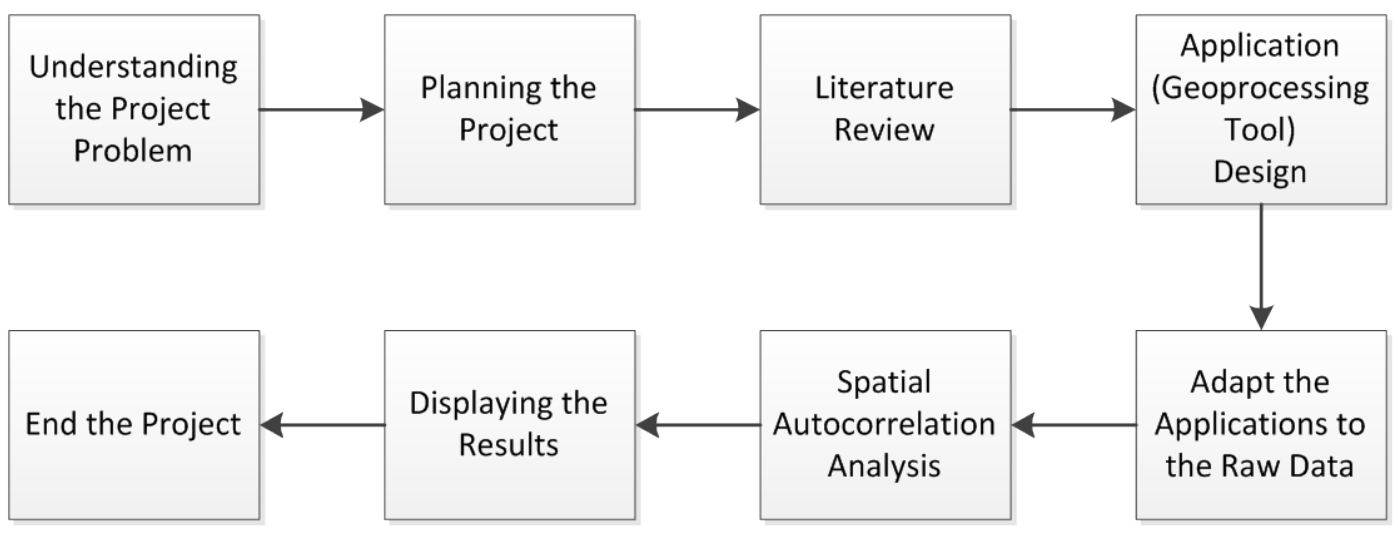

Figure 3-2 Revised Plan

\subsection{Summary}

The project plans consisted of a requirement analysis, system design, and project plan. The requirement analyses were divided into functional analysis and non-functional analysis, which was made up of technical, operational, and transitional requirements. The project plan introduced the initial plan and the updated plan. In order to complete the project on time and reduce many ongoing issues as it progressed, the three requirements' analyses (Technical, Operational, and Transitional) were introduced in this chapter. The components in the system requirements influenced one another. For instance, the system architecture design was helpful to build the project workflow, and the project plan was calibrated based on the project workflow diagram. 


\section{Chapter 4 - Database Design}

Database design for the project is introduced in this chapter. Specifically, the conceptual data model and the logical model are discussed. The conceptual data model shows major entities involved in the project and their relationship. Compared to the conceptual model which is an abstraction of the reality, the logical data model addresses the actual structure of the database. In this project, ArcGIS file geodatabase structure was implemented based on the conceptual data model. Data source and data scrubbing were also addressed, followed by a summary for the chapter.

\subsection{Conceptual Data Model}

Figure 4-1 illustrates the conceptual model for this project. There are four main entities: house, census tract, city, and county. The Housing Sale Records entity represents the house sale records from 2000 to 2009. The house sale records are aggregated to census tracts so that the mean housing unit price for each census tract can be calculated. With the housing unit prices, various intended spatial and temporal analyses are conducted.

Similarly the houses can also be aggregated to county to produce mean housing unit price by county. The last entity included in the conceptual model is City, which includes many census tracts. The analyses results obtained at the census tract level were summarized at the city level to find out which city is the most influential city in the study area.

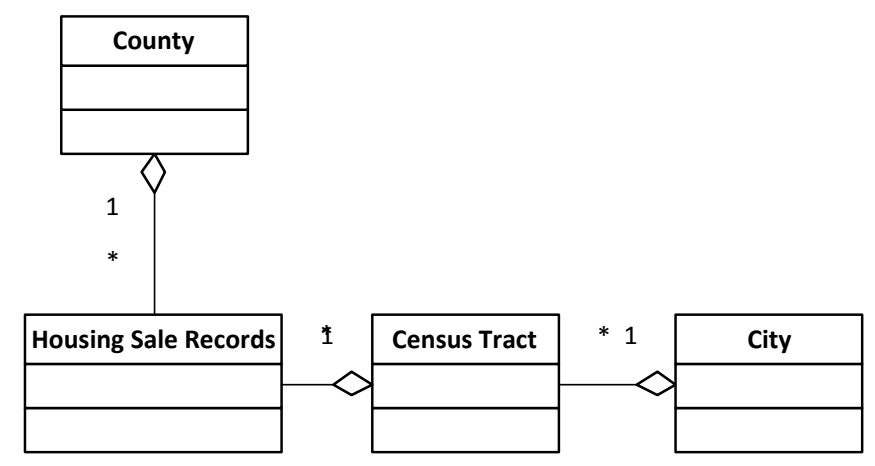

Figure 4-1: Conceptual Data Model

\subsection{Logical Data Model}

Once the conceptual model was designed, the logical data model was developed. In contrast with the conceptual diagram, the logical data model was a specific database design; an ArcGIS file geodatabase was designed and built by using ArcCatalog in ArcGIS Desktop. The purpose of having a file geodatabase was to organize and manage data easily.

While the conceptual data model was created using the UML diagram, the logical data model was designed by using ArcGIS Diagrammer chart. Figure 4-2 shows a snap shot of overall geodatabase structure; three feature datasets and two tables are contained. The two tables contain the house sale records provided by the client. The Original_Data was converted directly from the Excel file provided by the client. However, the sale 
records of the first two quarters of 2008 for Riverside and San Bernardino counties were missing, and therefore the client provided a PDF file at the later stage of the project. The missing data were then processed and imported into the geodatabase. Both data tables include many attributes among which only a few attributes are relevant to the project. They are housing addresses, transaction date, and housing information like sale values and housing square foot structure.

\begin{tabular}{|c|c|c|}
\hline Contents & \begin{tabular}{|l|l|} 
Preview & Description \\
\end{tabular} & \\
\hline Name & & Type \\
\hline 它Geoco & ded_Points & File Geodatabase Feature Dataset \\
\hline 号Spatia & I_Boundary & File Geodatabase Feature Dataset \\
\hline 占Spatia & I_Joined & File Geodatabase Feature Dataset \\
\hline 画Missin & Ig_Data & File Geodatabase Table \\
\hline 拝目Origin & al_Data & File Geodatabase Table \\
\hline
\end{tabular}

Figure 4-2: Logical Data Model

The three feature datasets were created to group the feature classes that share some common characteristics. The first feature dataset contains the geocoded houses that were contained in the two tables. The relevant attributes of the houses were kept in the All_Points_Geocoded feature class (Figure 4-3). The second feature dataset is Spatial_Boundary that includes the modified census tracts (Figure4-3)

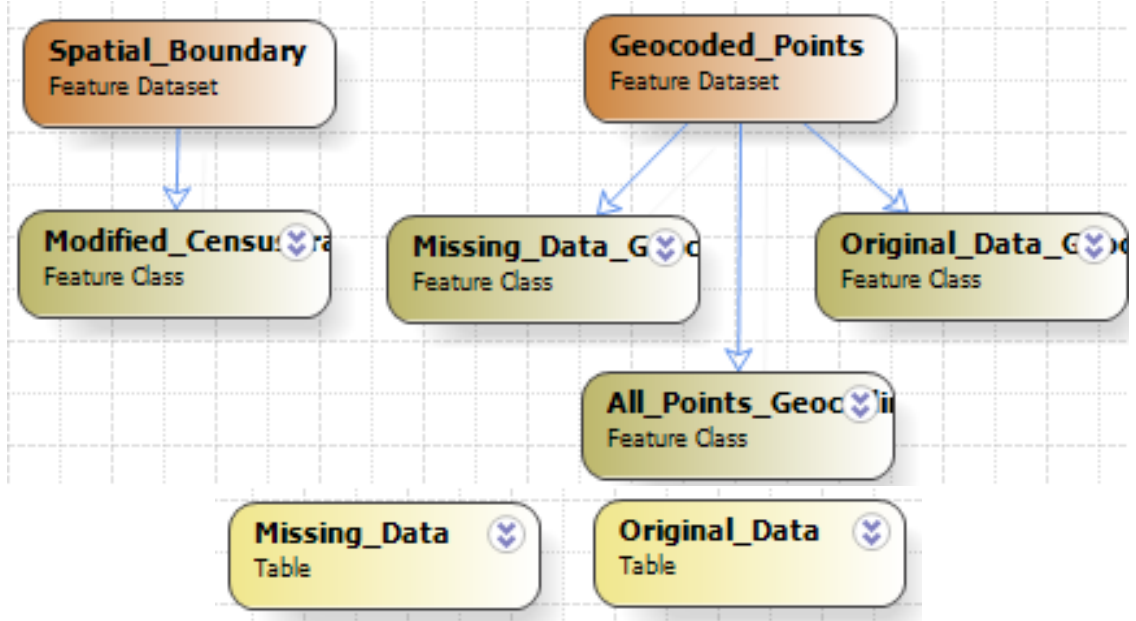

Figure 4-3: Tables, Feature Datasets, and Feature Classes.

To conduct the spatial analysis with the house sale records, the individual points needed to be aggregated to the modified census tracts. According to the client's requirement, the data aggregation was conducted quarterly. The spatial join results were stored in the Spatial Joined feature dataset (Figure 4-4). 


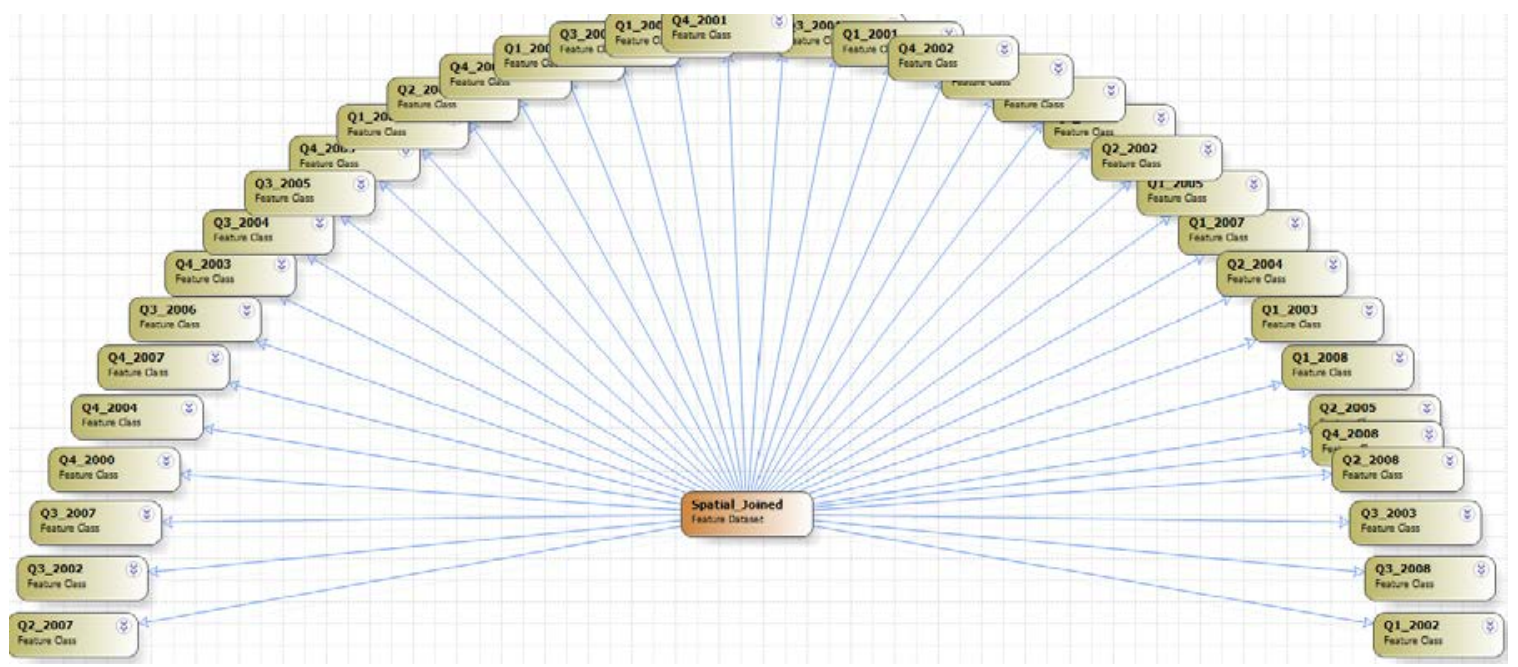

Figure 4-4: Spatial Joined Feature Dataset

The Spatial Joined feature dataset includes 37 feature classes (e.g., Q1_2000, Q2, 2000, Q3, 2000, etc.). Each feature class was named based on the quarter; for example, Q1 2000 indicates this feature class contains the sale records in the first quarter of 2000. These spatially joined feature classes contain four important attribute fields. As an example, the attributes of Q1 2000 are listed in Figure 4-5.

\begin{tabular}{|l|}
\hline Q1_2000 \\
Feature Class \\
\hline - Fields \\
OBJECTID \\
Shape \\
Join_Count \\
\hline TARGET_FID \\
TextVer_CountyFP_Num \\
Price_per_sqfft \\
Year \\
\hline Quarter \\
Shape_Length \\
Shape_Area
\end{tabular}

Figure 4-5: A Sample Feature Class Attribute Fields

The four essential attribute fields for this project highlighted in the black box are TextVer_CountyFP_Num indicating the census tract number with country FIPS code, Price_per_sq_ft for the price per square foot, and Year and Quarter that represent the sale time. 


\subsection{Data Sources}

There were two types of data input: tabular data and spatial data. The tabular data were downloaded from the client's personal website, which is hosted by the University of Redlands. The data were actually purchased by the School of Business at the University of Redlands from a commercial firm called 'DataQuick ${ }^{\circledR}$ ' located in San Diego, California. The missing housing data for San Bernardino and Riverside 2008 first and second quarter sales were collected from the Chicago Title Company. The spatial data were obtained from 2011 TIGER/Line ${ }^{\circledR}$ Shapefiles.

\subsection{Data Scrubbing and Loading}

The Microsoft Excel spreadsheets received from the client contained data necessary for this project except for that in Quarter field. Generating the Quarter field began with dates in Microsoft Excel's typical date format (e.g., 7-6-2008). However, not all the date field was in proper format, the field that has date information need to be checked. Some of the records were recorded as text type. This was particularly the case for 2002 Riverside County data.

The sale dates in the text format needed to be converted to the date formats. For the cases where days were recorded as 0 , such as ' $1-0-2002$ ', the ' 0 ' (day) was replaced with a ' 1 ' to convert the field into the date format that Excel would recognize (i.e., 1-0-2002 to 1-1-2002).

The missing data that were provided later by the client were PDF files, which had to be converted to Excel (.xlsx) before it could be processed with the ArcGIS Desktop. Utilizing free online data converter, Zamzar, the data were exported to .xlsx; however, the columns and rows of the .xlsx spreadsheet needed to be edited to eliminate extraneous data such as company information, and logo. (See Chapter Five for the further explanation of this scrubbing).

\subsection{Summary}

The conceptual and logical models of this study were introduced. The conceptual model was created with UML; the logical model was introduced using ArcGIS Diagrammers, and was built based on the conceptual model. The housing attribute data created by DataQuck ${ }^{\circledR}$ were purchased by the client. Lost data, for the first and second quarters of 2008 in Riverside and San Bernardino Counties were produced by Chicago Title Company in PDF. The PDF was converted to an Excel spreadsheet in order to be compatible with ArcGIS tools and to be able to function within the ArcGIS Desktop environment. The conversion from PDF to Excel was accomplished via an online converter. Finally, spatial and census tracts boundary data were downloaded from the U.S. Census TIGER website. 



\section{Chapter 5 - Implementation}

Once the geodatabase was designed, a set of tools was developed to streamline the data preparation process. Section 5.1 discusses the tools that were used for data cleaning, data conversion, field calculation, geocoding, and spatial join. The measures for spatial and temporal patterns of housing prices and changes in prices are discussed in Section 5.2.

The Python script for each tool and the models can be found in appendices A through $\mathrm{D}$ and I through M. Figure 5-1 shows the general workflow of the implementation, and the remainder of the chapter explains the workflow in detail.

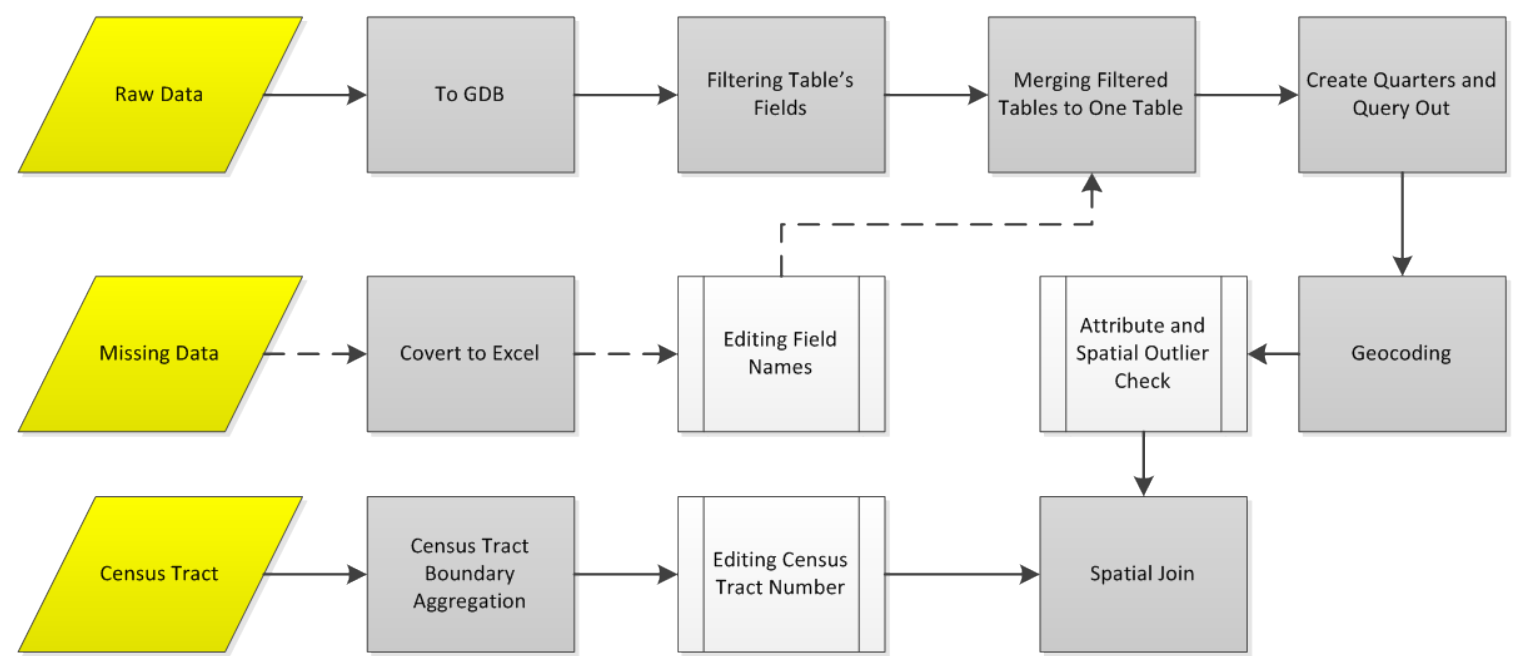

Figure 5-1: Workflow of the Delivered Tool. Dashed lines represent the workflow of the missing data, which is not needed for future analysis. Solid lines represent the workflow of the original data.

\subsection{Data Preparation}

Data preparation was very critical for this project. The raw data needed to be organized and cleaned up in order to be analyzed with desired spatial analysis methods. More importantly, the housing sale records will be updated in the future; therefore, a workflow is required to streamline the data preparation process for future data.

Figure 5-2 shows the geoprocessing tools that were developed for this project. Five of the tools were developed with ArcGIS ModelBuilder and the other four tools were customized using Python scripts. 


\begin{tabular}{|lr|}
\hline (1). Data Filtering and Cleaning & Toolbox Tool \\
(2). SingleFamilyQuery_QuarterGenerator & Toolbox Tool \\
(2.5) MissingDataFiltering & Toolbox Tool \\
(3). Geocode and Projection & Toolbox Tool \\
(3.5) Missing Data and Original Data MergingTool & Toolbox Tool \\
(4). Census Tract Integer Aggregation & Toolbox Tool \\
(5). Spatial Join & Toolbox Tool \\
(6). PercentChange & Toolbox Tool \\
(6.5). DivideByCounty & Toolbox Tool \\
\hline
\end{tabular}

Figure 5-2: Developed Geoprocessing Tools

The delivered tools were numbered based on the sequence of the workflow to help the client process his future data. Tools 2.5 and 3.5 were specifically implemented to work with the missing data. This is because the missing data were provided from a different source, which required additional processing. Tool 6.5 was applied for this project to produce descriptive analysis data by the four counties (Figure 6-1).

\subsubsection{Cleaning and Organizing Data}

Source data were stored in Microsoft Excel format (.xlsx). These raw data had to be imported into the file geodatabase table in the form of a file geodatabase table. Doing this allowed the data to be used directly with the ArcGIS tools that were developed for this project.

The client initially had 30 Excel spreadsheets for Los Angeles County, 11 for Orange County, ten for Riverside County, and nine for San Bernardino County. During the later stage of the project, the client sent a few additional PDF files that contained the missing data (See section 4.3 and 4.4). Processing the missing data will be introduced in Section 5.1.5.

Importing 60 spreadsheets to a file geodatabase proved to be a challenge. ArcGIS is not capable of importing all the table files at one time; therefore, spreadsheets were imported into the geodatabase sequentially, one county at a time.

Each table contains over 418,974 attributes among which many were not relevant, such as owners and loan type. Further, the naming of the same attribute is not always consistent across these tables. To make the data processing faster, these irrelevant attributes were removed; a tool was created for this purpose (Figure 5-3). 


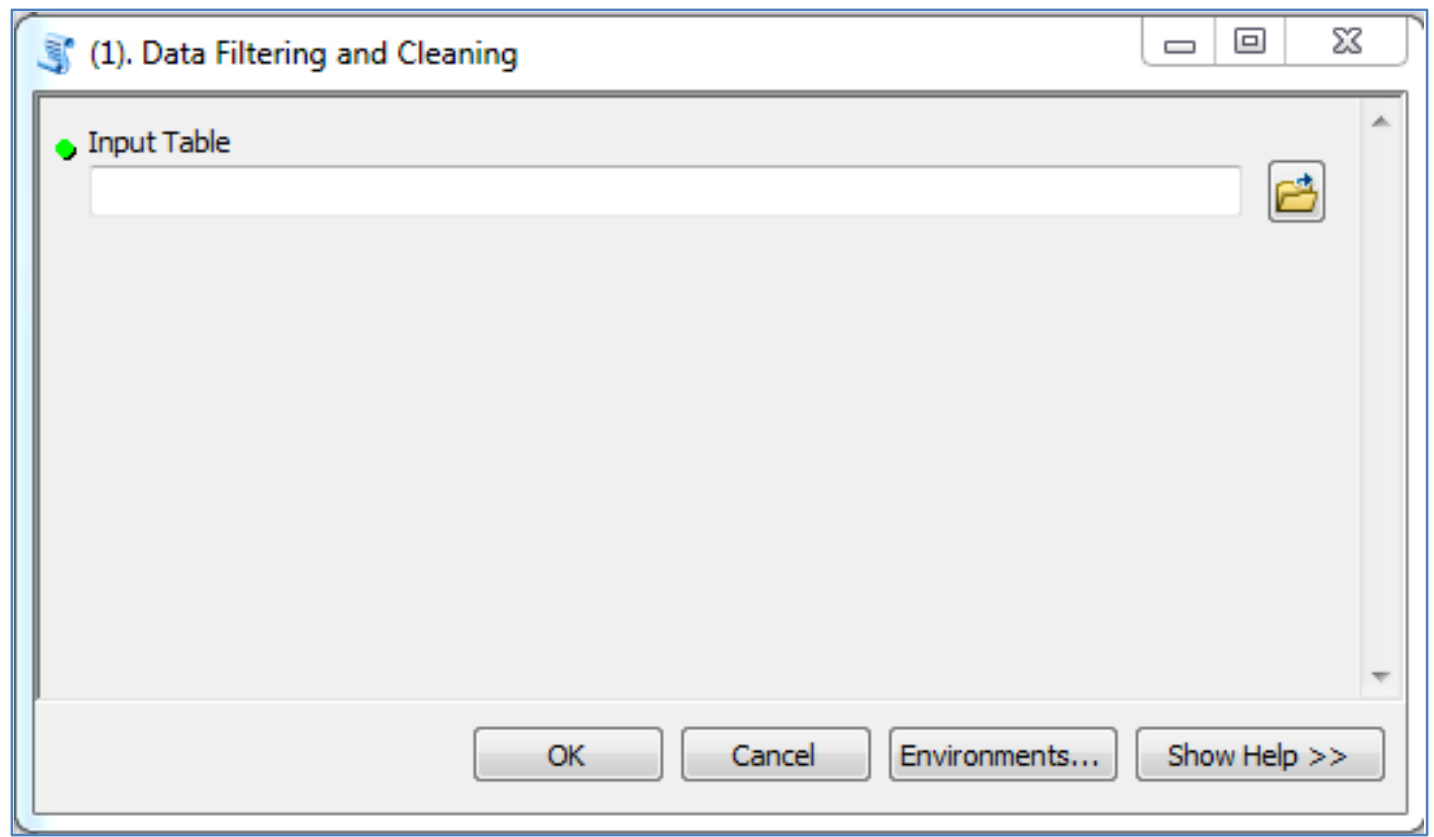

Figure 5-3: User Interface of Data Filtering and Cleaning Tool

The Data Filtering and Cleaning tool requires a geodatabase table as input. When the tool was executed, undesired attributes were filtered out. The attributes that remain in the table include housing address (i.e., Site Address, Site Address City, Site Address State, Site Address Zip, Site Address Zip4, County Name), housing values, and other information (e.g., Sale Date, Sale Value, SQ FT Structure, Use Code Description). Also, the housing records with a sale value of less than $\$ 50,000$, or with no housing information, were removed during the filtering process. The tool also renamed address fields as shown in Table 5-1 in order to make geocoding process faster (See section 5.1.2.). In addition, any sales records that did not come with the housing address were deleted, as were those that did not contain sale values.

Table 5-1. Changing Field Names

\begin{tabular}{|c|c|}
\hline Raw Data Housing Addresses Field Names & After Filtering \\
\hline Site Address & Address \\
\hline Site address City & City \\
\hline Site Address State & State \\
\hline Site Address Zip & Zip \\
\hline Site Address Zip4 & Zip4 \\
\hline
\end{tabular}

Because 60 tables needed to be filtered out using the Filter Irrelevant Attribute tool, the batch option was used to automate the process. Batch allows the user to execute this tool multiple times with different inputs without intervention (Esri, 2006).

After the 60 tables were cleaned, they were merged into a single table; this was accomplished using the Merge tool in ArcGIS. This resulted in single table containing information on 418,974 sale records. For this project, only single-family houses were of interest. A tool named SingleFamilyQuery_QuarterGenerator was created to select single-family houses from both residential and commercial real estate transactions 
(Figure 5-4). Each sale record has a field named Use Code Description to indicate the type of property. The tool only kept records of single-family houses. This reduced the total number of records to 283,654. Additionally, duplicate records (e.g., identical addresses with sale values) were deleted, which resulted in a reduction of records to $235,947$.

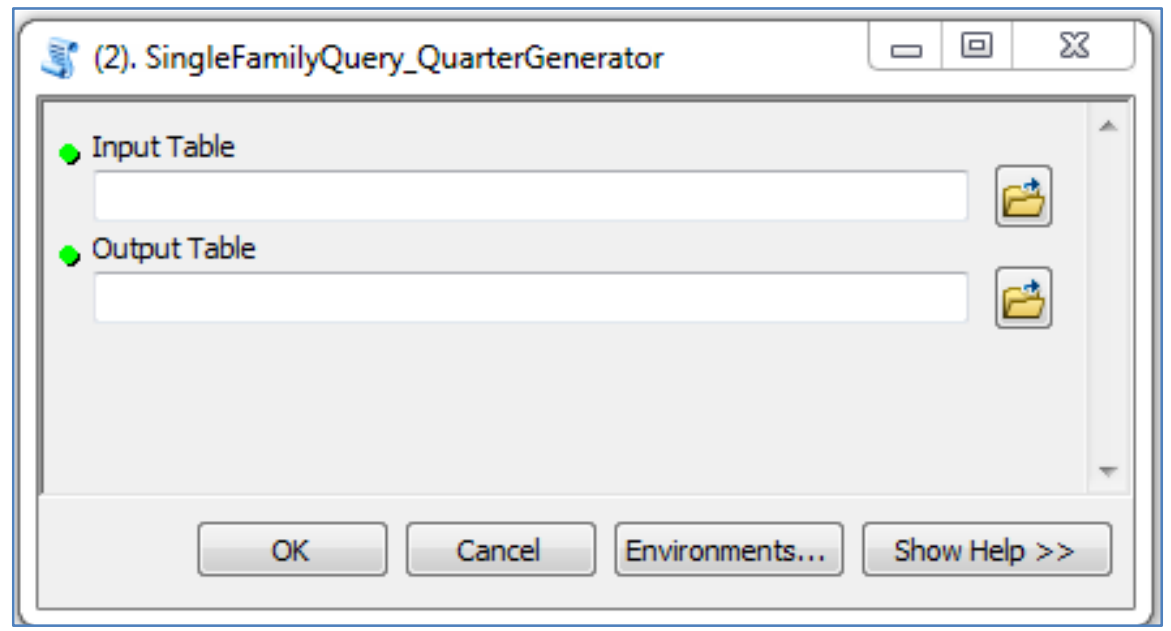

Figure 5-4: SingleFamilyQuery_QuarterGenerator Tool

The client wanted to conduct the analyses based on quarter; however, the raw data did not have a specific attribute for quarter. Therefore, the Quarter field was created and it was calculated based on the transaction dates. The

SingleFamilyQuery_QuarterGenerator tool (Figure 5-4), was developed using Python scripting and the code can be found in Appendix A.

\subsubsection{Geocoding}

Once the data were cleaned, geocoding was conducted to locate the sale records on the map. Geocoding in ArcGIS can be accomplished in one of the two ways: a user can create an address locator to geocode his or her own data, or he or she can use ArcGIS online geocoding services. Originally, the plan was to use ArcGIS online geocoding services because the alternate method requires an accurate road network data as references. The online services’ address locator already contains NAVTEQ’s Q4 2010 reference data for North America (Esri, Inc., 2012). NAVTEQ's techniques are widely used in commercial GPS, and it provides greater flexibility in finding house locations with insufficient housing addresses. However, according to Esri (2012), the online geocoding service is optimized to only geocode a couple of thousand addresses in a single job. For those who subscribe to ArcGIS Online geoservices from Esri, up to 25,000 addresses are able to be geocoded per job. If a user needs to geocode more than 25,000 addresses, Esri recommends dividing the addresses into multiple files of 25,000 addresses each. Because there were more than 25,000 houses that needed to be geocoded for this project, using ArcGIS online address locator was not the best option. The Redlands Institute provided another address locator created by Esri. This address locator is a composite of two different address locators: one for street addresses and the other for postal codes 
With permission from the Redlands Institute, the composite address locator was used directly in the geocoding tool to streamline the geocoding process (Figure 5-5).

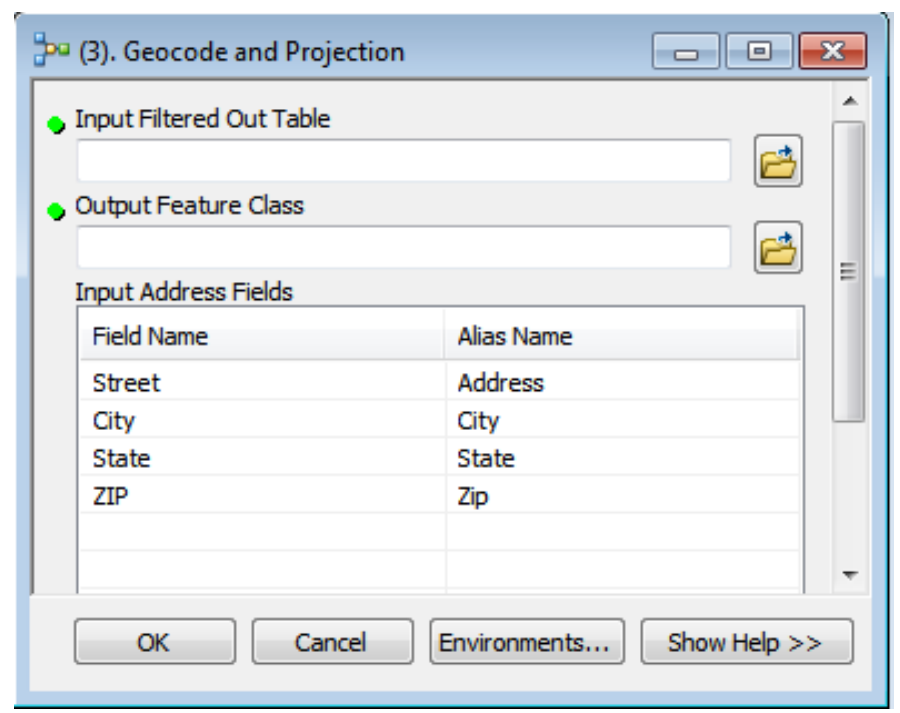

Figure 5-5: Geocoding Tool Interface

The default values for the alias names in the tool match the renamed address fields (Figure 5-5). However, the user could also select the corresponding address fields from the drop-down selection when necessary.

The geocoded points were then projected to 'Lambert Conformal Conic' (NAD 1983 StatePlane California Zone V FIPS 0405 Feet) with North America geographic coordinate system 1983 datum.

\subsubsection{Outlier Check}

After locating the sale records on the map, data accuracy needed to be checked. However, a manual check with this large dataset was not feasible; as an alternative, the ten most expensive and the ten least expensive records in each city were examined. The public real estate website Zillow (www.zillow.com) combined with Google Street View and ArcGIS Imagery Basemap was used to check these extreme values. For example, a house in Los Angeles was recorded for 37 million dollars in the delivered table and Zillow showed that the location of the house was next to an empty field. Based on Zillow's satellite images with the housing prices information, the house was considered as an outlier and removed.

In addition, the houses that had very few neighboring sales were removed. This was because the analyses needed to be conducted at the census tract level and representing the general housing prices for a census tract with only one or two sales might be misleading. Figure 5-6 shows all of Los Angeles County's housing points. The yellow arrowed points were deemed as spatial outliers and were removed from the following analyses. 


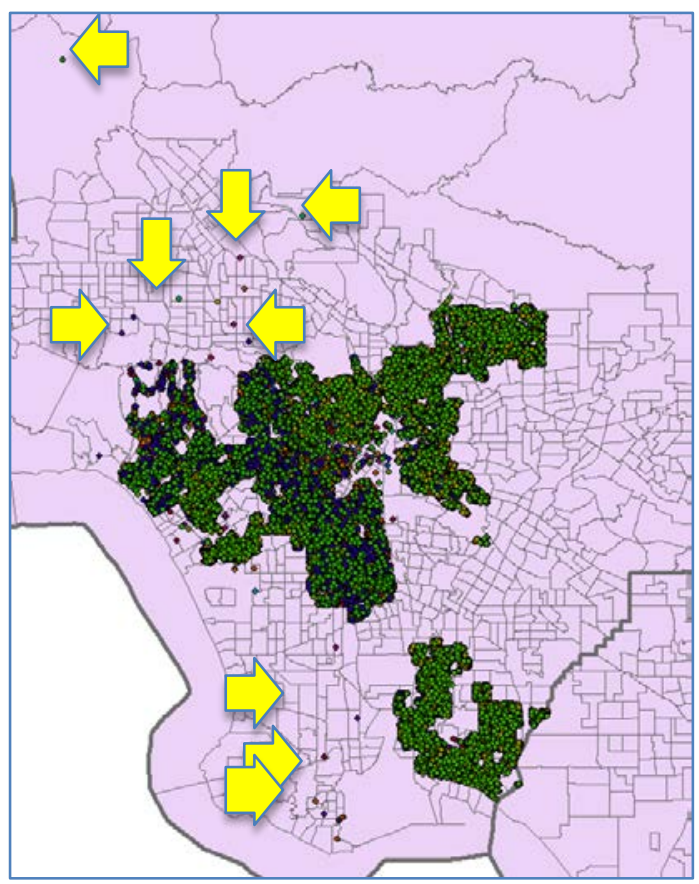

Figure 5-6: Spatial Outliers (Dots represent housing sale records in different year)

After the spatial and attribute outlier check, the overall number of housing points was reduced to 235,534 .

\subsubsection{Missing Data}

Missing data for the first and second quarters of 2008 for both Riverside and San Bernardino Counties were provided in 37 PDF files at the city level (for seven cities). The PDF files were produced by the Chicago Title Company. Because PDF is not compatible with ArcGIS, the PDF files needed to be converted to an Excel spreadsheet and stored in the geodatabase. A free online file conversion tool, Zamzar (http://www.zamzar.com/), was used to convert the PDF to Excel; however, the PDF files had different structure of displaying the data than the data from DataQuick ${ }^{\circledR}$. Therefore, some manual edits were required. Figure 5-7 shows the conversion between the PDF and Excel. The headings of the files were part of the spreadsheet and were manually deleted. 


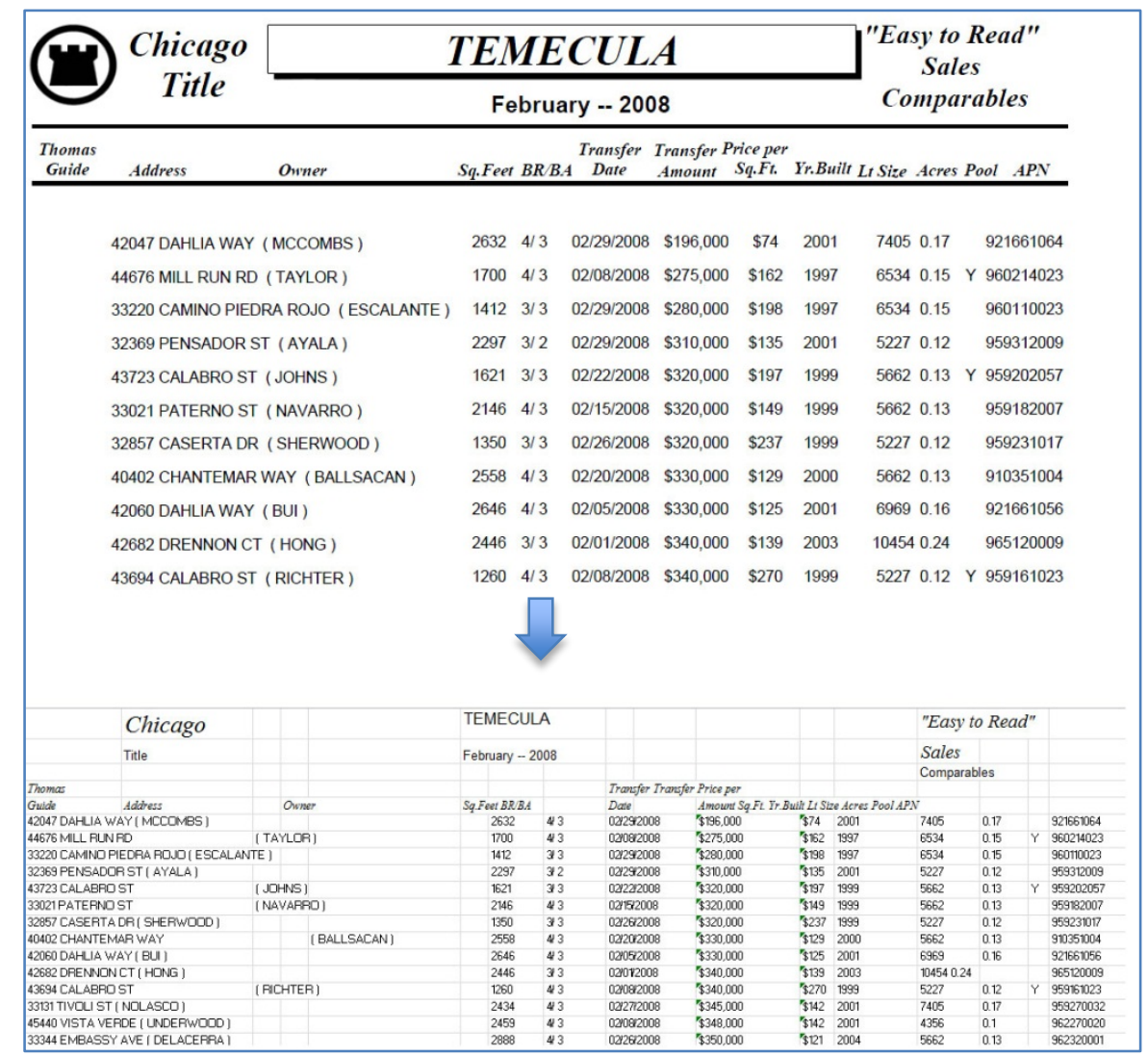

Figure 5-7: Missing Data in PDF (top) and Same Data in Excel (bottom)

The 37 Excel spreadsheets were combined to create seven spreadsheets (one spreadsheet was created for each city). At this stage, the missing data were ready to be filtered and geocoded using the same process that was described earlier in the chapter (Section 5.1.1 to 5.1.3).

The geocoded results of missing housing data and the original housing data points were merged together for spatial joining. The delivered merging tool (Missing Data and Original Data Merging Tool) needed to be used for this step to optimize the geocoded feature's attribute fields for the spatial join. The spatial joining will be discussed in Section 5.1.6.

The tool interface is shown in Figure 5-8. The inputs are the two geocoded feature classes and the output will be one merged feature class. 


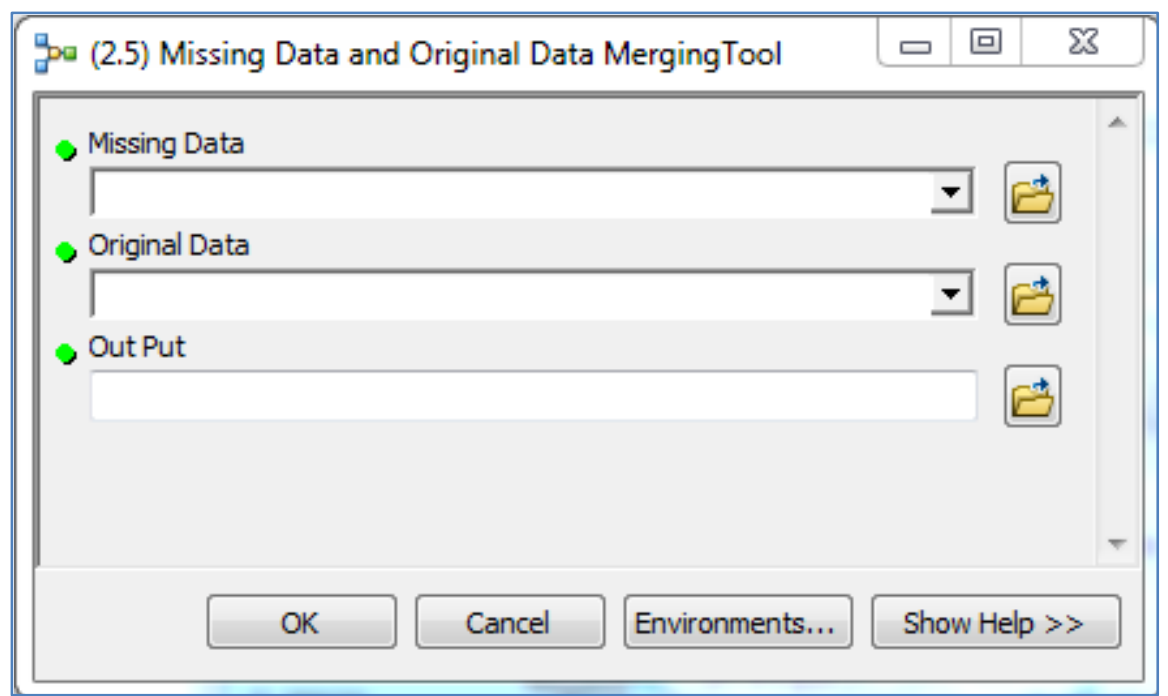

Figure 5-8: Missing Data and Original Data Merging Tool

\subsubsection{Census Track Modification}

One of the client's requests was to have census tract boundaries based on the integer value. For example, census tracts 102.23, 102.24, 102.25, and 102.26 need to be aggregated to one census tract (102) as they share the same integer value in their tract numbers. The Census Tract Integer Aggregation tool shown in Figure 5-9 allows the client to modify the census tracts that are downloaded from the U.S. Census Bureau website.

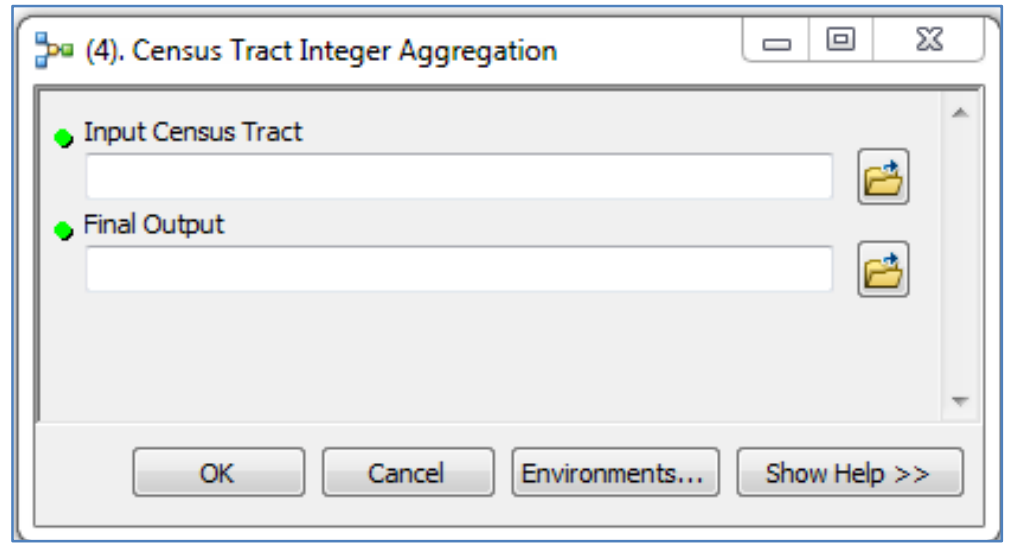

Figure 5-9: Census Tract Integer Aggregation Tool

Figure 5-10 shows an example of the aggregation, in which the blue units are the census tracts downloaded from the U.S. Census Bureau and the black units are the modified boundaries. 


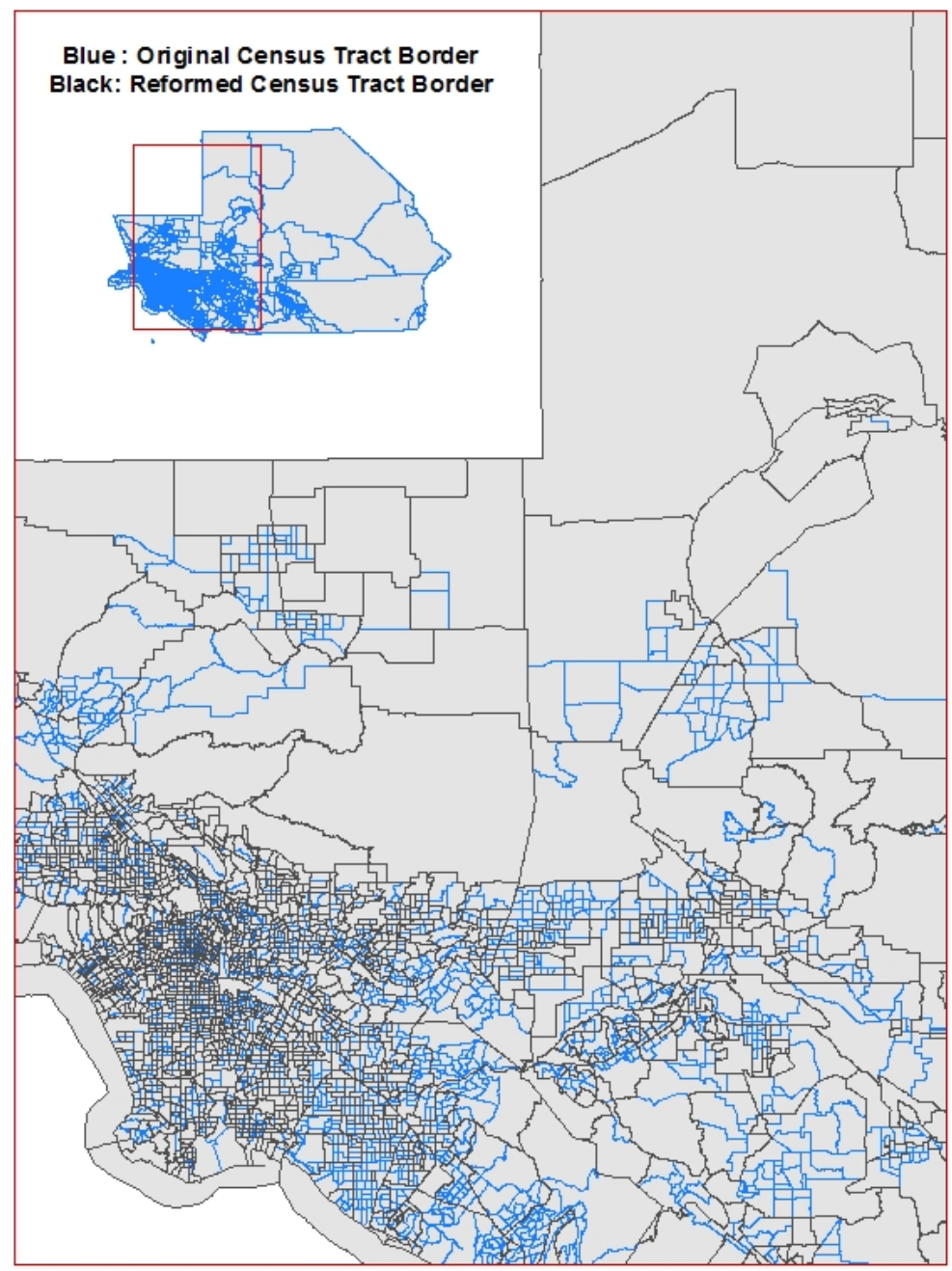

Figure 5-10: Census Tract Border Reform

After the census tract boundaries were redrawn, a minor problem was encountered: some census tracts that are geographically separated share the same integer number. To address this problem, the integer numbers of these census tracts were manually modified so that they can be distinguished at the integer level. For example, the purple census tracts in Figure 5-11 have the same integer number of 9800, but they are far apart. 


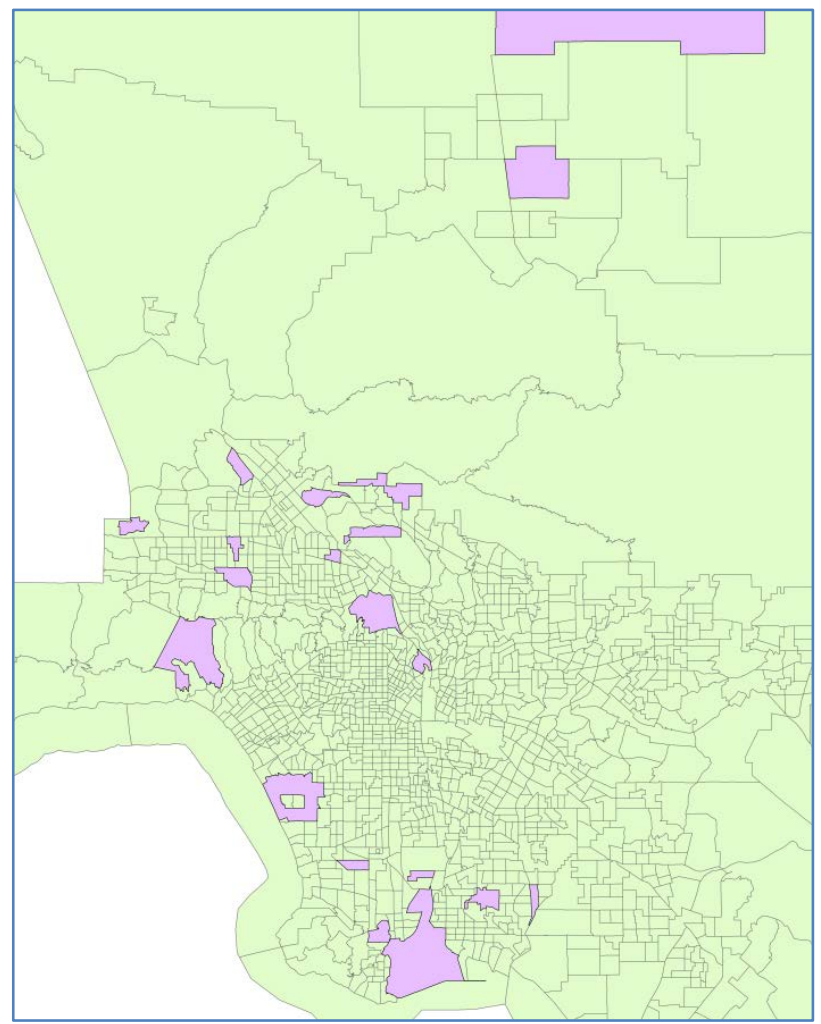

Figure 5-11: Census Tract 9800s in Los Angeles County

The integer numbers of these census tracts were changed to 9800a, 9800b, 9800c, and so forth, in order to distinguish them from each other.

\subsubsection{Spatial Join}

Spatial join in ArcGIS means joining point features to other (polygon) features based on their spatial relationship (Esri, Inc., 2012). In other words, a spatial join produces an aggregation of points that fall in the same geographic area and an aggregation of specific attributes. In this project, when the housing points were aggregated to the census tracts, the mean unit price for census tracts (price per square foot) was calculated. The Spatial Join tool, embedded in the ArcGIS Toolbox, was modified for this specific project (Figure 5-12).

When the tool was executed, the input housing points were first divided into quarters and years for the following spatial and temporal analyses. Then, the housing points within the same duration were aggregated to the specified spatial boundaries (in this case, the census tracts). 


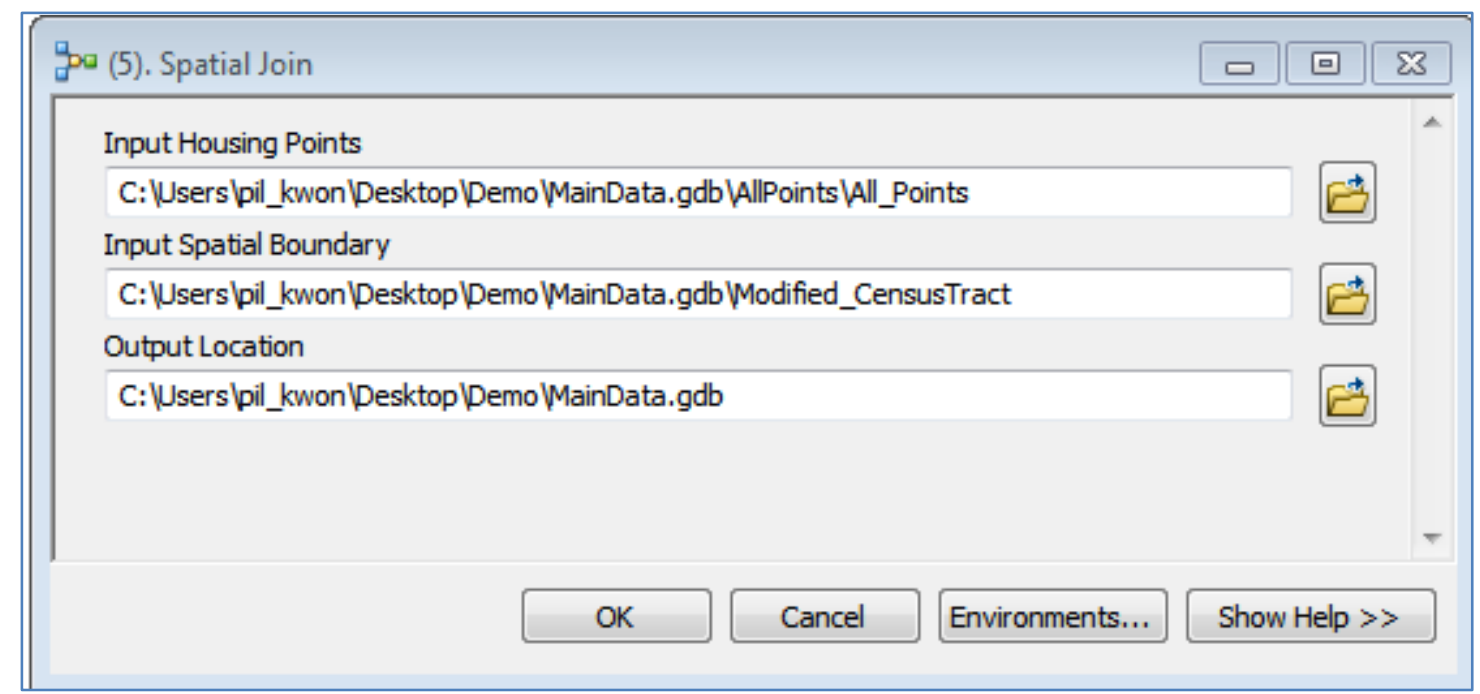

Figure 5-12: Spatial Join Tool Interface

The output feature classes were named automatically based on the time duration such as Q1_2000, Q2_2000, Q3_2000, and so forth. By default, this tool was set to produce mean values of housing unit prices. In reality, the median values are often used to represent housing markets; however, the ArcGIS Spatial Join tool only allows mean values. Based on a few tests, it was discovered that there was little difference between mean and median values.

\subsubsection{Percentage Changes Calculation}

One of the questions that this project aimed to answer was which neighborhoods had led price changes. To address this issue, the percentage change of housing unit price at different times was computed. The equation for calculating the price changes in percentage is shown below:

$$
\text { Housing Unit Price Percentage Changes }=\frac{Q(n+1)-Q(n)}{Q(n)} \times 100
$$

where $n$ is the quarter number. For instance, the housing unit price percentage changes between the second quarter of 2000 (\$100) and the first quarter of 2000 (\$50) would be calculated as $\frac{\$ 100-\$ 50}{\$ 50} \times 100=100 \%$. The result interpreted would be that in the year 2000 , the housing unit prices increased $100 \%$ from the first quarter to the second quarter.

A GIS tool was created to automate the computation process for more than 20,000 census tracts over 36 quarters. Figure 5-13 shows the interface of this tool. 


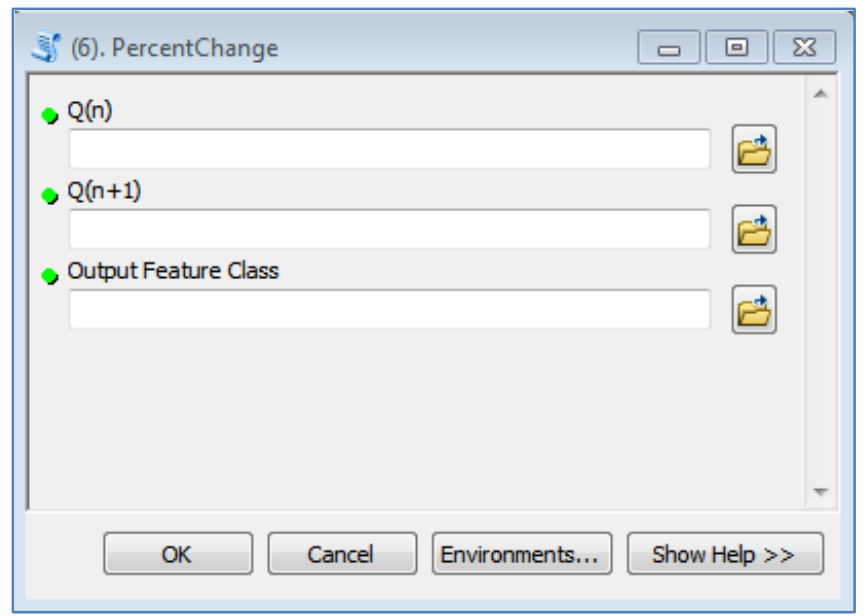

Figure 5-13: PercentChange Tool

Because not every quarter had transactions for a census tract, the denominator could be zero; therefore, if $\mathrm{Q}_{(n)}$ is zero (no data), an error would occur. When this tool is executed, any occurrences where $\mathrm{Q}_{(n)}$ equals zero are removed before processing the calculations.

For large datasets, the batch option is recommended.

\subsection{Data Analysis}

After the data were prepared using the previously described tools, they were ready for spatio-temporal analyses. Based on the literature review, Moran's I, local Moran's $I$, and $G i^{*}$ statistic were used to evaluate spatial patterns of the housing prices. To identify the most influential neighborhoods, spatial patterns of price changes were evaluated using local Moran's $I$.

Moran's I was applied first to assess the overall spatial distribution of housing unit prices and percentage changes in prices; therefore, it is a global measure. Specifically, Moran's I measures a variable over a space to look for randomness, clusters, or uniformity in its geographical location. The formulation of Moran's $I$ index is expressed as:

$$
I=\frac{n}{S} * \frac{\sum_{i=1}^{n} \sum_{j=1}^{n} W_{i j}\left(x_{\mathrm{i}}-\bar{x}\right)\left(x_{\mathrm{j}}-\bar{x}\right)}{\sum_{i=0}^{n}\left(x_{\mathrm{i}}-\bar{x}\right)^{2}}
$$

where $n$ is the number of geographic units, $\bar{x}$ is the mean of the variable, $x i$ and $x_{j}$ are the variable values at locations $i$ and $j$ respectively. $W_{i j}$ is the spatial weight between observations, while $s$ is the sum of the elements of the weight matrix given as:

$$
\sum_{i=0}^{n} \sum_{j=0}^{n} W_{i j}
$$

The results of the $I$ index will be between -1 and 1 . A negative value of the $I$ index indicate the tendency of the variable to be uniformly distributed (negative autocorrelation); a positive value of the $I$ index indicates the tendency of clustering (positive autocorrelation). 
Compared to the global Moran's I, local measures like local Moran's I and Getis \& Ord's $G i^{*}$ statistic detect local variation in spatial autocorrelation. The local Moran's I formula is defined as:

$$
I_{\mathrm{i}}=Z_{i} \sum_{j}^{n} W_{\mathrm{ij}} Z_{j}
$$

where $z_{i}$ is the original variable $x_{i}$ in standardized form as:

$$
Z_{i}=\frac{X_{i}-\bar{x}}{S D_{x}}
$$

Using local Moran's $I$, four different neighborhoods were identified: clusters of neighborhoods with high values, clusters of neighborhoods with low values, the abnormal geographic area in the neighborhoods with low values, and the abnormal geographic area in the neighborhoods with high values. In contrast, Getis \& Ord's Gi* statistic can only identify clusters of high values and clusters of low values. It was not designed to detect local outliers.

In all of these measures, spatial weight matrix needs to be specified because it defines the spatial relationships of all geographic units. In this project, the census tracts were not continuous; polygon contiguity is an inappropriate way to define the spatial relationship between the census tracts. Therefore, the spatial relationship was based on the squared inverse distance. That is, the further census tracts have much less of an influence than closer census tracts. This reflects the strong locational dependence of housing prices.

The spatial autocorrelation analyses with these measures were implemented with the ArcGIS Spatial Statistical Toolset, and the results were exported to .dbf format (dBase table, which is compatible with Microsoft Excel) for further analysis in Excel.

\subsection{Summary}

In Chapter 5, the geoprocessing tools developed in this project were explained, and a description of how they work was provided. For this project, there were three sets of input data. The main data source was housing data that came in the form of Microsoft Excel spreadsheets. Another was the missing housing data that was provided in PDF format. The final input was a spatial boundary of census tract from the U.S. Census Bureau. After the inputs were processed through customized and developed tools, the output data was prepared for running through spatial statistical analysis tools and temporal analysis with Excel. 


\section{Chapter 6 - Results and Analysis}

Once data were summarized and organized into tables (as described in Chapter Five), various spatial and temporal analyses were conducted to analyze housing unit price patterns over time and housing unit price changes. Chapter Six discusses the descriptive statistics of housing unit price trends over time and the results of the spatial statistical analyses, which include Moran’s I result, local Moran’s I maps, and Gi* maps.

\subsection{General Pattern of Housing Unit Prices in Southern California}

Data provided by the clients included sales records for 16 different cities located in four counties. After the sale records were aggregated by county, the mean housing unit prices (sale price per square foot) were calculated for each quarter as shown in Figure 6-1.

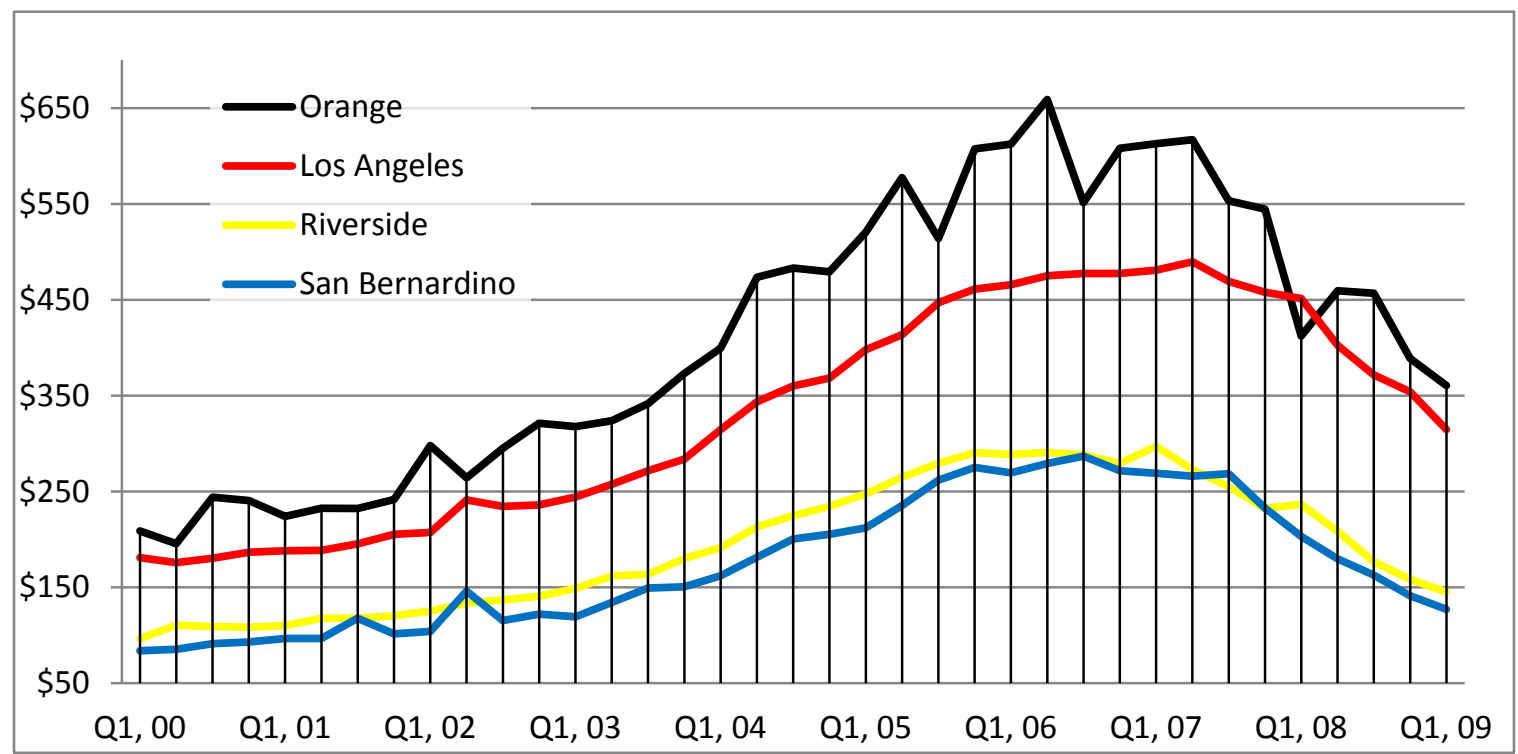

Figure 6-1: Mean Housing Unit Prices by County (Unit: \$/Sq.Ft)

In general, housing prices kept increasing until the subprime mortgage crisis that began in 2006 and 2007. As shown in Table 6-1, the housing markets in the four counties reached their peaks in either 2006 or 2007 depending on the county. After the onset of the subprime mortgage crisis, overall unit prices dropped so significantly that by the end of 2008 the housing market in the study area was roughly comparable to that of five years earlier.

Table 6-1. Highest Housing Unit Prices in Each County

\begin{tabular}{|l|l|l|}
\hline & $\begin{array}{l}\text { Quarters when the highest housing price occurred } \\
\text { before the crisis }\end{array}$ & $\begin{array}{l}\text { Highest unit housing } \\
\text { prices }\end{array}$ \\
\hline Orange & Q2, 2006 & $\$ 658.99$ \\
\hline Los Angeles & Q2, 2007 & $\$ 489.71$ \\
\hline Riverside & Q1, 2007 & $\$ 297.07$ \\
\hline San Bernardino & Q3, 2006 & $\$ 286.76$ \\
\hline
\end{tabular}


Figure 6-1 also indicates that housing unit prices in both Orange and Los Angeles Counties were much higher than those in Riverside and San Bernardino Counties. It is worth noting that the housing price trends depicted in Figure 6-1 were obtained from sale records for 16 cities. If sales records from other cities were available, the general housing price in the four counties could change. Compared to the curve for Orange County (the black curve in the figure), the other three curves for Los Angeles, Riverside, and San Bernardino Counties are smoother. This suggests that sale prices in Orange County experienced greater variations. Figure 6-2 shows an example in which two significant price drops can be found at Q3, 2005 and Q3, 2006.

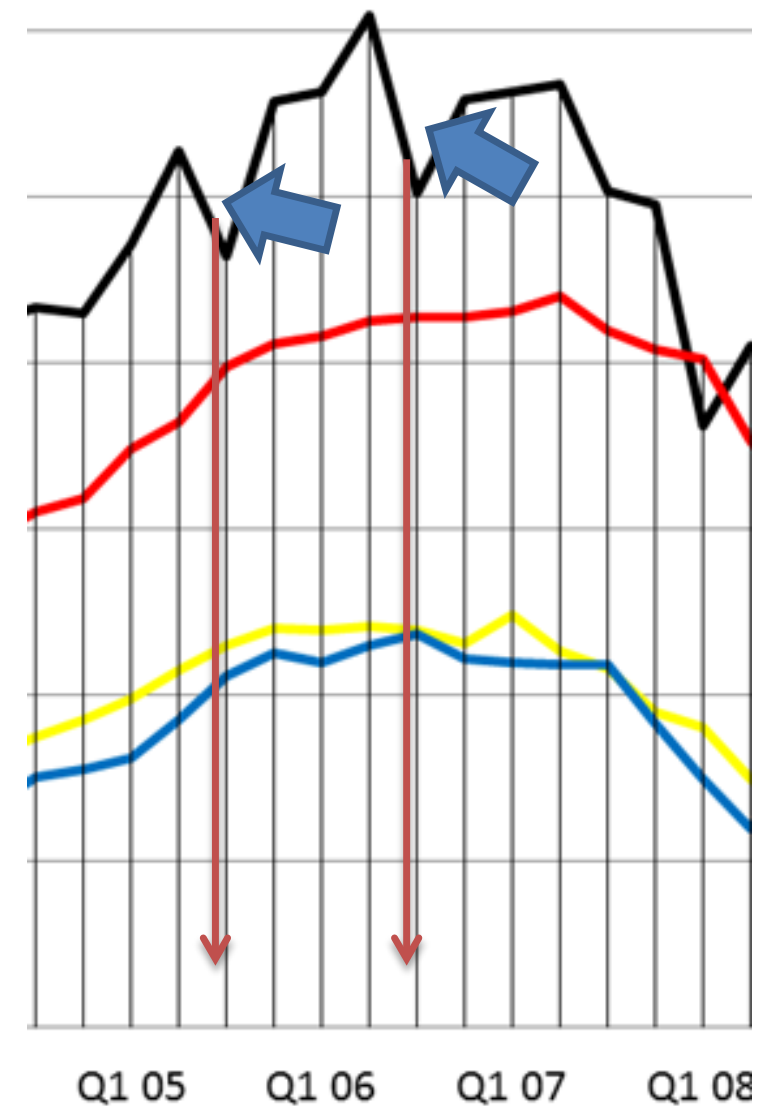

Figure 6-2: Price Variations in Orange County

Figure 6-3 displays the mean unit prices by census tract in Orange County for Q2-Q4, 2005 and Q2-Q4, 2006 respectively. The comparison of sale prices indicates that the price drops at Q3, 2005 and Q3, 2006 were actually caused by the price variations among local neighborhoods. For example, neighborhoods close to the coastline such as Newport Beach had much higher sale prices than inland neighborhoods, such as Irvine. Because there were no sales in the expensive neighborhoods during the two quarters, the overall unit prices of Orange County dropped correspondingly. 

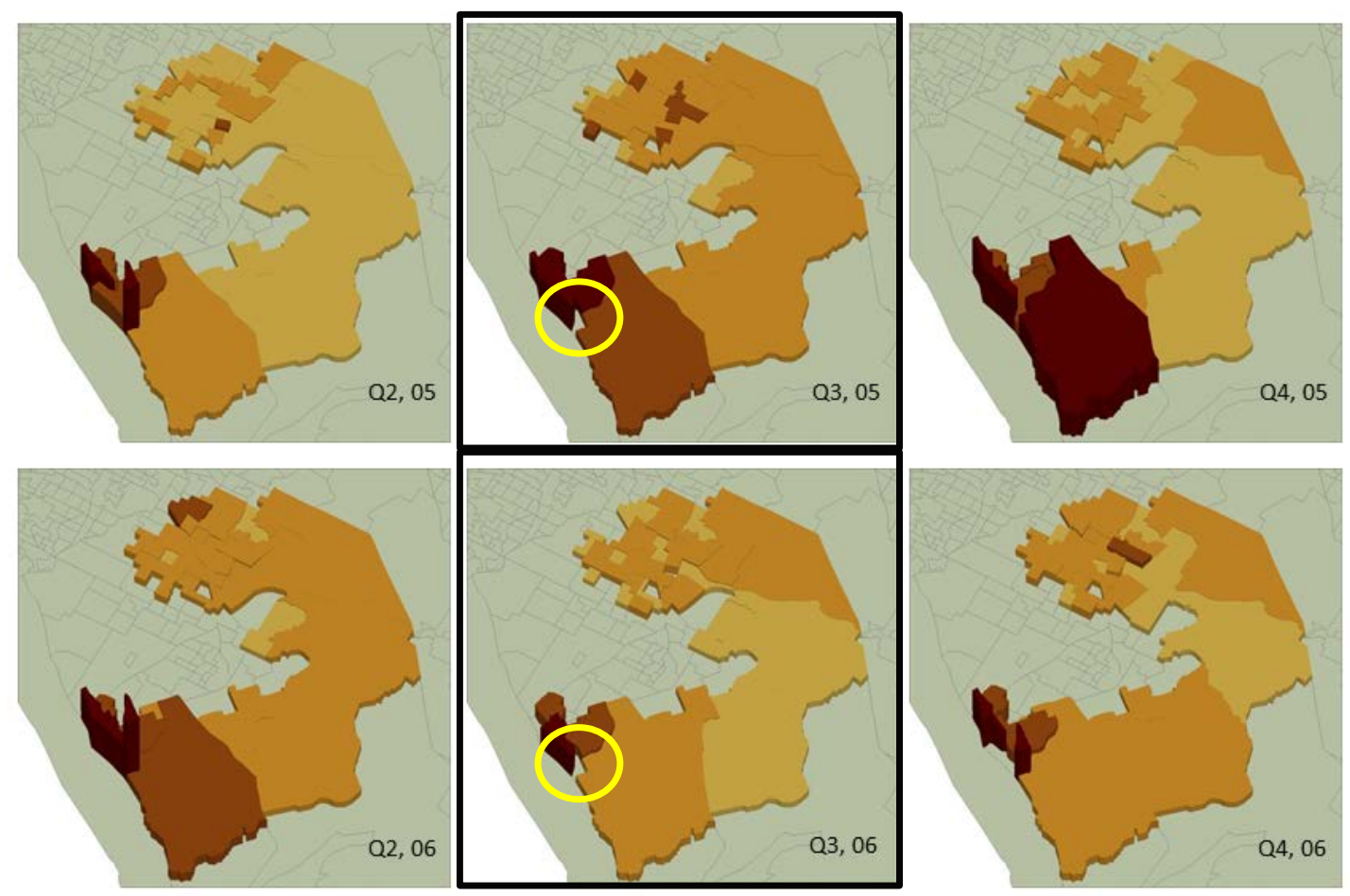

Figure 6-3: Housing Price Changes in Orange County during 2005 and 2006

\subsection{Spatial Patterns of Housing Prices per Square Foot}

The spatial pattern of unit housing prices was examined using different spatial autocorrelation measures, and the results were visualized chronologically to identify the how the spatial distribution of unit housing prices varied over time.

Table 6-2 lists the global Moran's I for the entire census tracts in the study area. Apparently, the global Moran's I indices are all positive, and the significance test shows that the unit housing prices are significantly clustered at the census tracts level. This result is anticipated because housing price is known to be locational dependent and neighboring areas that are often share similar socio-economic characteristics are likely to have similar housing prices. The global Moran's I was also calculated for each county and the results indicate that housing unit prices are clustered within each county. However, the spatial autocorrelation patterns very across different cities. For example, the city of Los Angeles has much more census tracts than other cities. Its global Moran's $I$ result shows that housing prices of census tracts were significantly clustered. The global Moran's I results for cities that contain few census tracts (e.g., Palm Springs, Redlands, Ontario, Chino, and Newport Beach) indicate that the tracts in these city boundaries had random spatial distribution. 
Table 6-2. Moran's I of Housing Unit Prices from 2000 to 2009 by Census Tracts

\begin{tabular}{|c|c|c|c|c|c|}
\hline Quarter & Moran's I & $p$-value & Quarter & Moran's I & $p$-value \\
\hline Q1 00 & 0.21 & 0.00 & Q1 05 & 0.26 & 0.00 \\
\hline Q2 00 & 0.42 & 0.00 & Q2 05 & 0.23 & 0.00 \\
\hline Q3 00 & 0.32 & 0.00 & Q3 05 & 0.29 & 0.00 \\
\hline Q4 00 & 0.29 & 0.00 & Q4 05 & 0.23 & 0.00 \\
\hline Q1 01 & 0.39 & 0.00 & Q1 06 & 0.25 & 0.00 \\
\hline Q2 01 & 0.42 & 0.00 & Q2 06 & 0.18 & 0.00 \\
\hline Q3 01 & 0.39 & 0.00 & Q3 06 & 0.29 & 0.00 \\
\hline Q4 01 & 0.43 & 0.00 & Q4 06 & 0.16 & 0.00 \\
\hline Q1 02 & 0.31 & 0.00 & Q1 07 & 0.14 & 0.00 \\
\hline Q2 02 & 0.02 & 0.00 & Q2 07 & 0.17 & 0.00 \\
\hline Q3 02 & 0.34 & 0.00 & Q3 07 & 0.28 & 0.00 \\
\hline $\mathrm{Q} 402$ & 0.33 & 0.00 & Q4 07 & 0.23 & 0.00 \\
\hline Q1 03 & 0.38 & 0.00 & Q1 08 & 0.13 & 0.00 \\
\hline Q2 03 & 0.45 & 0.00 & Q2 08 & 0.26 & 0.00 \\
\hline Q3 03 & 0.43 & 0.00 & Q3 08 & 0.31 & 0.00 \\
\hline Q4 03 & 0.42 & 0.00 & Q4 08 & 0.19 & 0.00 \\
\hline Q1 04 & 0.43 & 0.00 & Q1 09 & 0.36 & 0.00 \\
\hline Q2 04 & 0.34 & 0.00 & & & \\
\hline Q3 04 & 0.34 & 0.00 & & & \\
\hline Q4 04 & 0.30 & 0.00 & & & \\
\hline
\end{tabular}

Although the global Moran's I results show a clustering pattern, it does not prove where the clusters are located. To detect local clusters, Anselin's local Moran's I and Getis \& Ord's $G_{i}{ }^{*}$ statistic were utilized.

Based on local Moran's I statistic, the statistically significant clusters of areas that have high housing unit prices were Newport Beach in Orange County, north Santa Monica and Los Angeles in Los Angeles County. On the other hand, San Bernardino in San Bernardino County had clusters of low housing unit prices. The Gi* statistic also suggest the similar pattern. The results from local measures confirm common knowledge of the housing market in Southern California: expensive areas are located in the west (the coastline), while inland areas experience much lower housing prices. To explore how spatial autocorrelations varied over time, both local measures were evaluated by year and by quarter. Figure 6-4 shows the local Moran's $I$ by year in the study area. The red census tracts show the clusters of high housing price areas, while blue census tracts show the clusters of low housing price areas. Usually, the census tracts located in the coastline such as Santa Monica and Newport Beach had higher housing unit prices than inland areas like San Bernardino and Riverside throughout the years. However, a few census tracts in downtown Los Angeles were observed as low even though they are located to close to the coastline. 


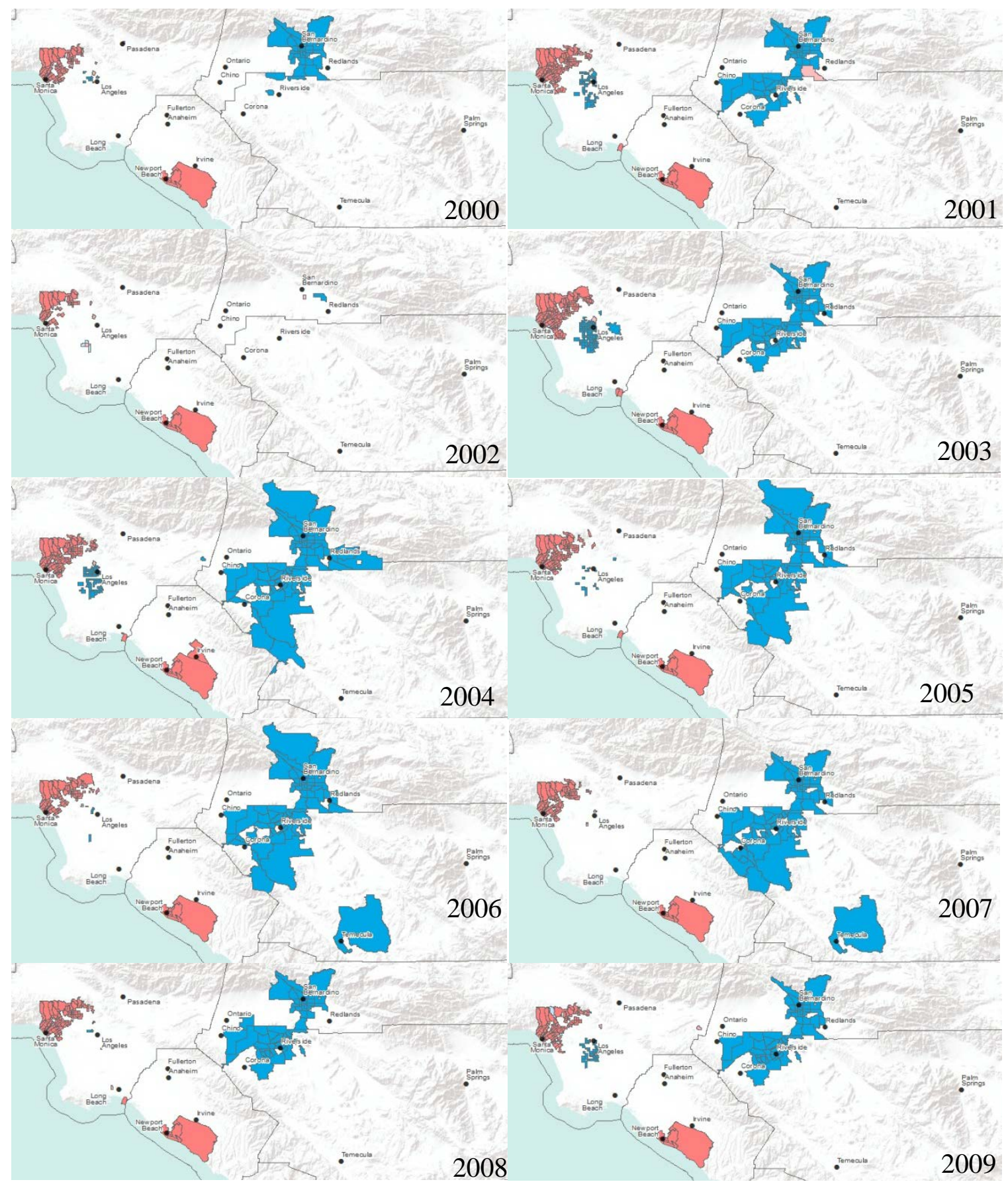

Figure 6-4: Spatial Clusters of Housing Price by Year

The local Moran's I maps by quarter also show a very similar pattern as seen in Figure 6-4: over time, clusters of expensive areas lie on the coastal areas, while inland areas are relatively inexpensive. The city center of Los Angeles was detected as a cluster of low housing values. In addition, $G i^{*}$ statistic was also calculated by quarter (Appendix F). The $G i^{*}$ maps suggest that Santa Monica, Newport Beach, southern Long Beach, and occasionally Redlands are the significant clusters of high housing prices. However, very few significant clusters of inexpensive areas were detected by the $G i^{*}$ statistic. 


\subsection{Spatial Pattern of Percentage Changes}

One of the project goals was to find out which neighborhoods were leading the housing prices in the study area. To find the answer, the rates of housing unit prices change over time were examined. Positive changes means rising prices, while negative changes suggest declining prices. First, the census tracts that had top percentage changes, including both positive and negative values, were examined by quarter to identify the individual leading census tracts. However, there were no census tracts that continuously observed a greater price changes than others throughout the study time. This indicates that no single census tract could always lead price changes. Therefore, groups of census tracts were analyzed with spatial autocorrelation measures.

Evaluating, the spatial pattern of the percentage changes can show which neighborhoods (a group of census tracts) experienced the fastest price changes. It was anticipated to identify one or more consistent significant clusters where prices always increased or decreased faster than other neighborhoods.

Based on the calculated price changes in percent global Moran's I was calculated to examine the overall spatial autocorrelation of price changes for the entire study area. The results shown in Table 6-3 indicate that over time, there were mostly no significant spatial patterns of price changes. In other words, there were no significant clusters in which price consistently grew/dropped faster than other areas.

\section{Table 6-3. Moran's I of Percentage Changes of Housing Unit Prices from 2000 to 2008}

\begin{tabular}{|l|rr|l|r|r|}
\hline Quarter & Moran's I & p-value & Quarter & Moran's $I$ & p-value \\
\hline Q1,00 - Q2,00 & 0.03 & 0.09 & Q1,04 - Q2,04 & 0.00 & 0.89 \\
Q2,00 - Q3,00 & 0.00 & 0.96 & Q2,04 - Q3,04 & 0.03 & 0.07 \\
Q3,00 - Q4,00 & 0.02 & 0.16 & Q3,04 - Q4,04 & -0.01 & 0.64 \\
Q4,00 - Q1,01 & -0.05 & 0.02 & Q4,04 - Q1,05 & -0.02 & 0.16 \\
\hline Q1,01 - Q2,01 & -0.02 & 0.40 & Q1,05 - Q2,05 & 0.03 & 0.02 \\
Q2,01 - Q3,01 & 0.03 & 0.03 & Q2,05 - Q3,05 & -0.03 & 0.08 \\
Q3,01 - Q4,01 & 0.00 & 0.87 & Q3,05 - Q4,05 & -0.03 & 0.12 \\
Q4,01 - Q1,02 & 0.02 & 0.30 & Q4,05 - Q1,06 & 0.04 & 0.01 \\
\hline Q1,02 - Q2,02 & 0.00 & 0.76 & Q1,06 - Q2,06 & 0.03 & 0.05 \\
Q2,02 - Q3,02 & 0.00 & 0.78 & Q2,06 - Q3,06 & 0.00 & 0.92 \\
Q3,02 - Q4,02 & 0.01 & 0.58 & Q3,06 - Q4,06 & 0.02 & 0.16 \\
Q4,02 - Q1,03 & -0.01 & 0.60 & Q4,06 - Q1,07 & -0.01 & 0.47 \\
\hline Q1,03 - Q2,03 & -0.02 & 0.28 & Q1,07 - Q2,07 & 0.00 & 0.88 \\
Q2,03 - Q3,03 & -0.01 & 0.55 & Q2,07 - Q3,07 & -0.01 & 0.52 \\
Q3,03 - Q4,03 & 0.01 & 0.38 & Q3,07 - Q4,07 & 0.04 & 0.00 \\
Q4,03 - Q1,04 & 0.00 & 0.86 & $04,07-$ Q1,08 & 0.02 & 0.16 \\
\hline
\end{tabular}

Although the global Moran's I result indicates that the overall pattern of percentage changes of housing unit prices were mostly random over time, local measures may still suggest consistent local clusters in which prices always changes the fastest. The $G i^{*}$ statistic and local Moran's I maps for percentage changes by quarter are available in Appendices $\mathrm{G}$ and $\mathrm{H}$. 

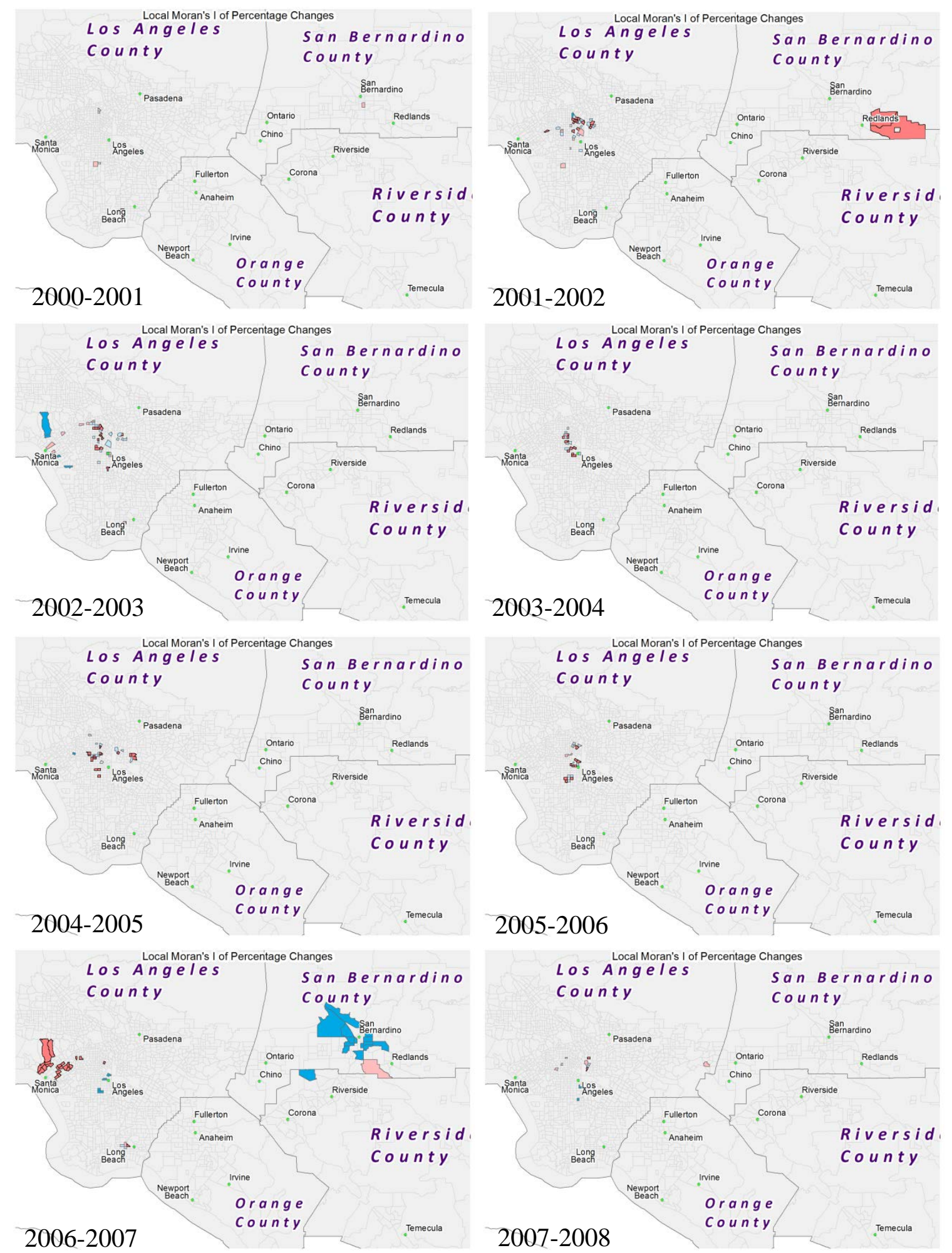

\section{Figure 6-5: Local Moran's I of Percentage Changes}

Figure 6-5 shows the local Moran's I of price changes in 2000 to 2009. The red represents high clusters of high positive percentage changes with neighborhoods that have high positive percentage changes (HH-Clusters), while pink represent high 
percentage changes with neighborhoods that have low positive percentage changes (HLOutliers). The blue represent high negative percentage changes with neighborhoods that have high negative percentage changes values (LL-Clusters), while light blue shows high negative percentage changes values surrounded by low negative percentage changes (LHOutliers).

Since there was no consistent spatial pattern of price changes over time, further analysis of the price changes was conducted at the city level. In this analysis, the ratio between the number of census tracts that had led price changes at any point in time and the maximum number of census tracts that could led price changes was calculated for each city. The criteria for leading census tracts was defined by $G i^{*}$ statistic. If the $G i^{*}$ statistic of a census tract in a specific time period was significant, the census tract was considered as a leading census tract during that period of time. If the $G i^{*}$ statistic indicates that the census tract was a cluster of hotspots (positive changes), it was regarded as leading prices up and vice versa. The analysis result is listed in Table 6-4. The first column shows the total number of census tracts in each city. The second column indicates the maximum number of census tracts in each city. The second column indicates the maximum number of census tracts in each city that could lead price changes from 2000 to 2009, which is calculated by multiplying the numbers of tracts by the number of quarters 36 quarters in total. The third column represents the number of census tracts that had led price changes, and the ratio of significant census tracts is listed in the last column.

Table 6-4. Gi* Statistic Hot/Cold Spot Census Tracts Numbers by Cities

\begin{tabular}{|l|r|r|r|r|r|}
\hline & $\begin{array}{l}\text { \# of Census } \\
\text { Tracts }\end{array}$ & $\begin{array}{l}\text { \# of Census } \\
\text { Tract * } 36\end{array}$ & $\begin{array}{l}\text { \# of High/Low } \\
\text { Census Tracts }\end{array}$ & $\begin{array}{l}\text { Ratio of \# of } \\
\text { High\&Low Census } \\
\text { Tracts }\end{array}$ & $\begin{array}{l}\text { Rank of } \\
\text { Ratio }\end{array}$ \\
\hline Newport Beach & 6 & 216 & 25 & 0.116 & 1 \\
\hline Pasadena & 27 & 972 & 31 & 0.032 & 2 \\
\hline Palm Springs & 12 & 432 & 13 & 0.030 & 3 \\
\hline LA & 596 & 21456 & 567 & 0.026 & 4 \\
\hline Redlands & 6 & 216 & 4 & 0.019 & 5 \\
\hline Santa Monica & 12 & 432 & 8 & 0.019 & 6 \\
\hline Riverside & 25 & 900 & 16 & 0.018 & 7 \\
\hline Long Beach & 63 & 2268 & 40 & 0.018 & 8 \\
\hline San Bernardino & 10 & 364 & 14 & 0.016 & 9 \\
\hline Fullerton & 7 & 252 & 3 & 0.008 & 10 \\
\hline Corona & 18 & 648 & 2 & 0.008 & 11 \\
\hline Anaheim & 1 & 36 & 0 & 0.000 & N/A \\
\hline Irvine & 5 & 180 & 0 & 0.000 & N/A \\
\hline Chino & 11 & 396 & 0 & 0.000 & N/A \\
\hline Ontario & 36 & 0 & 0.000 & N/A \\
\hline Temecula & & & 0.000 & N/A \\
\hline
\end{tabular}


Compared to other cities, the percentage changes of housing unit prices in Newport Beach that ever led price changes was the highest during 2000 and 2009. Therefore, Newport Beach was the most influential cities among the 16 cities. The results from local Moran's I also corroborate this conclusion (Table 6-5).

Table 6-5. Local Moran's I Cluster and Outlier Types Census Tract Numbers by Cities

\begin{tabular}{|c|c|c|c|c|c|}
\hline & $\begin{array}{l}\text { \# of Census } \\
\text { Tracts }\end{array}$ & $\begin{array}{l}\text { \# of Census } \\
\text { Tracts * } 36\end{array}$ & $\begin{array}{l}\text { \# of High/Low } \\
\text { Census Tracts }\end{array}$ & $\begin{array}{l}\text { Ratio of \# of } \\
\text { High\&Low Census } \\
\text { Tracts }\end{array}$ & $\begin{array}{l}\text { Rank of } \\
\text { Ratio }\end{array}$ \\
\hline Newport Beach & 6 & 216 & 20 & 0.093 & 1 \\
\hline LA & 596 & 21456 & 502 & 0.023 & 2 \\
\hline Riverside & 25 & 900 & 17 & 0.019 & 3 \\
\hline Pasadena & 27 & 972 & 17 & 0.017 & 4 \\
\hline Palm Springs & 12 & 432 & 7 & 0.016 & 5 \\
\hline Long Beach & 63 & 2268 & 31 & 0.014 & 6 \\
\hline Santa Monica & 12 & 432 & 5 & 0.012 & 7 \\
\hline Corona & 7 & 252 & 2 & 0.008 & 8 \\
\hline Ontario & 11 & 396 & 2 & 0.005 & 9 \\
\hline San Bernardino & 24 & 864 & 4 & 0.005 & 10 \\
\hline Redlands & 6 & 216 & 1 & 0.005 & 11 \\
\hline Fullerton & 10 & 360 & 1 & 0.003 & 12 \\
\hline Anaheim & 18 & 648 & 1 & 0.002 & 13 \\
\hline Irvine & 1 & 36 & 0 & 0.000 & \\
\hline Chino & 5 & 180 & 0 & 0.000 & \\
\hline Temecula & 1 & 36 & 0 & 0.000 & \\
\hline
\end{tabular}

The two measures tell that the Newport Beach were the most influential areas, and the ranking from both measures appear to be similar. To make statistical confirmation of this observation, Spearman's rank correlation coefficient was calculated with the rank. As a result, the city ranks produced by $G i^{*}$ statistic and local Moran's $I$ were significantly correlated $(r=0.821$ and $p<0.01)$. In conclusion, the Spearman's rank correlation coefficient test confirmed the city of Newport Beach was the most influential areas.

\subsection{Summary}

One of the primary goals for this project was to examine the spatio-temporal autocorrelation of housing prices between residential areas in Southern California; in other words, how the housing unit prices have been changed and what the geographic patterns were, over a period of time. Strong high housing unit price spatial autocorrelations were found in northern Santa Monica, parts of Pasadena, Long Beach, and Newport Beach areas (in Los Angeles and Orange Counties); alternatively, strong low housing unit prices spatial autocorrelations were found mostly in areas around San Bernardino, Riverside, Corona, and Chino (in San Bernardino and Riverside Counties). 
Another goal was to identify the most influential neighborhoods. Housing unit price change rates between two continuous quarters were calculated. Because there were no significant clusters of high price change rates throughout the study years at census tract level, as well as at city level, the proportion of census tracts that reside in city boundaries was counted. Gi* statistic and local Moran's I showed that Newport Beach had higher number of standardized census tract numbers compared to other cities. Thus, it can be concluded that Newport Beach was the most influential areas in price changes between 2000 and 2009. 


\section{Chapter 7 - Conclusions and Future Works}

Achieving the primary project goal was fulfilled by the automated GIS tool set and analyses after. Chapter Seven summarized the project based on previous chapters with possible future works that derivative from this project.

\subsection{Summary of Deliverables}

To simplify what the project delivered a summary of list of tools and tested analyses were introduced.

\section{Delivered Tools}

- Filtering Data

- Querying Out and Creating Quarter

- Geocoding

- Census Tract Integer Aggregation

- Spatial Join

- Percent Change Calculator

- Divide by County (for this project only)

\section{Tested Analyses}

- Global Moran's I

- Anselin's local Moran's I

- Getis and Ord's Gi* statistic

\subsection{Future Work}

The delivered ArcGIS geoprocessing tools and analyses were benefit of those whom are interested in similar project. Yet, the limited study areas and time constrain left much to be desired. However, by expanding the concept of this project and the delivered tools adaptation in another academic discipline, more works can be accomplished. A few suggested works are introduced.

\subsubsection{Standardizing Tables}

For this project, the main data source of housing information was from DataQuick ${ }^{\circledR}$. The tools that were delivered were suitable for DataQuick ${ }^{\circledR}$, where the School of Business (the client) gets data mainly. In order to work with the tools, the attributes' field names should be standardized (or same as DataQuick ${ }^{\circledR}$ ). Yet, the project was facing an issue that a few quarter data were omitted. The missing part of housing information was derived from The Chicago Title Company. Unfortunately, the table field names were different from the main housing data source. Therefore, the field names from the Chicago Title Company were changed. Fortunately, the missing data were not so much. For the future work, a tool that standardizes the field names might be helpful when the client gets data from other sources. 


\subsubsection{Study Area}

Another extendable work is that expanding the study areas. For this project, the analysis was limited to the four counties in Southern California. This study area could be expanded to entire Southern California or the state of California.

\subsubsection{Customizing Tools for Different User}

Separate from the project, one future work, in fact, was suggested by the Institute for Spatial Economic Analysis (ISEA) in the School of Business at the University of Redlands that modifying the delivered tools for industrial data within the state of California and produce an updating tools for every year. Besides, the ISEA planned was if spatial and attribute outlier check could be automated for their specific criteria. By modifying currently delivered tools for this project, the ISEA's proposal could certainly be approachable.

\subsection{Summary}

This project was relatively taken longer than it was expected to be, for lack of data and lack of economics' knowledge of the project executer. However, the project was achieved the objectives and produced results from the raw data.

This project delivered what it was supposed to provide include, a tool set of data preparation, geodatabases, static and animated maps, and documents. The possible future works would provide more convenience to users and reduce amount of work. 



\section{Works Cited}

Anselin, L. (1998). GIS Research Infrastructore for Spatial Analysis of Real Estate Markets. Housing Research, 9(1), 113-133.

Anselin, L., Syabri, I., \& Smirnov, O. (2002). Visualizing Multivariate Spatial Correlation with Dynamically Linked Windows. The Regional Economics Applications Laboratory.

Astutik, S., Rahayudi, B., Iskandar, A., Fitriani, R., \& Murtini, S. (2011). Detection of Spatial-Temporal Autocorrelation using Multivariate Moran and Lisa Method on Dengue Hemorrhagic Fever (DHF) Incidence, East Java, Indonesia. European Journal of Scientific Research, 279-285.

Boots, B., \& Tiefelsdorf, M. (2000). Global and local spatial autocorrelation in bounded regular tessellations. Geographical Systems, 2, 319-348.

Briggs, R. (2010, November 22). Home page of Ronald Briggs, Ph.D., GISP. Retrieved June 6, 2012, from The University of Texas at Dallas: http://www.utdallas.edu/ briggs/

Burt, J. E., Barber, G. M., \& Rigby, D. L. (2009). Elementary Statistics for Geographers . New York: The Guilford Press.

Can, A. (1998). GIS and Spatial Analysis of Housing and Mortgage Markets. Journal of Housing Research, 9(1), 61-86.

Carnes, R. (2012). GIS 693 Project Analysis and Design. Redlands.

Chang, H. J., \& Kwon, W. T. (2007). Spatial variations of summer precipitation trends in South Korea, 1973-2005. Environmental Research Letters, 1-9.

Chang, S.-S., Gunnell, D., Wheeler, B. W., Yip, P., \& Sterne, J. A. (2010, January). The Evolution of the Epidemic of Charcoal-Burning Suicide in Taiwan: A Spatial and Temporal Analysis. PLoS Med, 7(1), 1-10.

Cliff, A., \& Ord, J. (1981). Spatial Processes, Models and Applications. Economic Geography, 322-325.

Esri, Inc. (2006, November 9). An overview of batch processing. Retrieved July 30, 2012, from ArcGIS 9.2 Desktop Help:

http://webhelp.esri.com/arcgisdesktop/9.2/index.cfm?TopicName=an_overview_o f_batch_processing

Esri, Inc. (2012, March 7). ArcGIS Resource Center. Retrieved June 4, 2012, from Help Desktop 10:

http://help.arcgis.com/en/arcgisdesktop/10.0/help/index.html\#//005p0000000n000 000

Esri, Inc. (2012, April 4). ArcGIS Resource Center Desktop 10. Retrieved from Spatial Join (Analysis) :

http://help.arcgis.com/en/arcgisdesktop/10.0/help/index.html\#//00080000000q000 000

Esri, Inc. (2012, March 30). North American Address Locator. Retrieved from ArcGIS.com: http://www.arcgis.com/home/item.html?id=919dd045918c42458f30d2c85d566d6 8 
Eyanoer, P. C., Singhasivanon, P., Kaewkungwal, J., \& Apisarnthanarak, A. (2011, May). Human Avian Influenza in Indonesia: Are They Really Clustered? Southeast Asian journal of tropical medicine and public health, 42(3), 583-595.

GeoDa Center. (N.D.). Moran Scatter Plot. Retrieved June 30, 2012, from Glossary of Key Terms: https://geodacenter.asu.edu/node/390

Getis, A. (2008). A History of the Concept of Spatial Autocorrelation: A Geographer's Perspective. Geographical Analysis, 40, 297-309.

Gilbert, E. (1958, June). Pioneer Maps of Health and Disease in England. The Geographical Journal, 124, 172-183.

Haider, M., \& Miller, E. J. (2000). Effet of Transportaion Infrastructure and Location on Residential Real Estate Values: Application of Spatial Autoregressive Techniques. Transportation Research Record (1722), 1-8.

Hui, F.-M., Xu, B., Chen, Z.-W., Cheng, X., Liang, L., Huang, H.-B., et al. (2009). Spatio-Temporal Distribution of Malaria in Yunnan Province, China. The American Society of Tropical Medicine and Hygiene, 503-509.

Jepsen, M. R., Simonsen, J., \& Ethelberg, S. (2009, February 20). Spatio-temporal cluster analysis of the incidence of Campylobacter cases and patients with general diarrhea in a Danish county, 1995-2004. International Journal of Health, 8, 1-12.

Kim, Y. H., \& Baik, J. J. (2005). Spatial and Temporal Structure of the Urban Heat Island in Seoul. American Meteorological Society, 591-605.

Lai, P., Wong, C., Hedley, A., Lo, S., Leung, P., Kong, J., et al. (2004, November). Understanding the Spatial Clustering of Severe Acute Respiratory Syndrome. Environmental Health Perspectives, 112, 1550-1556.

Miler, H. J. (2004). Tobler's First Law and Spatial Analysis. Taylor \& Francis, Ltd. on behalf of the Association of American Geographers, 94, 284-289.

Nakhapakorn, K., \& Jirakajohnkol, S. (2006). Temporal and Spatial Autocorrelation Statistics of Dengue Fever. Dengue Bulletin, 30, 177-183.

Ord, J., \& Getis, A. (2001). Testing for local spatial autocorrelation in the presence of global atocorrelation. Regional Science, 41, 411-432.

Sawada, M. (2009, November 23). Global Spatial Autocorrelation Indices - Moran's I, Geary's C and the General Cross-Product Statistic. Ottawa, Ontario, Canada: University of Ottawa. Retrieved from http://www.lpc.uottawa.ca/publications/moransi/moran.htm

Schiller, R. J. (2008). The Subprime Soluton. Princeton, New Jersey, USA: Princeton University Press.

Tenkorang, F., \& Bridges, D. (2008, Feburary). Spatial Analysis of U.S. Ethanol Production. American Society of Business and Behavioral Sciences, 15, 14631469.

Tobler, W. (1970). A computer movie simulating urban growth in the Detroit region. Economic Geography, 46(2), 234-240.

Tomlinson, R. (2011). Thinking about GIS. Redlands, California, United States of America: ESRI Press.

U.S. Census Bureau. (2011, February 18). Geographic Terms and Concepts - Census Tract. Retrieved from U.S. Census: www.census.gov/geo/www/2010census/gtc/gtc_ct.html 
U.S. Census Bureau, Population Division. (2011, Septeber). U.S. Census Bureau. Retrieved October 20, 2011, from Intercensal Estimates of the Resident Population for Counties of California: April 1, 2000 to July 1, 2010: http://www.census.gov/popest/intercensal/county/CO-EST00INT-01.html 



\section{Appendix A. Python Script (1). Data Filtering and Cleaning}

import arcpy

arcpy.env.overwriteOutput $=$ True

\# Script Arguments

table $=$ arcpy.GetParameterAsText(0)

\# for loops and delete field.

keepFields = ["Site_Address", "Site_Address_City","Site_Address_State", "Site_Address_Zip", "Site_Address_Zip4", "CountyName", "Sale_Date", "Sale_Quarter", "Sale_Value", "SQ_FT_Structure","Use_Code_Description"]

deleteFields $=[]$

fields $=$ arcpy.ListFields(table)

for field in fields:

if not field.name in keepFields and not field.required: deleteFields.append(field.name)

arcpy.DeleteField_management(table, deleteFields)

\# Process: Add Field arcpy.AddField_management(table, "City", "TEXT", "', "', "', "', "NULLABLE", "NON_REQUIRED", "')

\# Process: Calculate Field arcpy.CalculateField_management(table, "City", "'"'[Site_Address_City]"'"', "VB", "')

\# Process: Delete Field arcpy.DeleteField_management(table, "Site_Address_City")

\# Process: Add Field (2) arcpy.AddField_management(table, "Address", "TEXT", "', "', "', "', "NULLABLE", "NON_REQUIRED", "')

\# Process: Calculate Field (2) arcpy.CalculateField_management(table, "Address", "[Site_Address]", "VB", "') \# Process: Delete Field (2) 
arcpy.DeleteField_management(table, "Site_Address")

\# Process: Add Field (3)

arcpy.AddField_management(table, "State", "TEXT", "', "', "', "', "NULLABLE",

"NON_REQUIRED", "')

\# Process: Calculate Field (3)

arcpy.CalculateField_management(table, "State", "[Site_Address_State]", "VB", "')

\# Process: Delete Field (3)

arcpy.DeleteField_management(table, "Site_Address_State")

\# Process: Add Field (4)

arcpy.AddField_management(table, "Zip", "LONG", "', "', "', "', "NULLABLE",

"NON_REQUIRED", "')

\# Process: Calculate Field (4)

arcpy.CalculateField_management(table, "Zip", "[Site_Address_Zip]", "VB", "')

\# Process: Delete Field (4)

arcpy.DeleteField_management(table, "Site_Address_Zip")

\# Process: Add Field (5)

arcpy.AddField_management(table, "Zip4", "LONG", "', "', "', "', "NULLABLE",

"NON_REQUIRED", "')

\# Process: Calculate Field (5)

arcpy.CalculateField_management(table, "Zip4", "[Site_Address_Zip4]", "VB", "')

\# Process: Delete Field (5)

arcpy.DeleteField_management(table, "Site_Address_Zip4")

\# Process: Delete Rows based on Criteria

rows $=$ arcpy.UpdateCursor(table)

for row in rows:

if row.Sale_Value $<=50000$ :

rows.deleteRow(row)

elif not row.Address:

rows.deleteRow(row)

\# Finish the processes

arcpy.AddMessage("Data Filtering and Chaning Field Name for Geocoding are Finished") 


\section{Appendix B. Python Script (2). SingleFamilyQuery_QuarterGenerator}

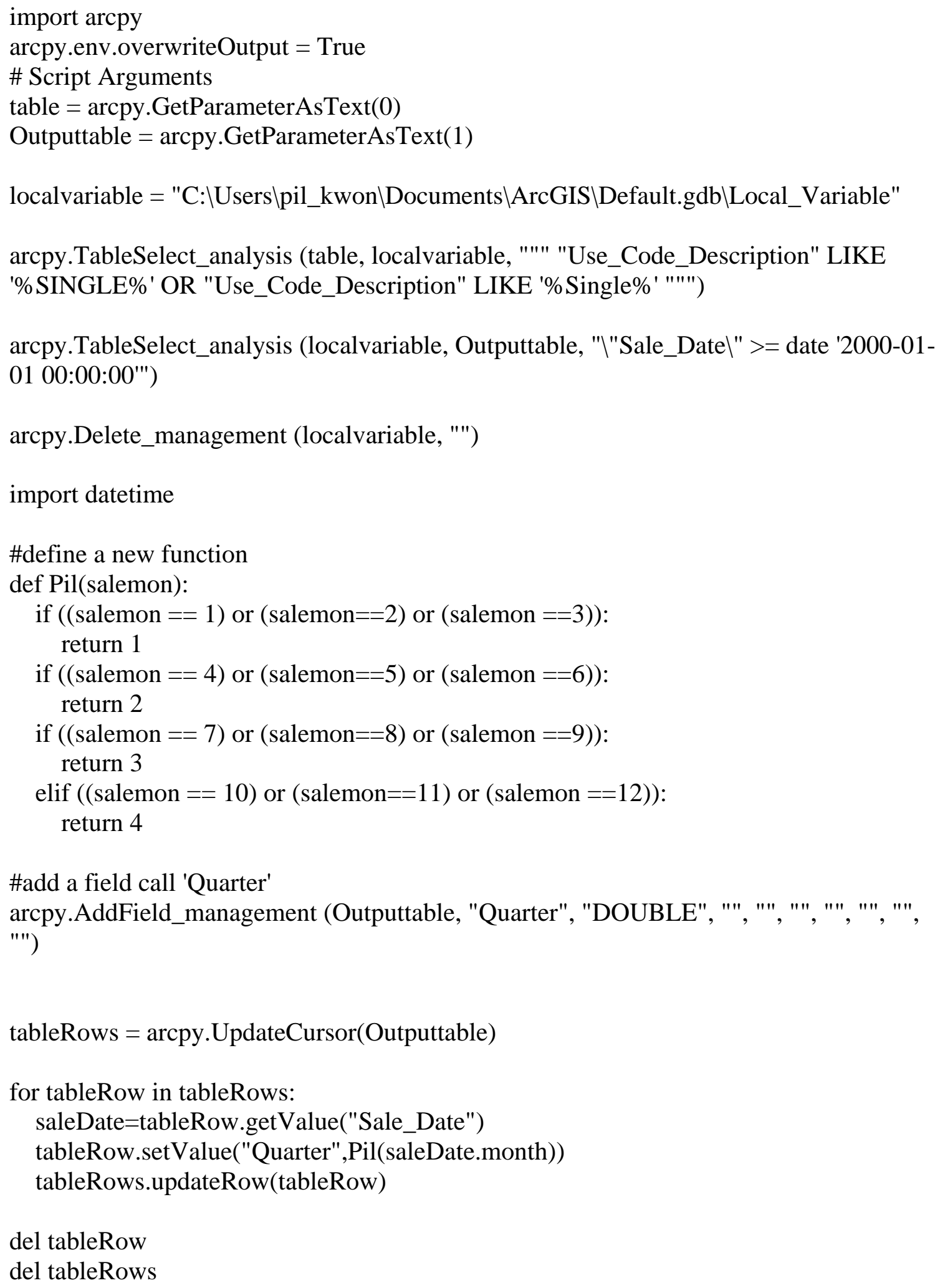


arcpy.Delete_management (table)

arcpy.AddField_management(Outputtable, "Price_per_sq_ft", "DOUBLE", "', "', "', "', "NULLABLE", "NON_REQUIRED", "')

arcpy.CalculateField_management(Outputtable, "Price_per_sq_ft", "[Sale_Value] /

[SQ_FT_Structure]", "VB", "')

arcpy.AddField_management(Outputtable, "Year", "TEXT", "', "', "', "', "NULLABLE", "NON_REQUIRED", "')

arcpy.CalculateField_management(Outputtable, "Year", "!Sale_Date![-4:]",

"PYTHON_9.3", "')

rows $=$ arcpy.UpdateCursor(Outputtable)

for row in rows:

if row.Price_per_sq_ft $<0$ :

rows.deleteRow(row)

arcpy.DeleteIdentical_management(Outputtable,

"Sale_Date;Sale_Value;City;Address;State;Zip;Zip4", "', "0")

arcpy.AddMessage("Selecting Single Housing Family Data and Creating Quarter Field are Finished") 


\section{Appendix C. Python Script (6). PercentageChanges}

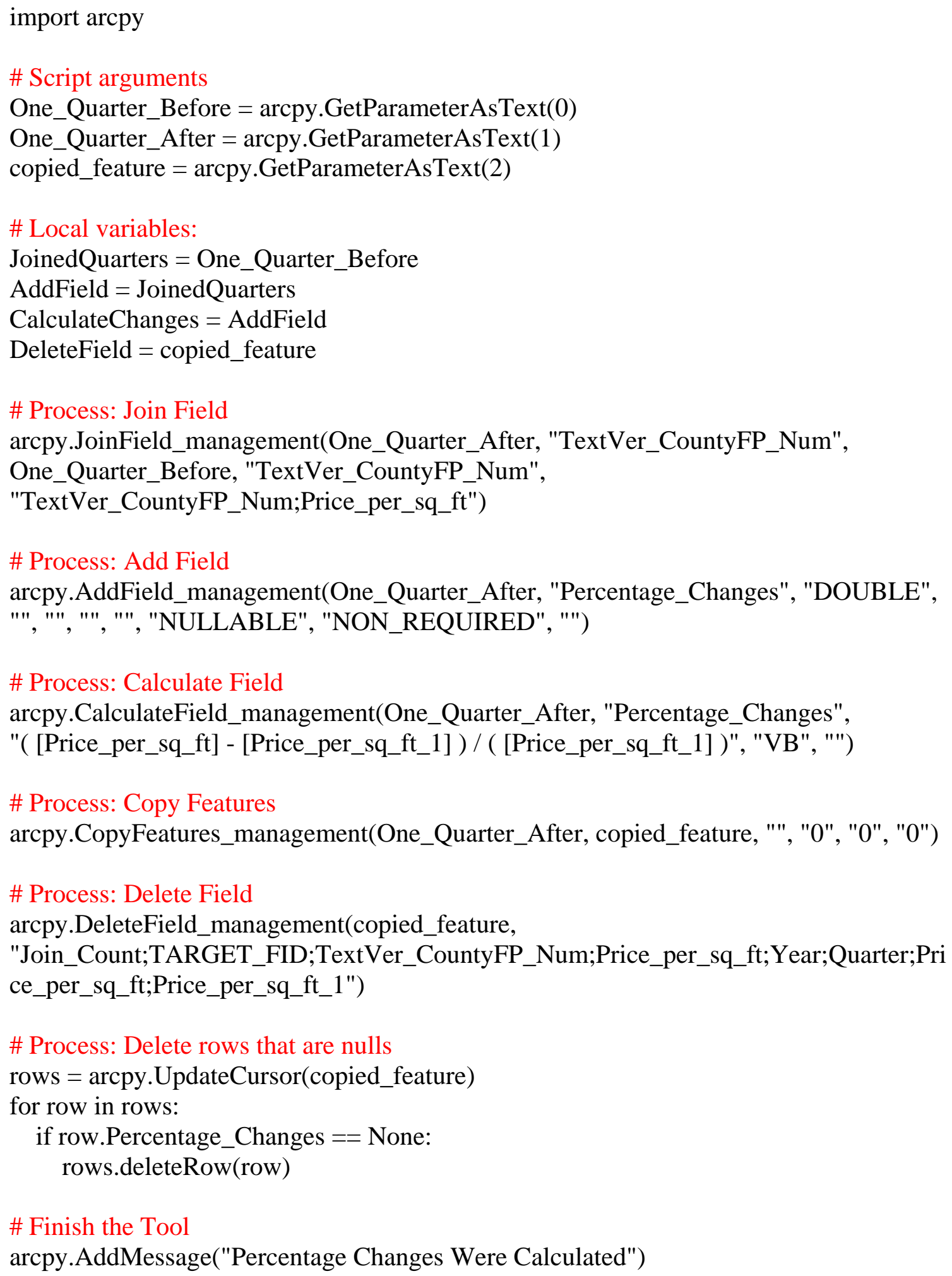




\section{Appendix D. Python Script (2.5). MissingDataFiltering}

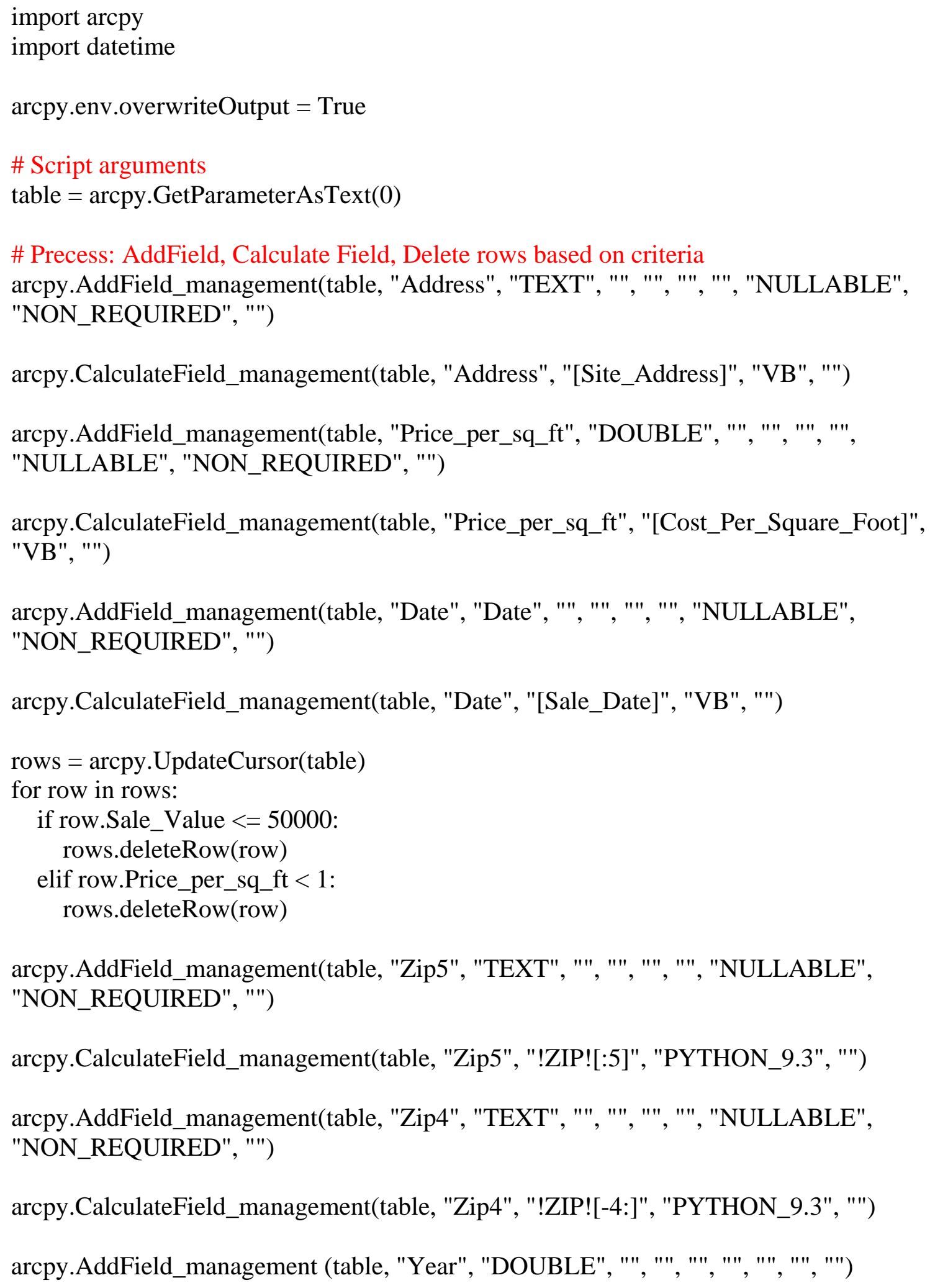




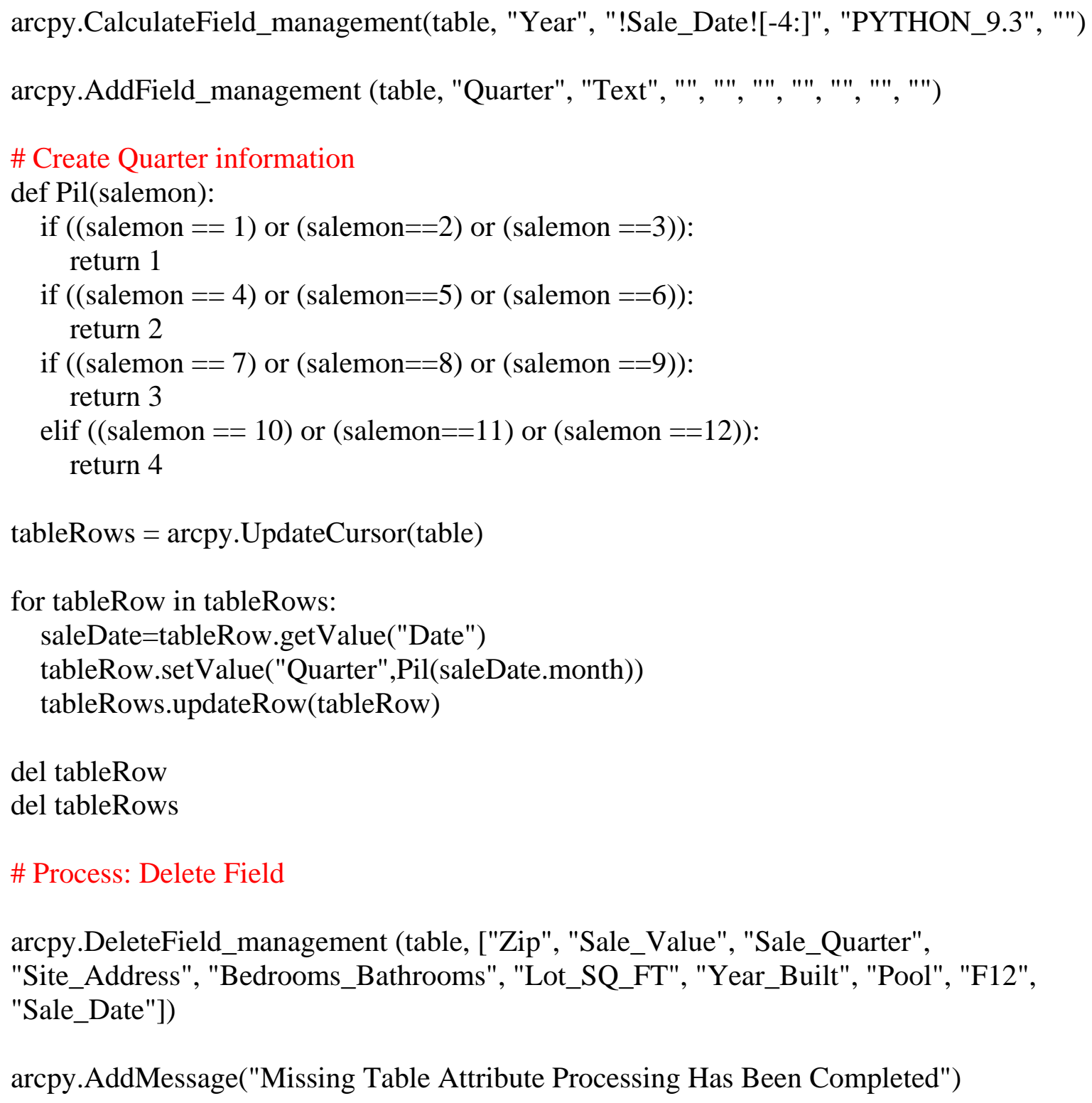




\section{Appendix E. Local Moran's I}
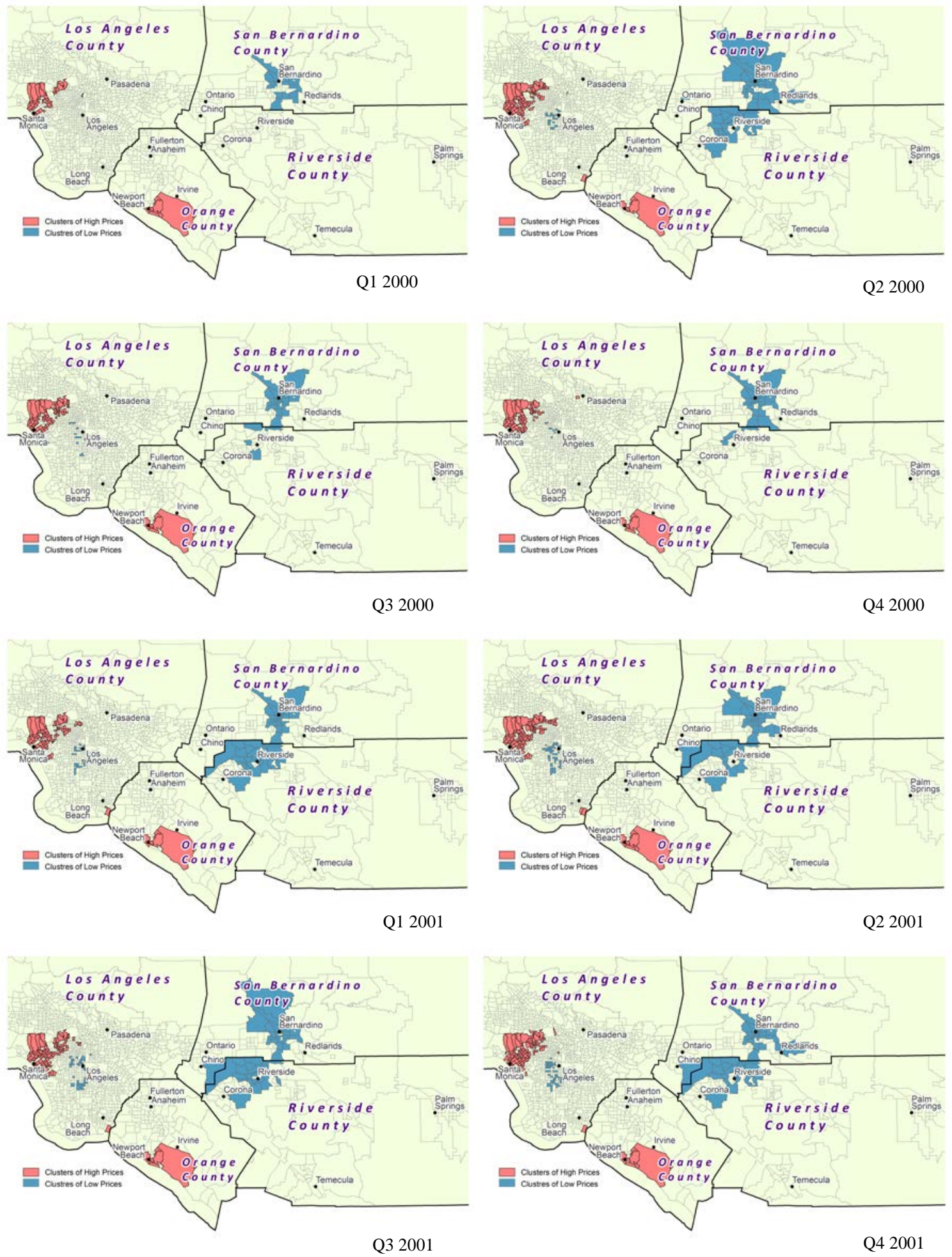

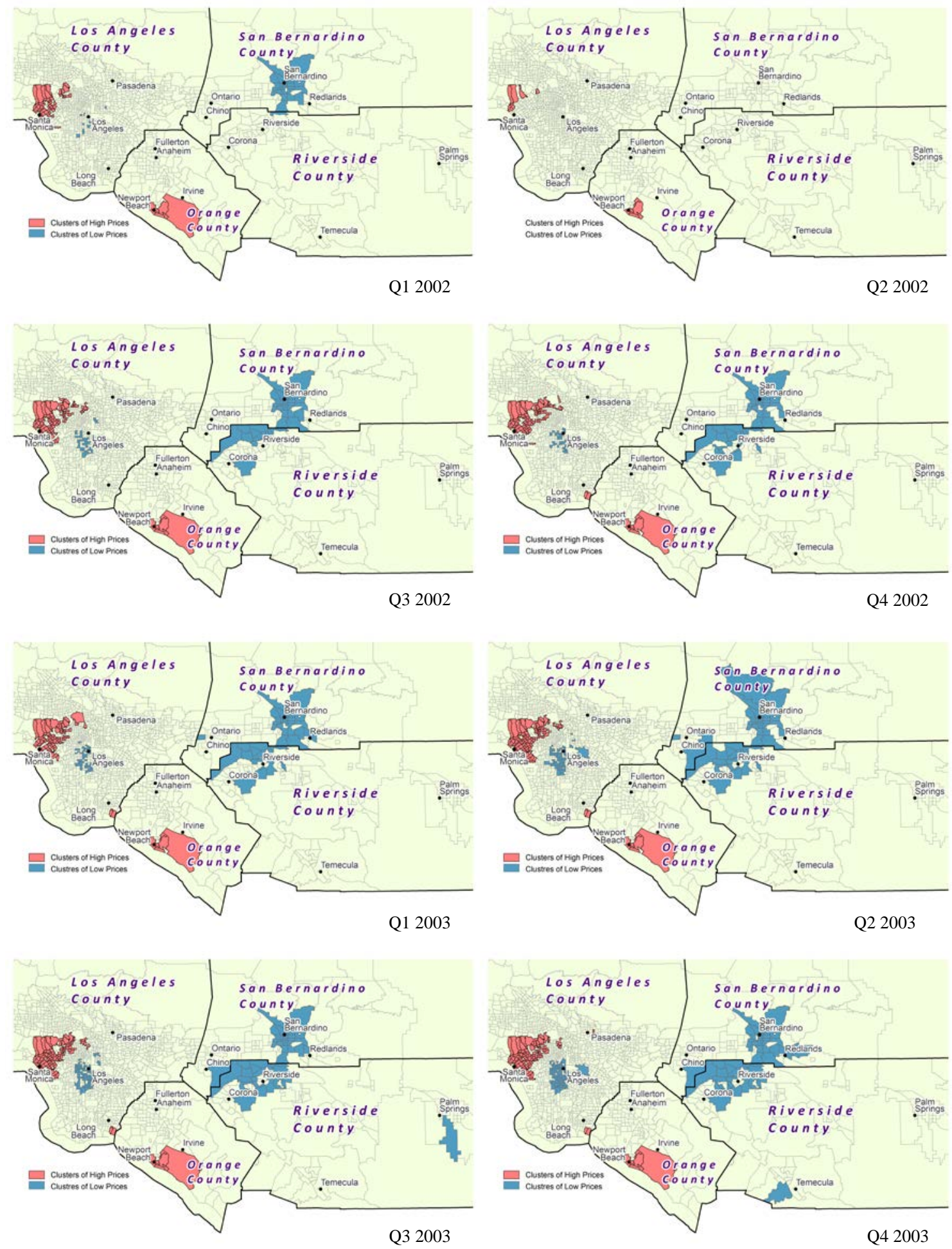

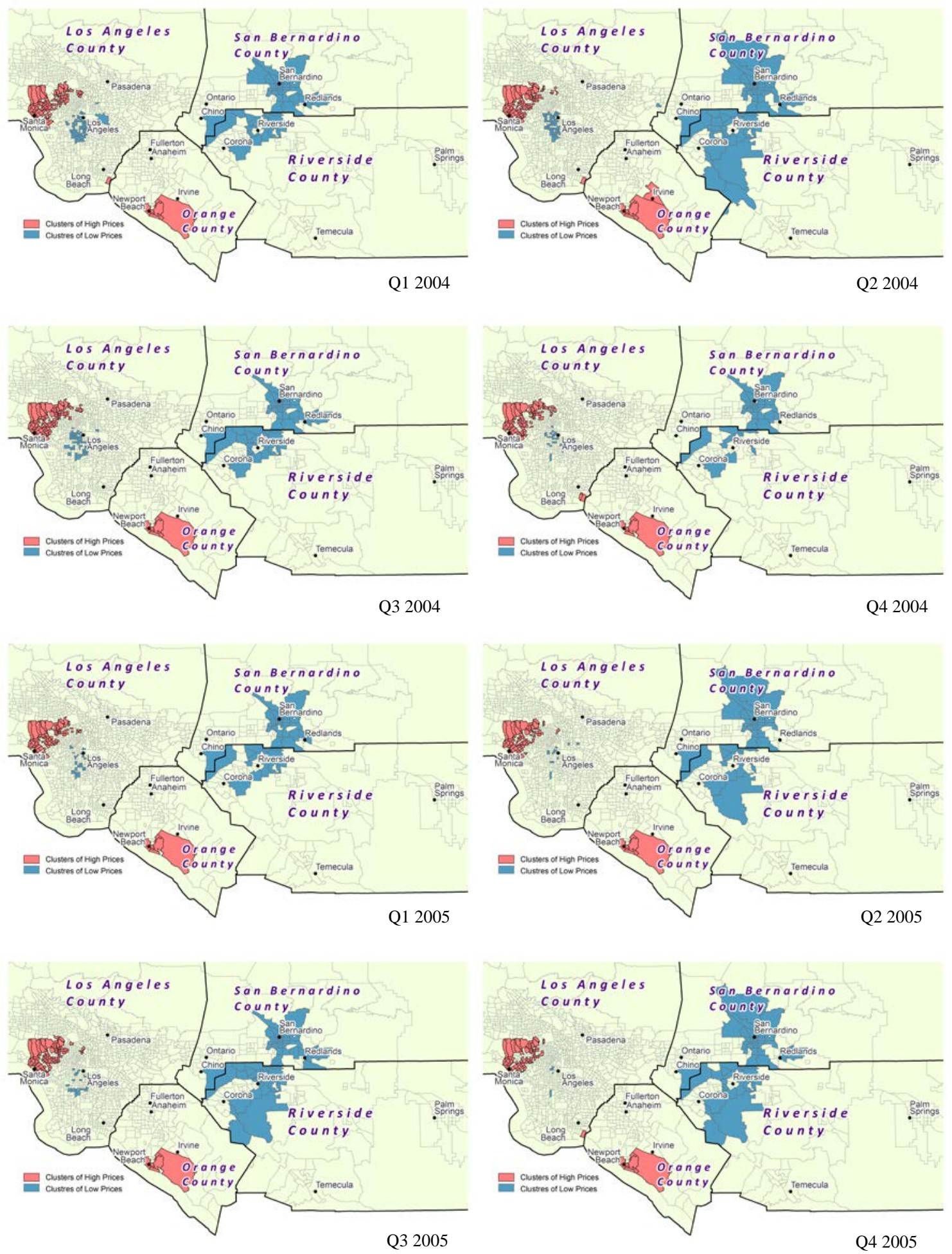

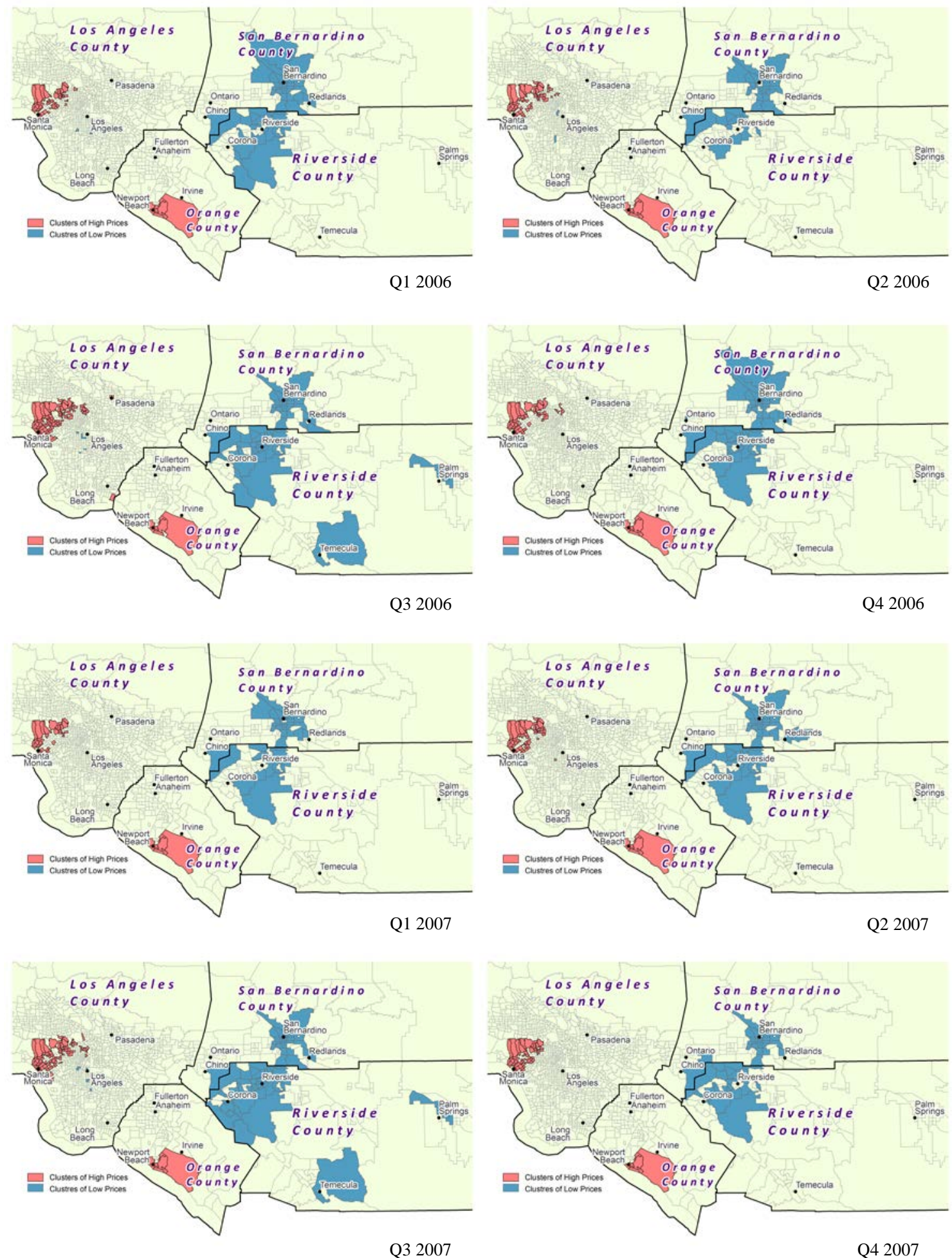

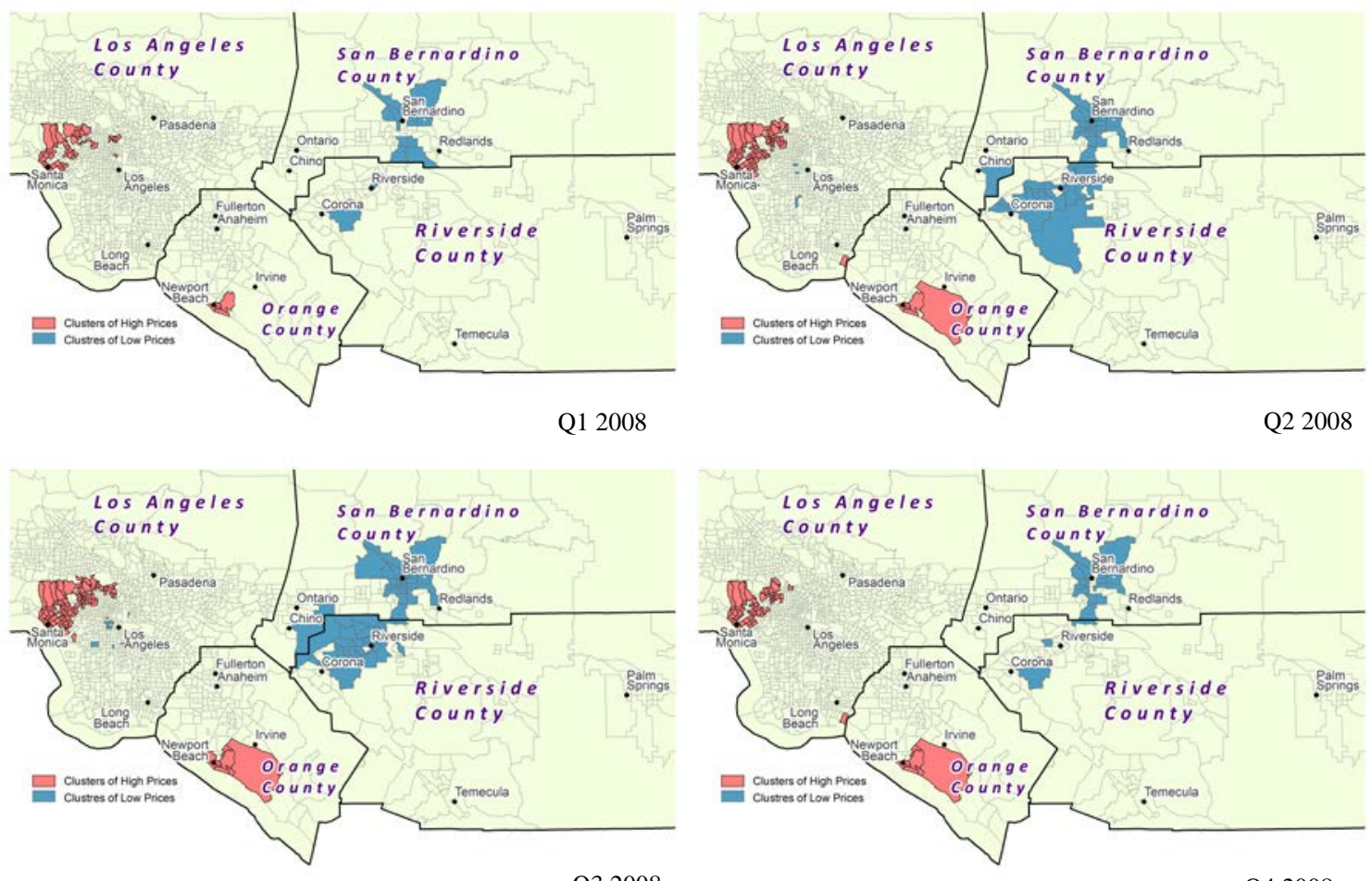

Q3 2008

Q4 2008

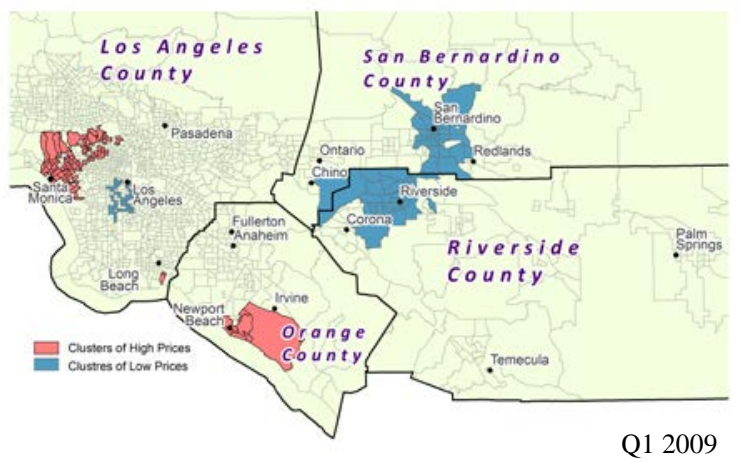




\section{Appendix F. Gi* Statstic}

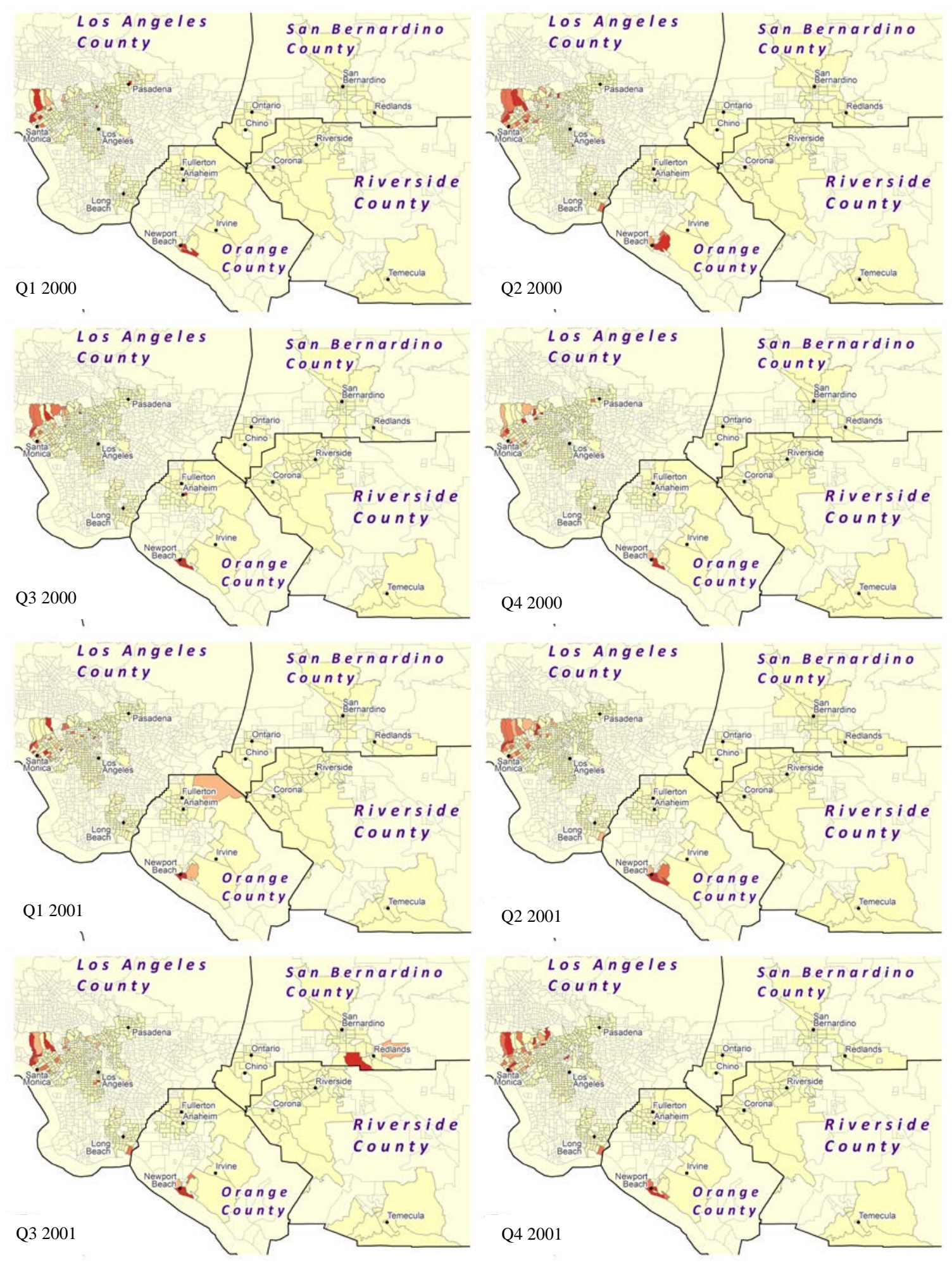



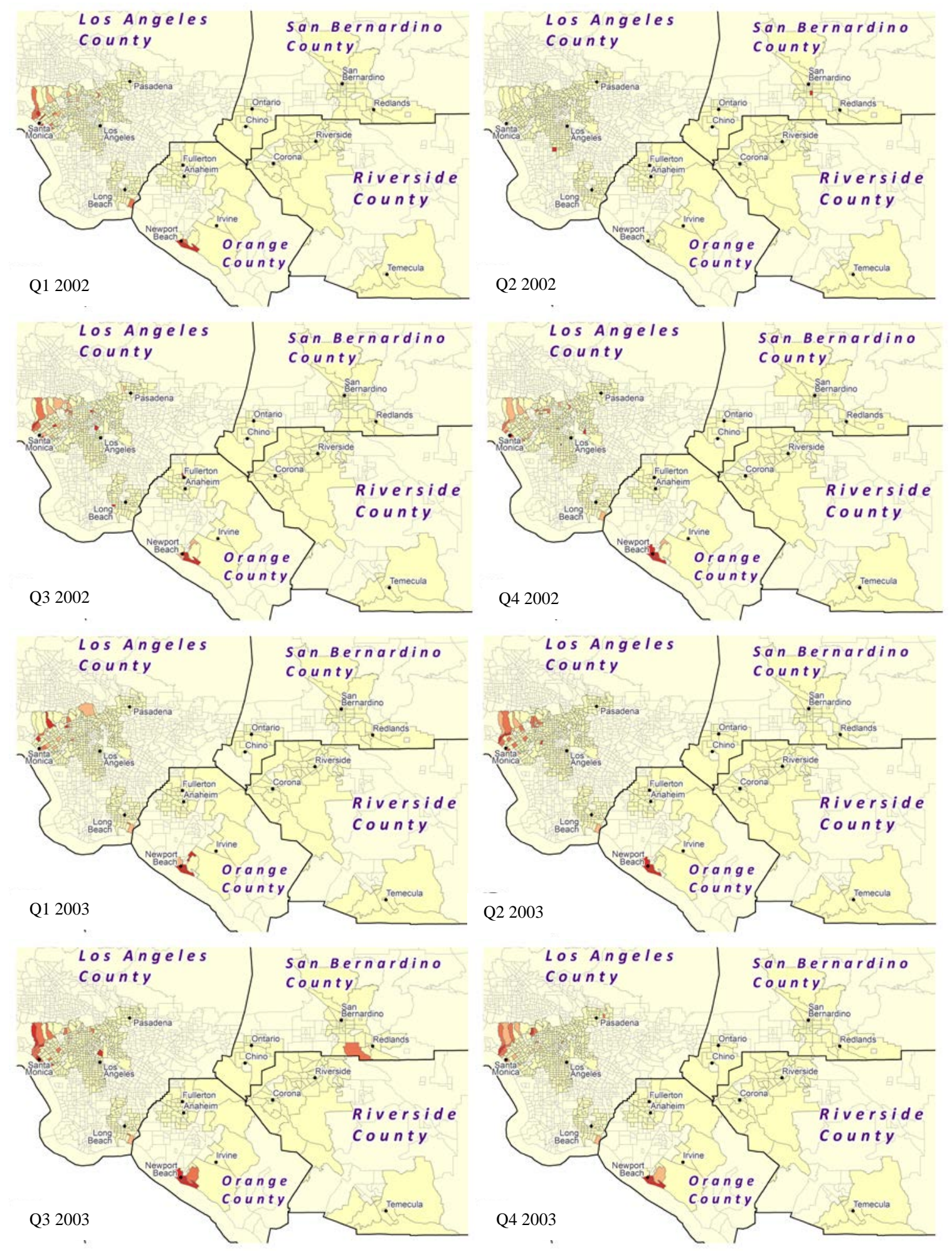

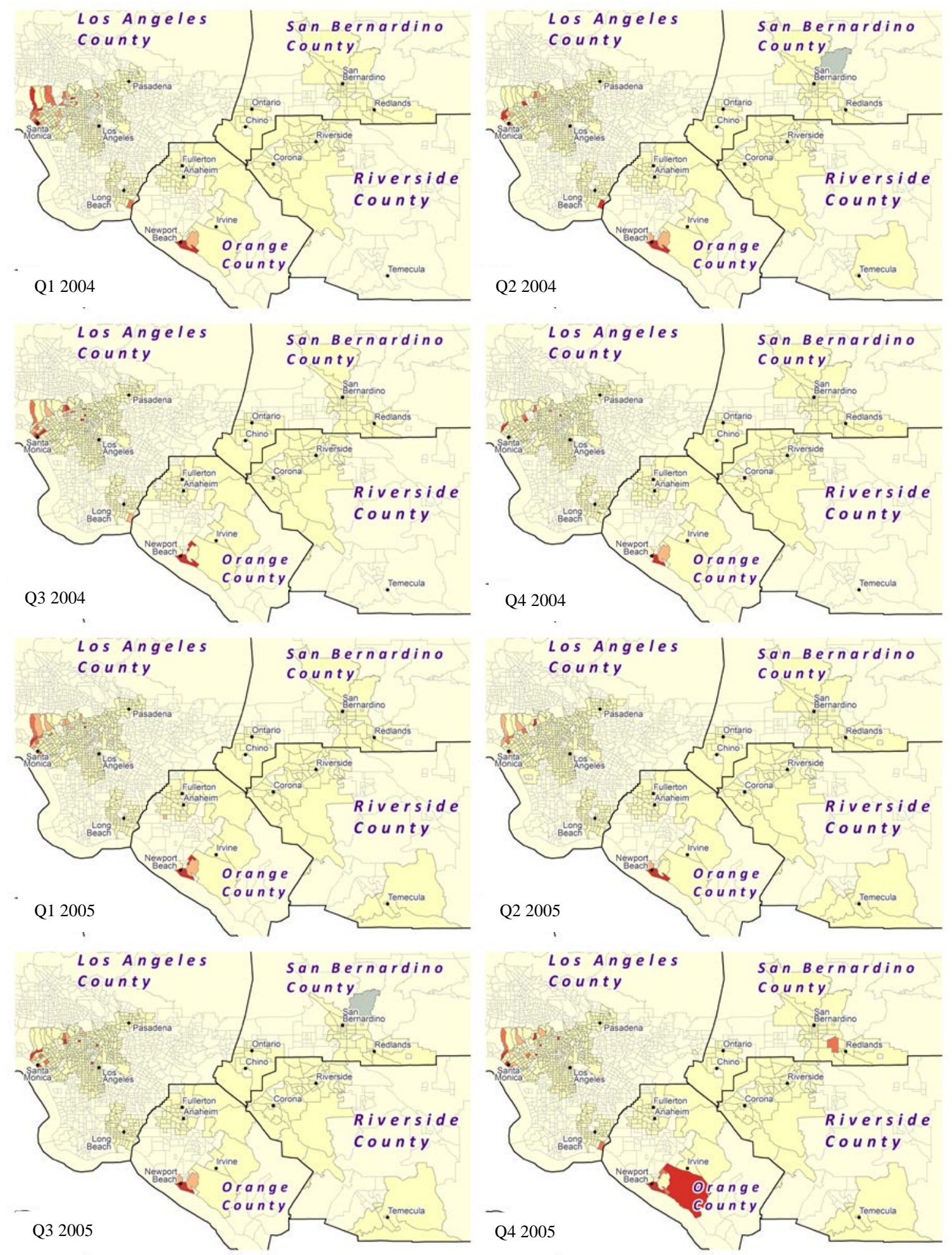


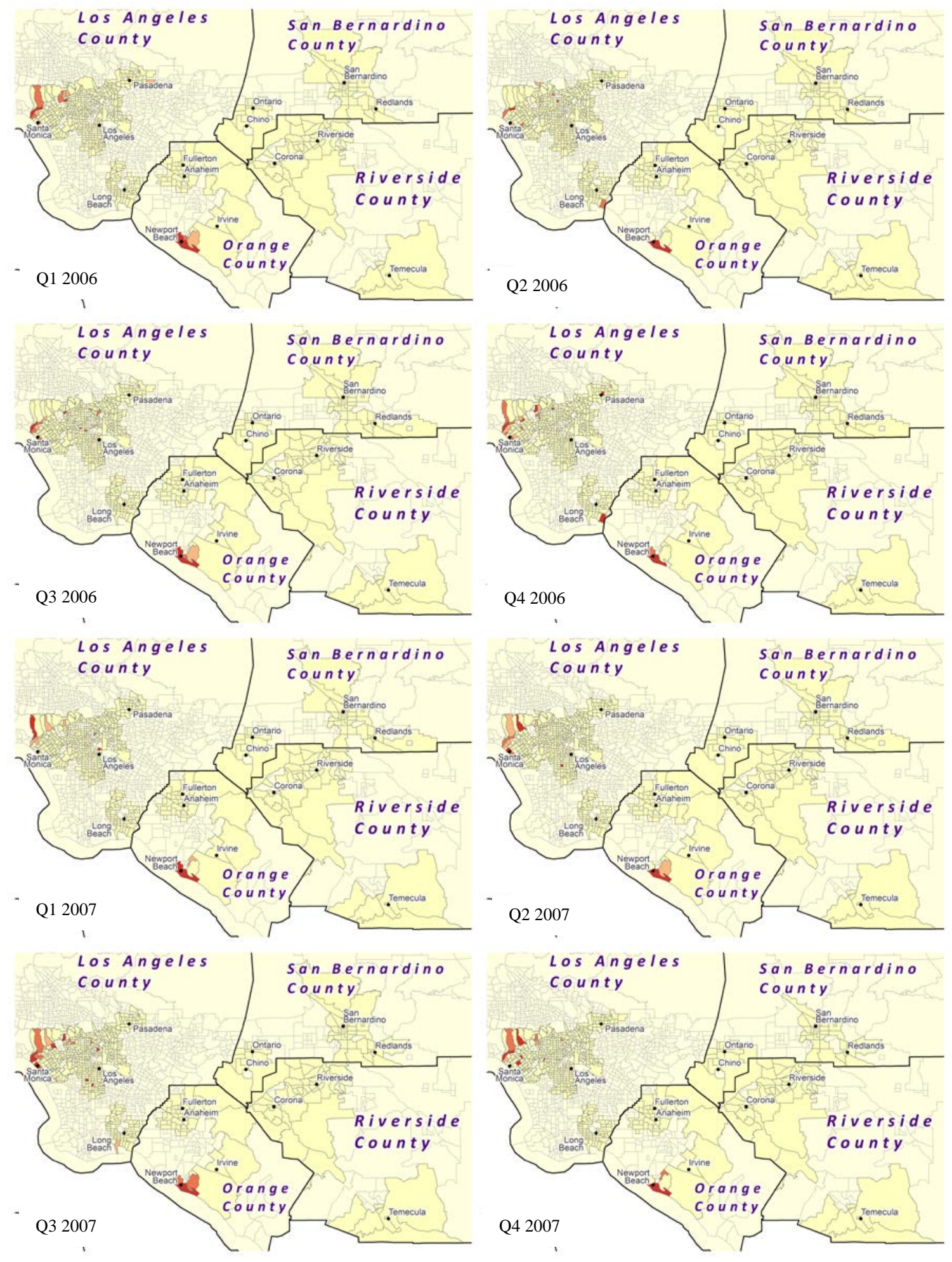



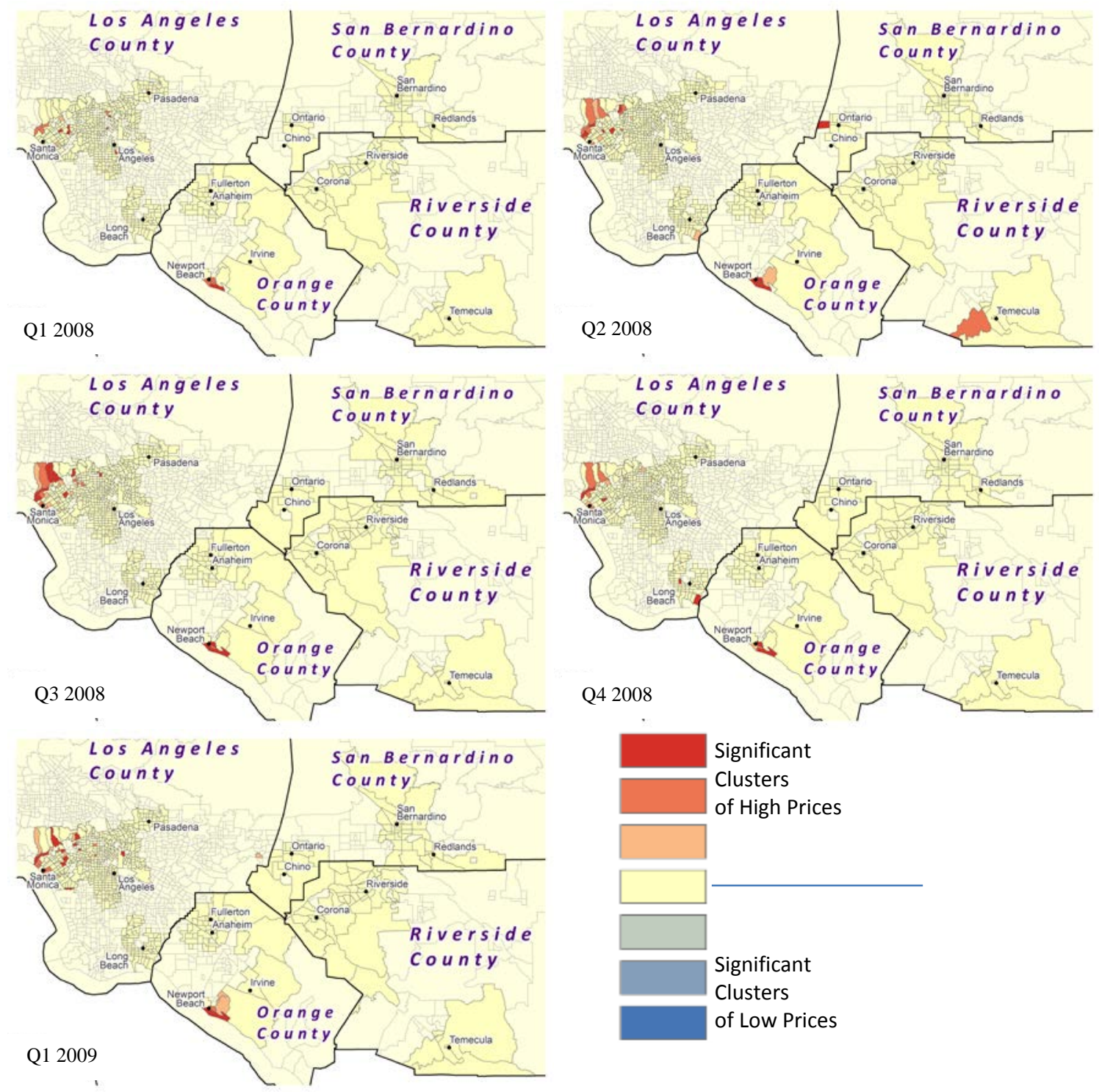


\section{Appendix G. Gi* Statistic of Percentage Changes}
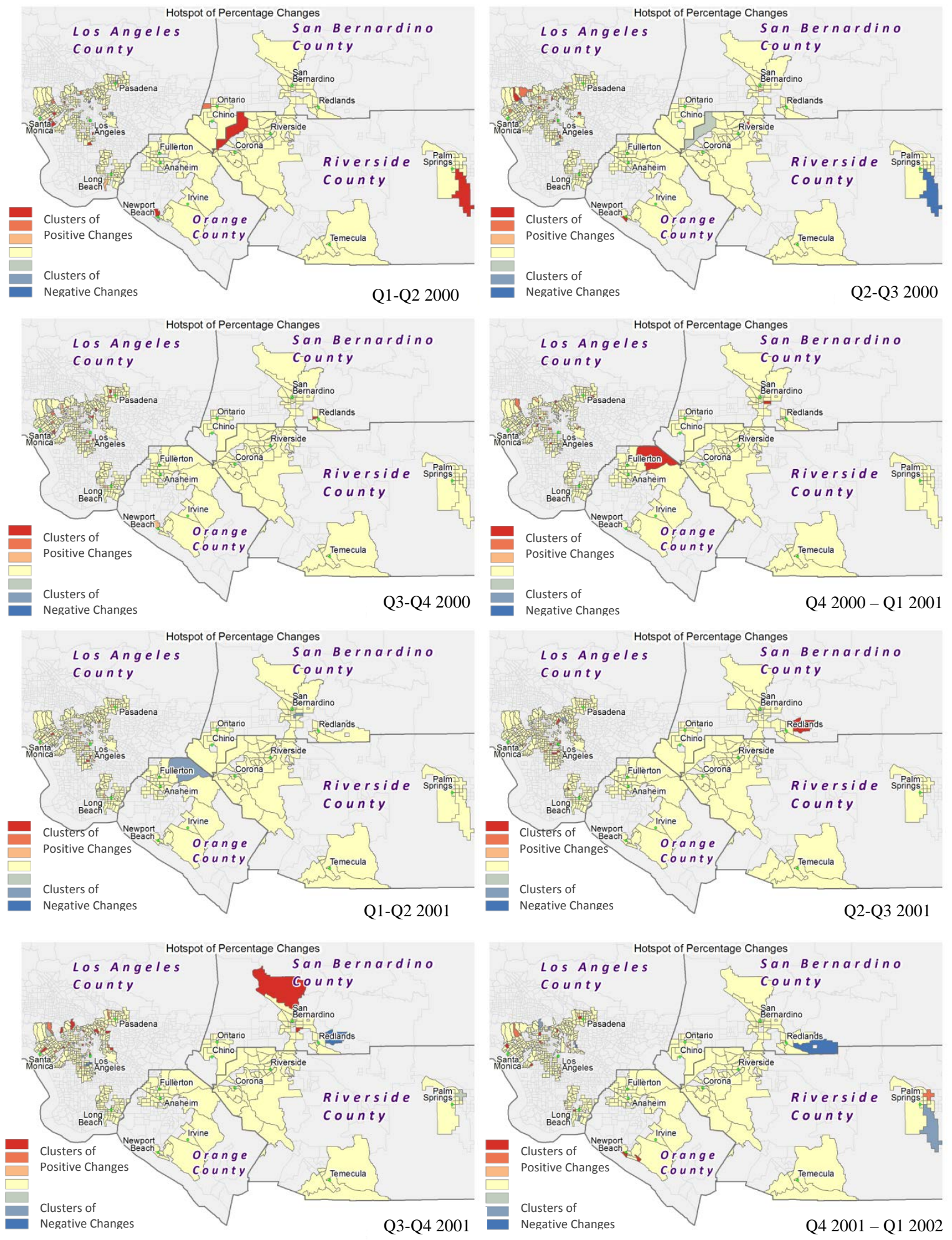

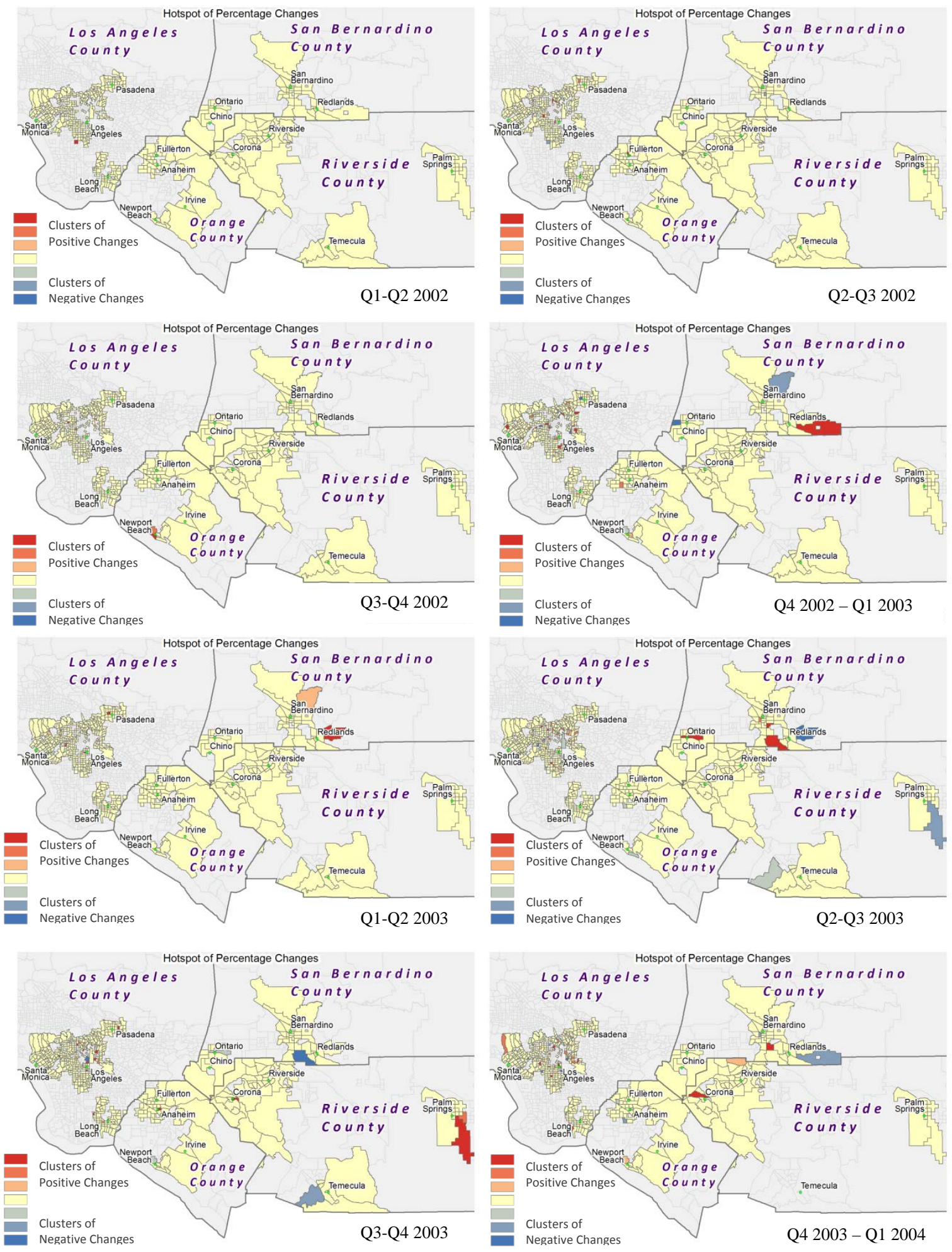

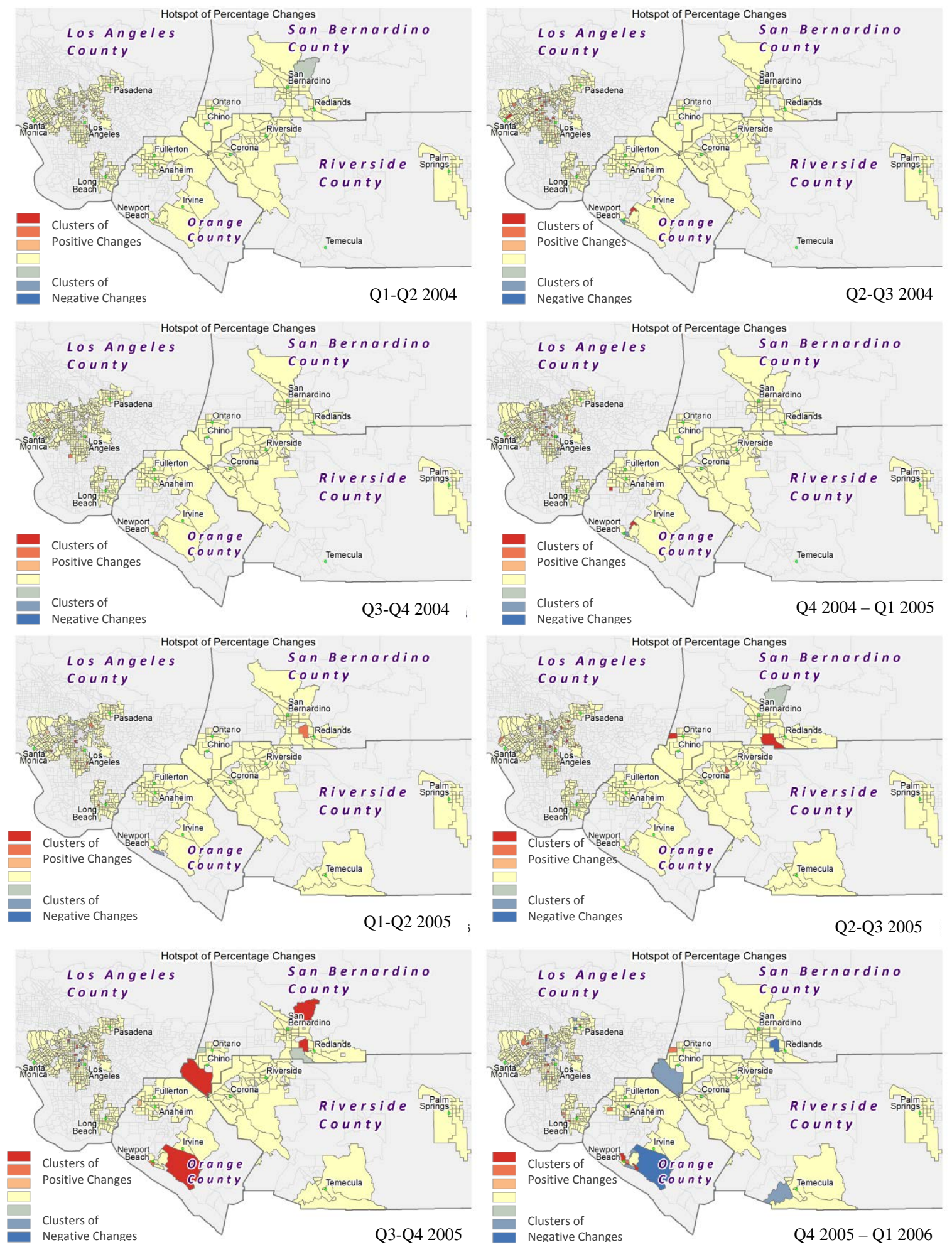

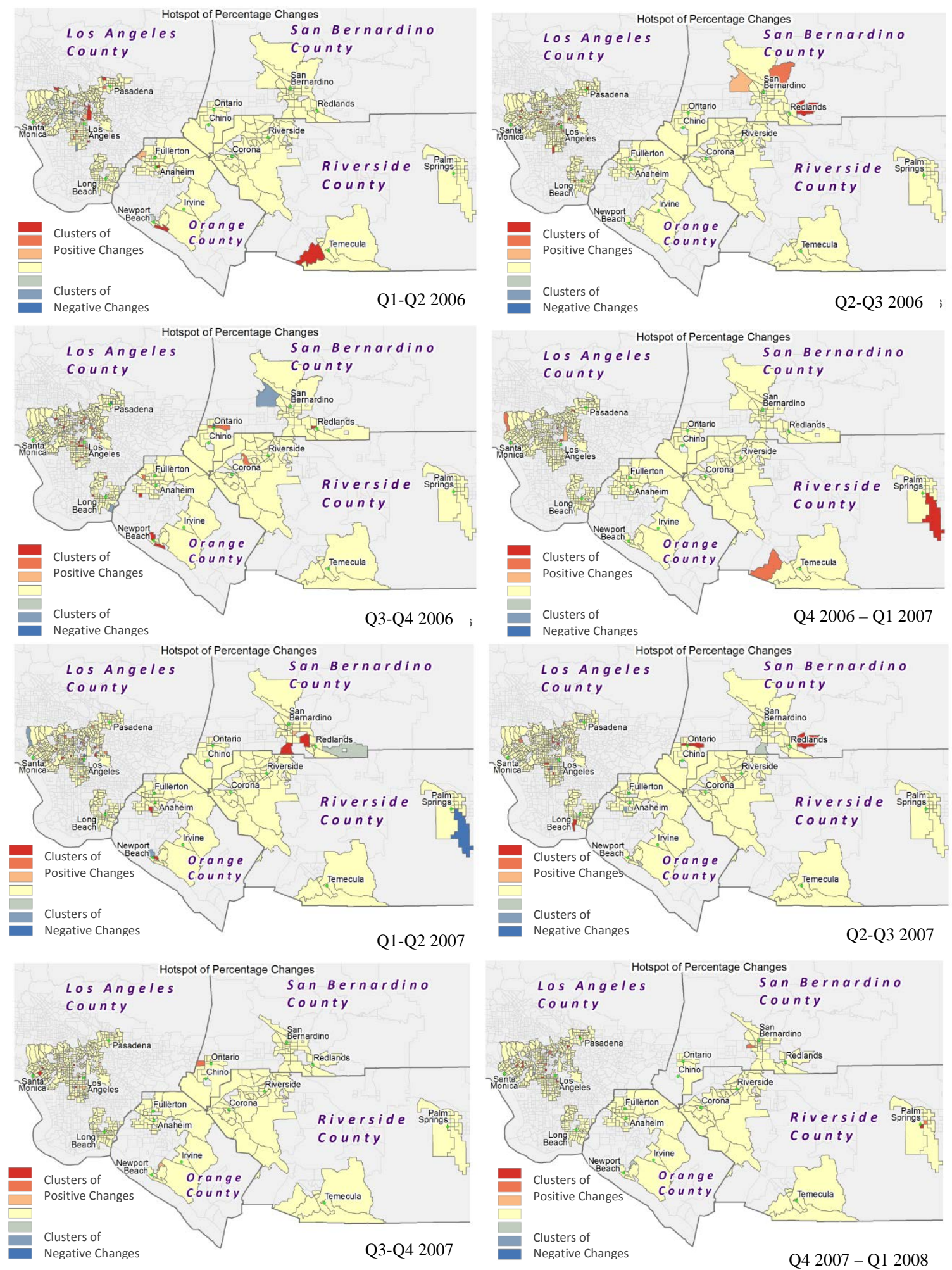

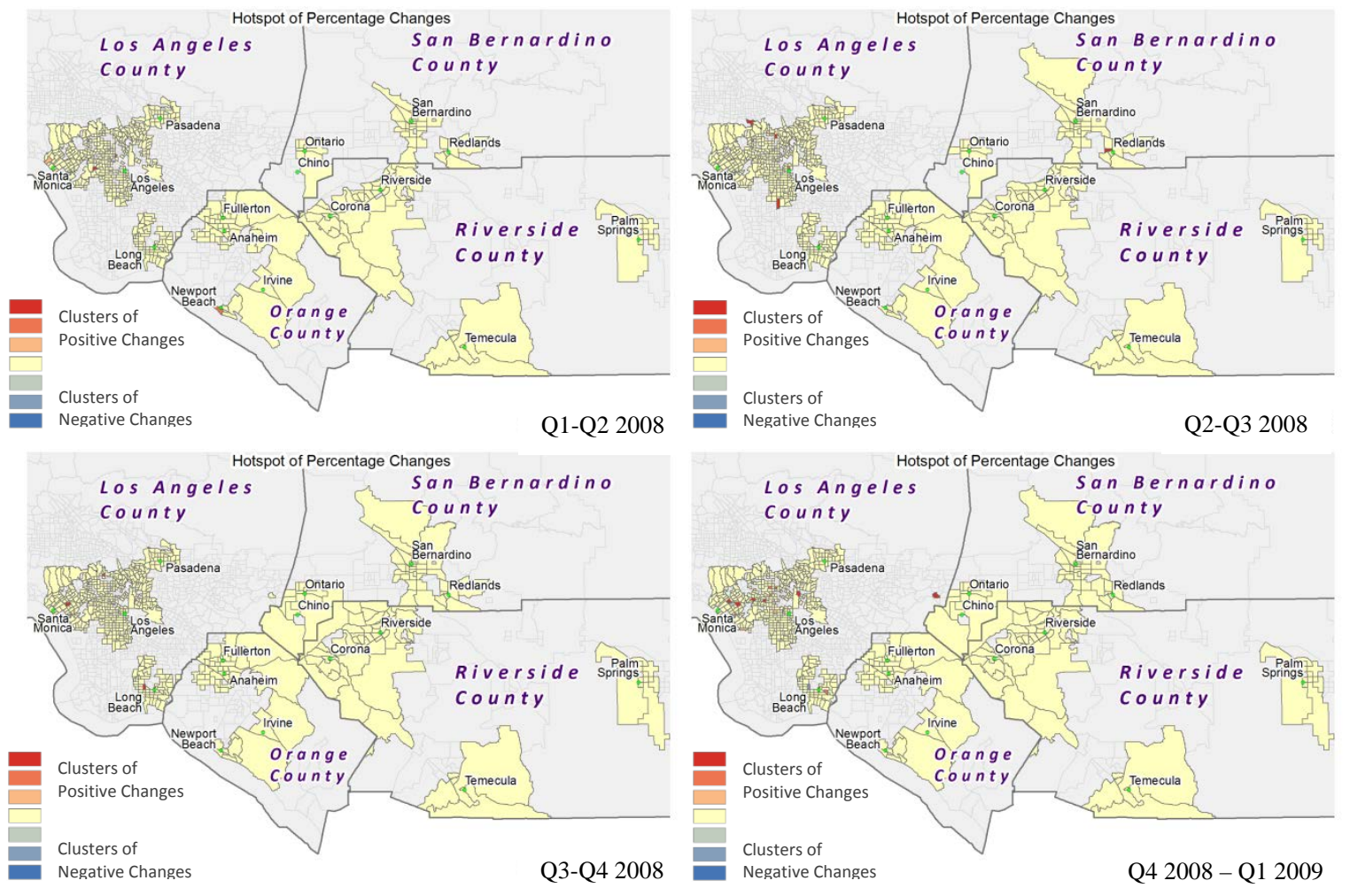


\section{Appendix H. Local Moran's I of Percentage Changes}
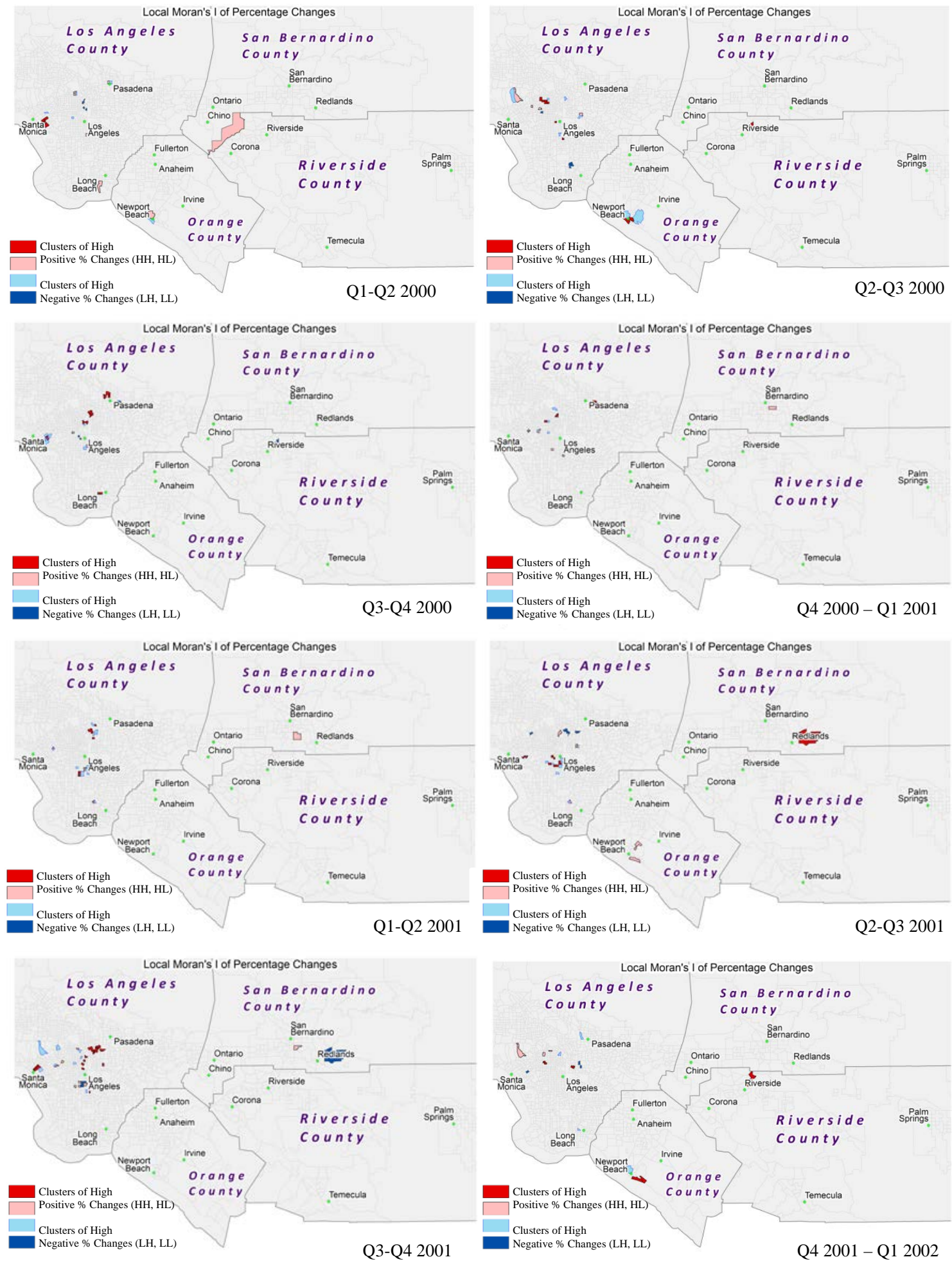

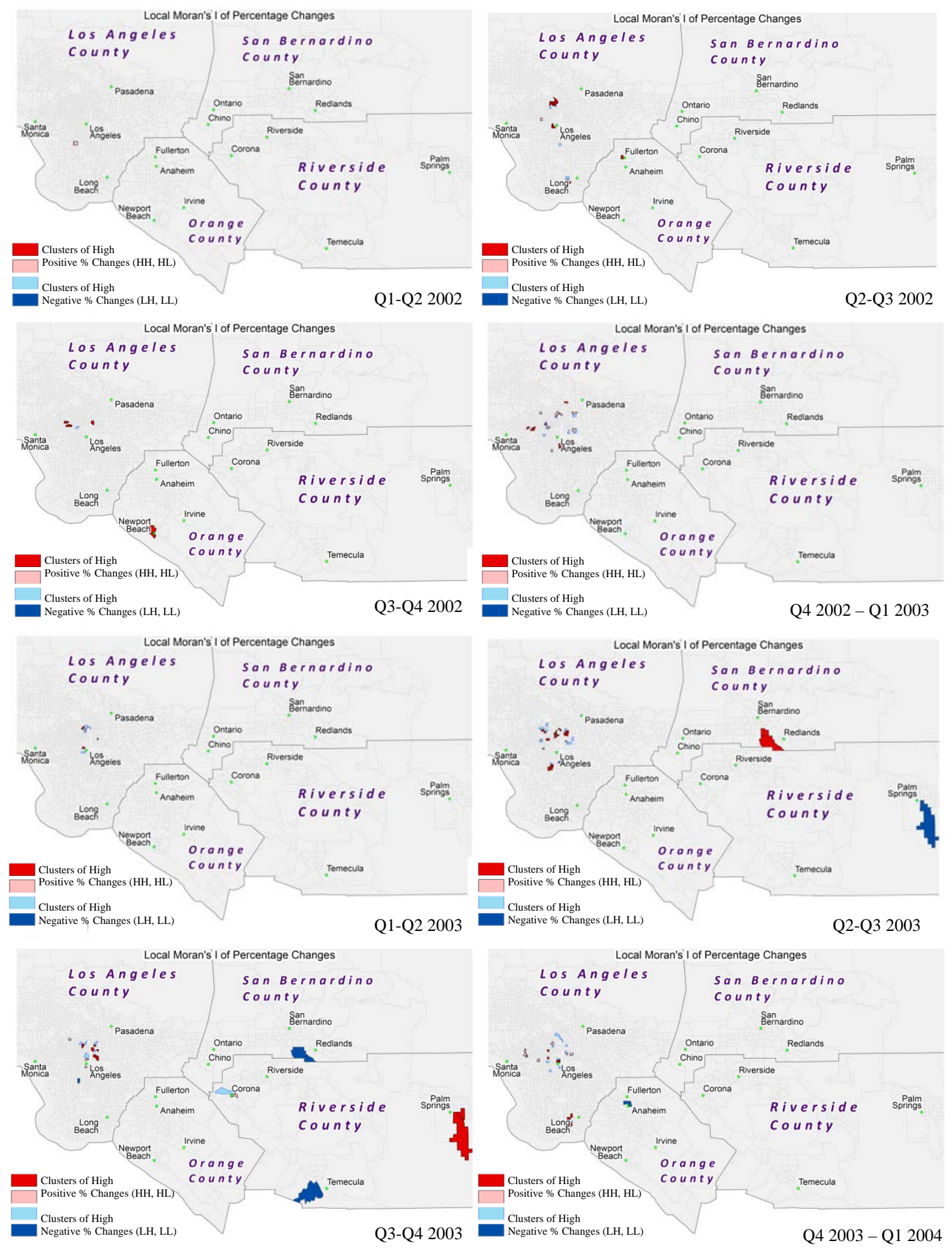

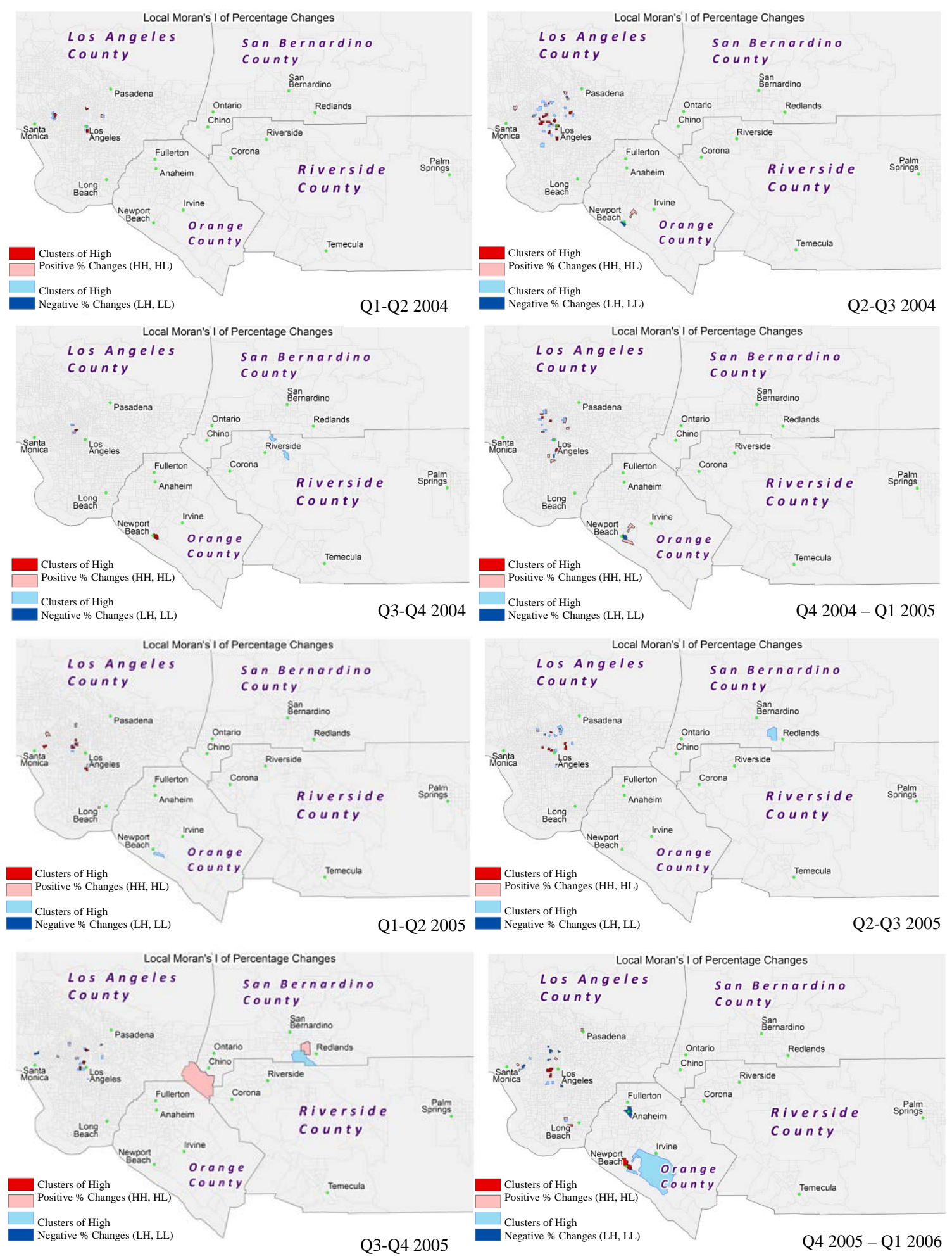

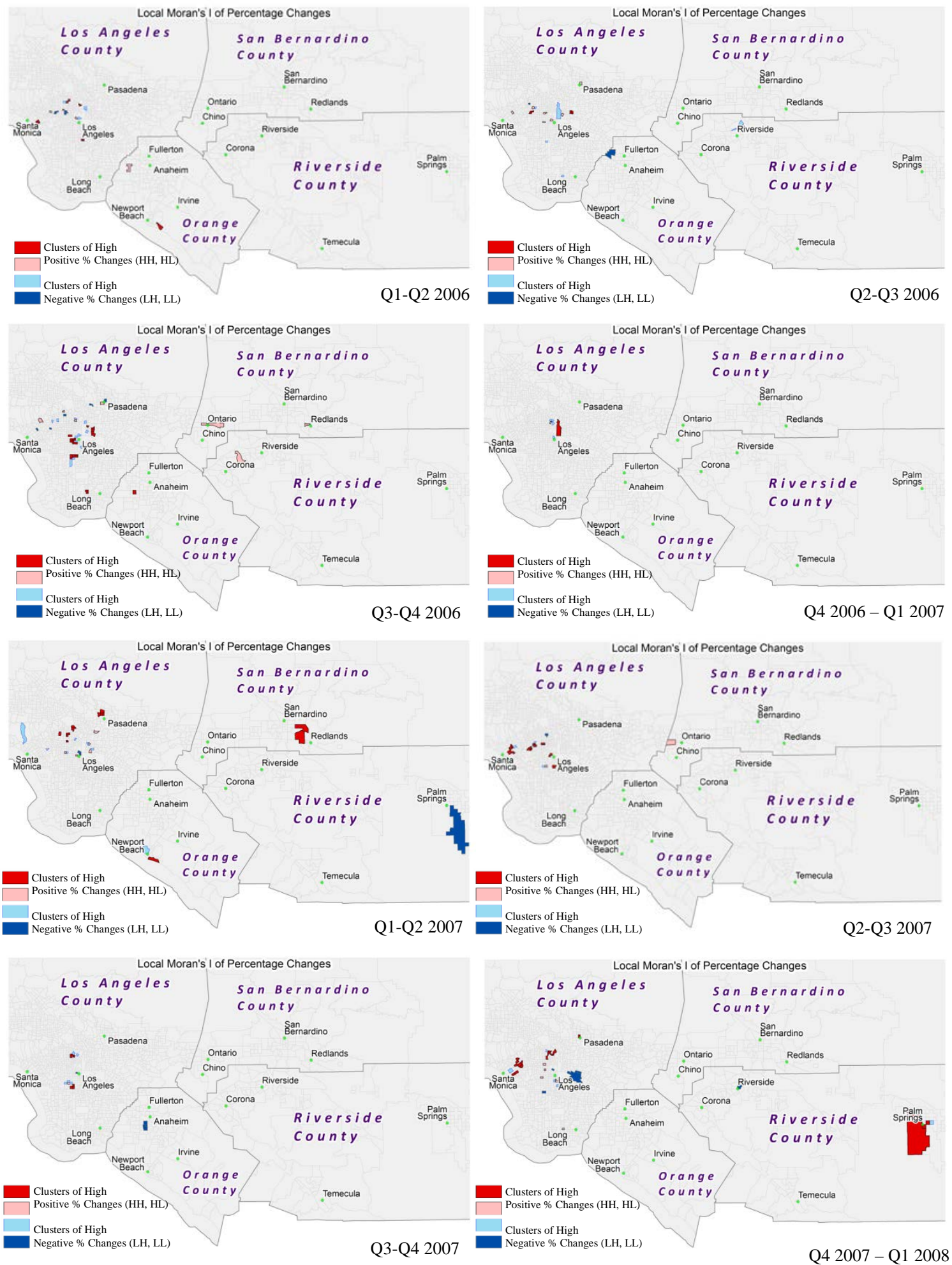

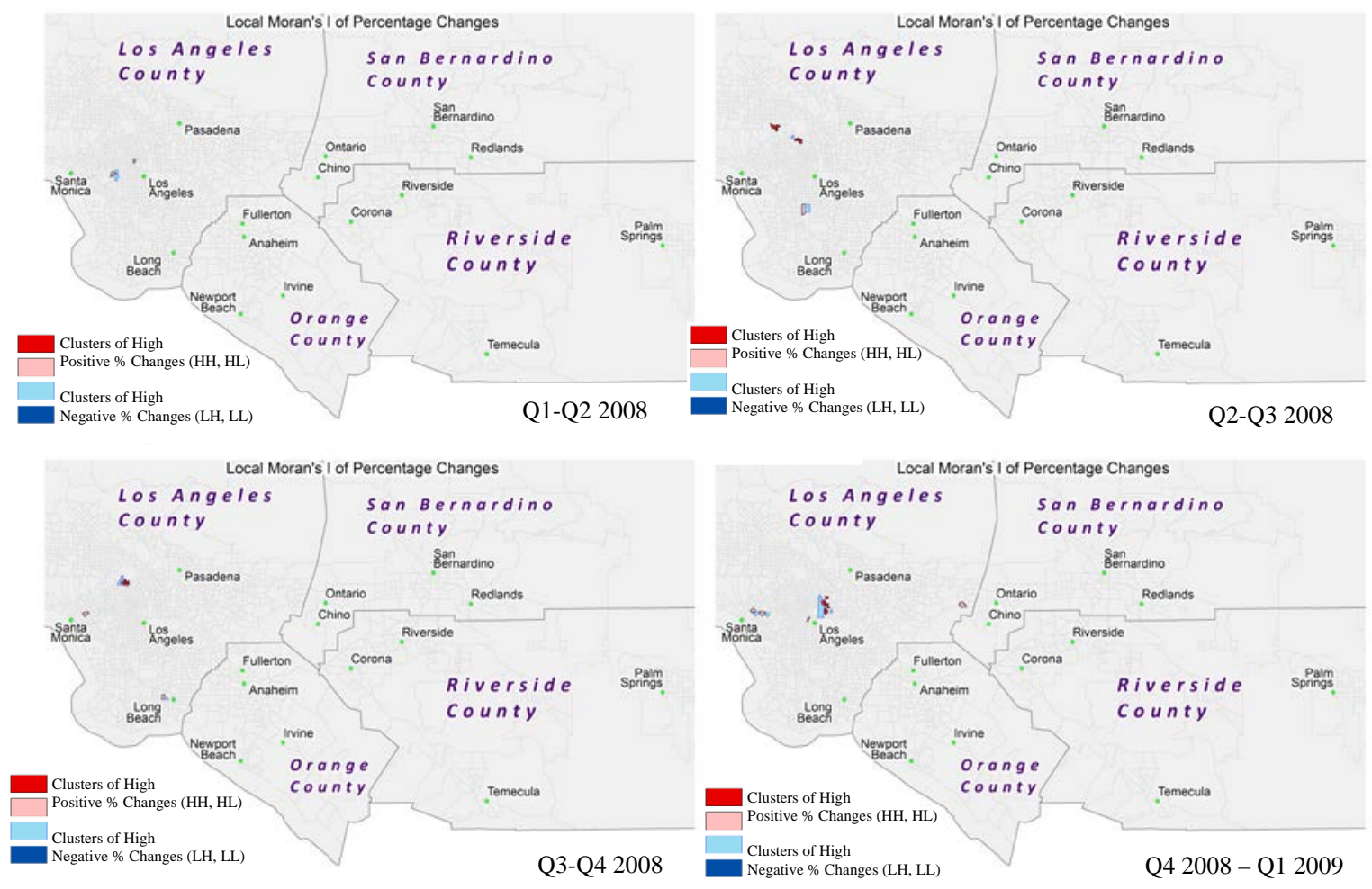

Appendix I. ModelBuilder Image (3).Geocode and Projection

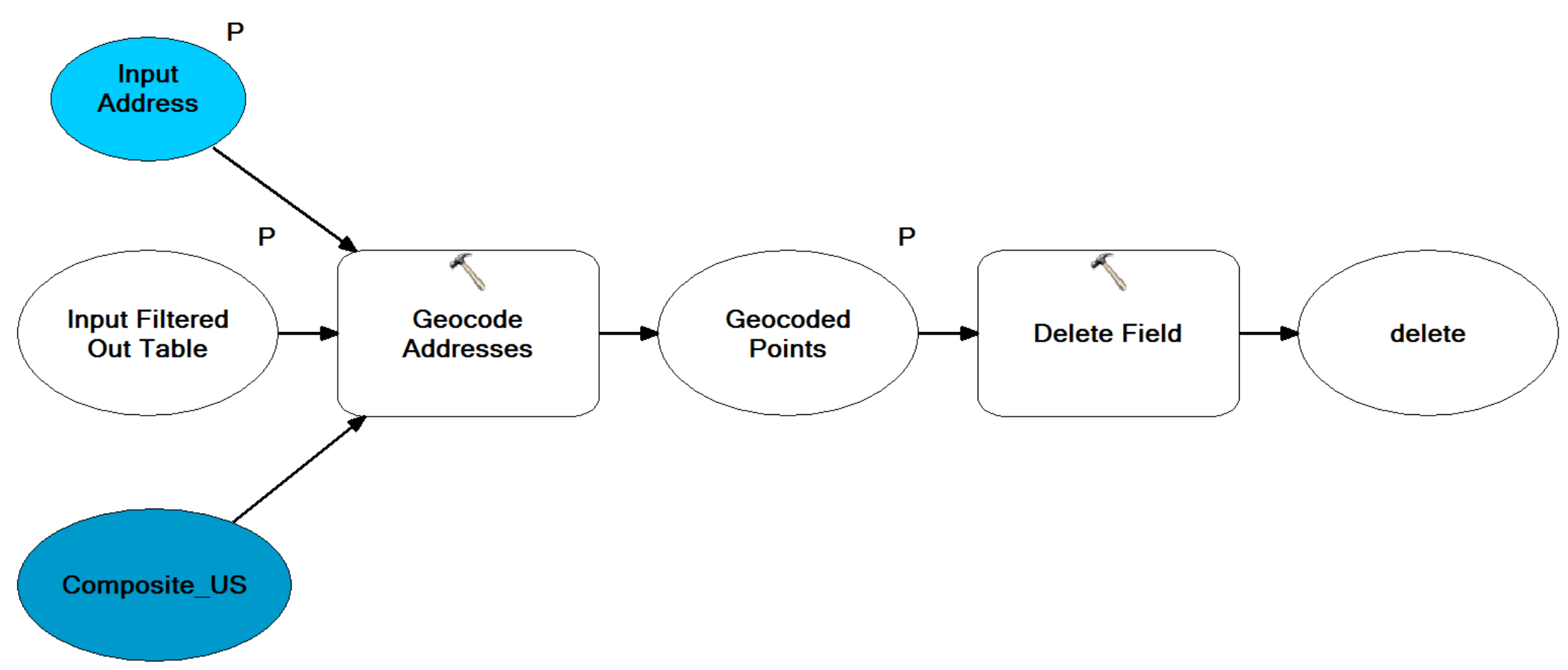





\section{Appendix J. ModelBuilder Image (4). Census Tract Integer Aggregation}

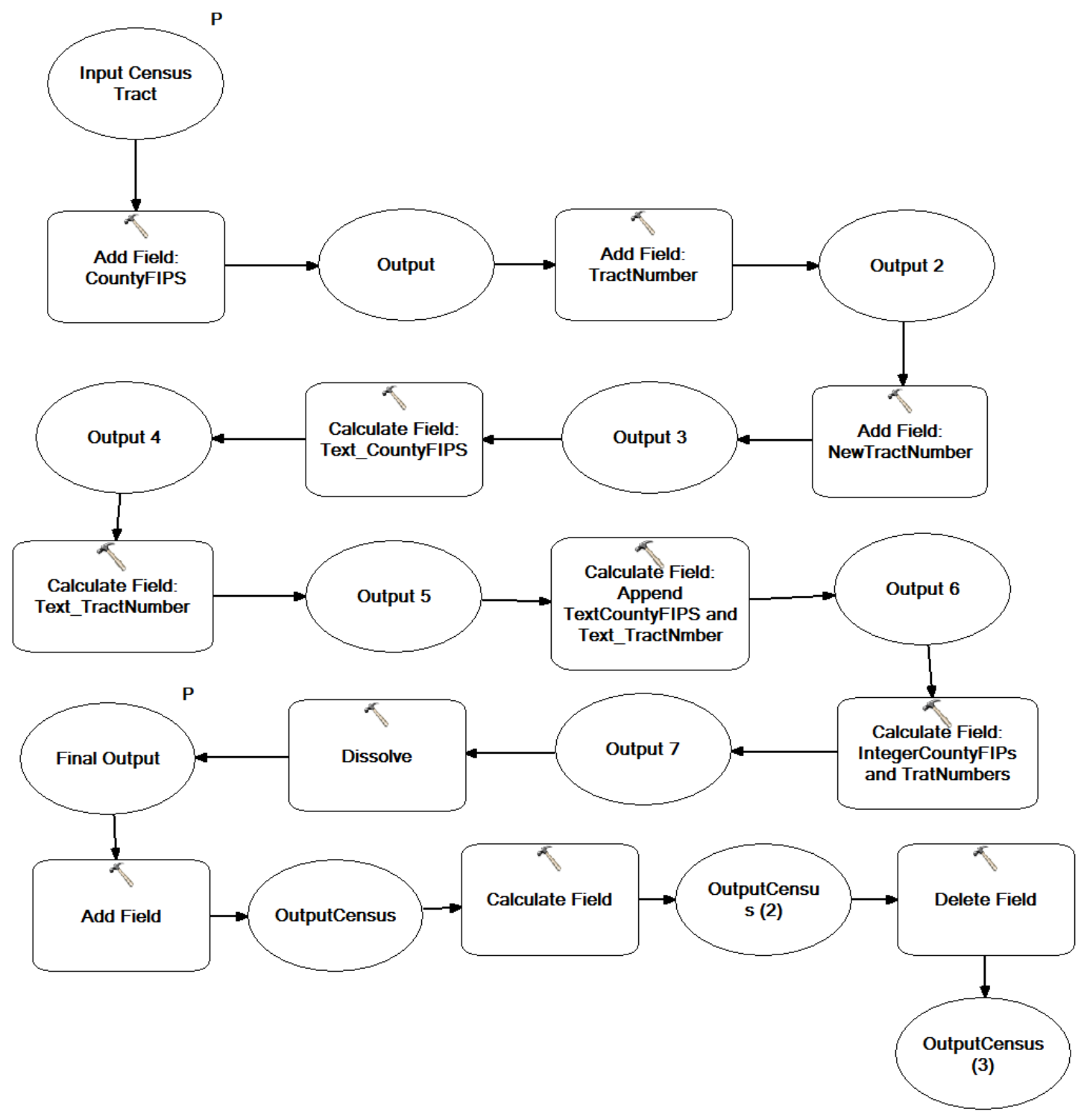



Appendix K. ModelBuilider Image (5). Spatial Join

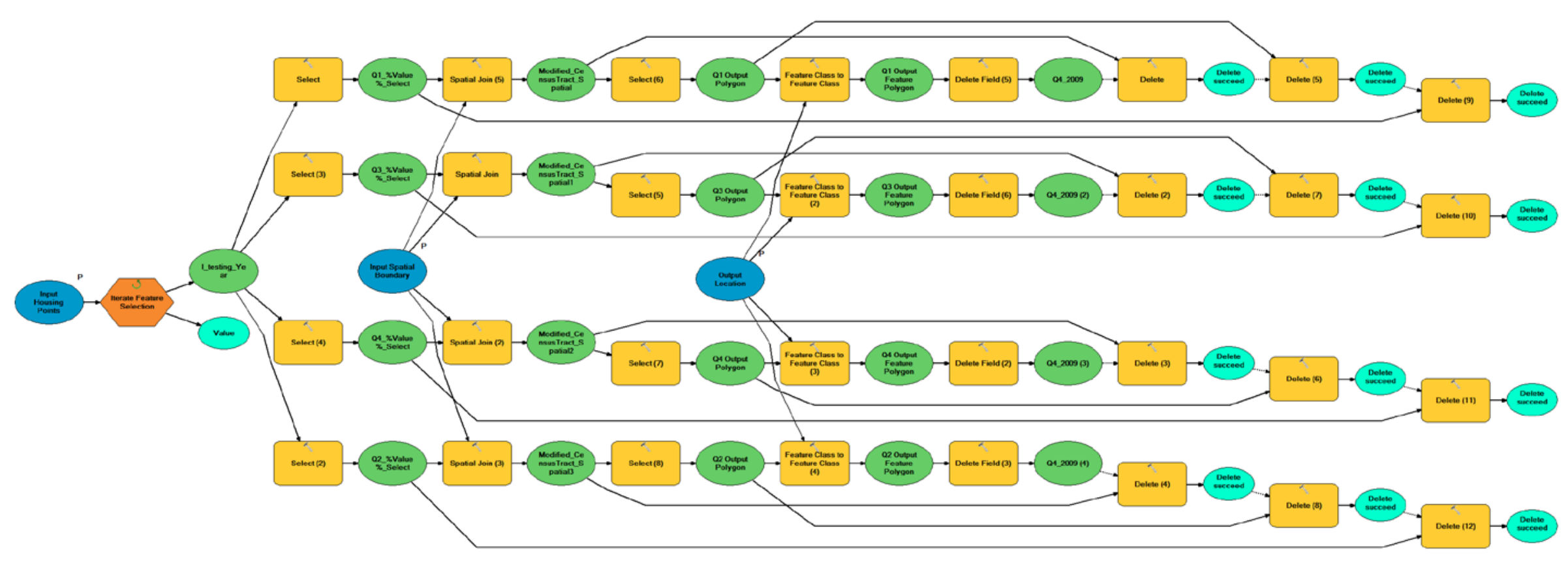





\section{Appendix L. ModelBuilder Image (3.5). Missing Data and Original Data Merging Tool}

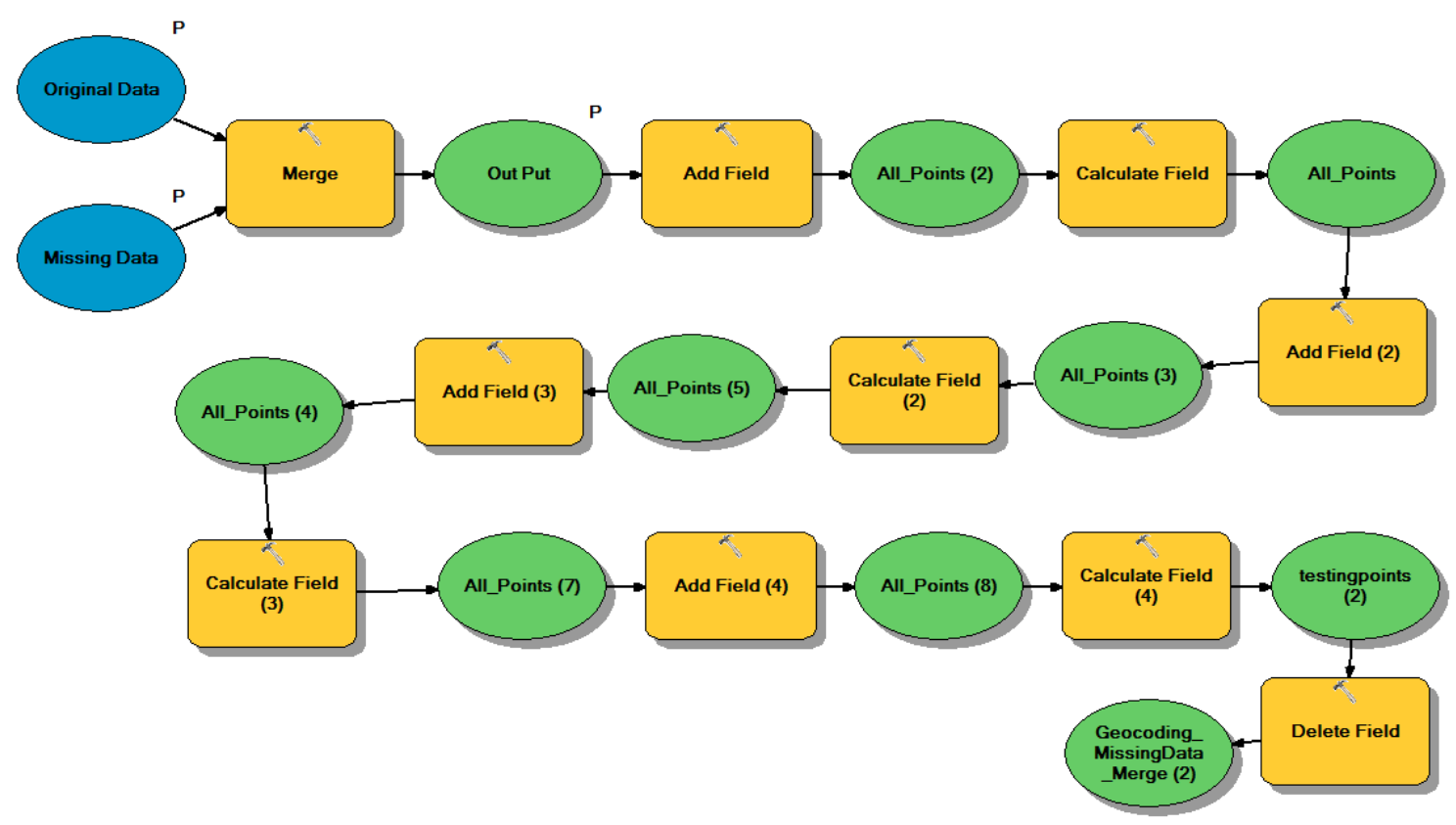



Appendix M. ModelBuilder Image (6.5). DivideByCounty

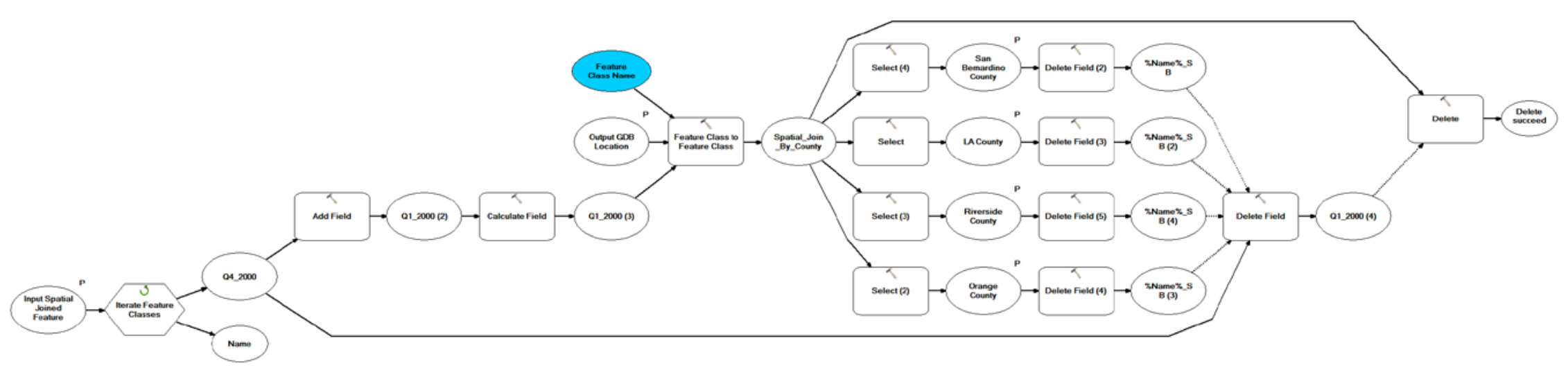

